\title{
Relocation, mobility and migration : the dynamics of workers and firms in the Netherlands
}

Citation for published version (APA):

Kronenberg, K. (2012). Relocation, mobility and migration : the dynamics of workers and firms in the Netherlands. [Doctoral Thesis, Maastricht University]. Datawyse / Universitaire Pers Maastricht. https://doi.org/10.26481/dis.20120608kk

Document status and date:

Published: 01/01/2012

DOI:

10.26481/dis.20120608kk

Document Version:

Publisher's PDF, also known as Version of record

\section{Please check the document version of this publication:}

- A submitted manuscript is the version of the article upon submission and before peer-review. There can be important differences between the submitted version and the official published version of record.

People interested in the research are advised to contact the author for the final version of the publication, or visit the DOI to the publisher's website.

- The final author version and the galley proof are versions of the publication after peer review.

- The final published version features the final layout of the paper including the volume, issue and page numbers.

Link to publication

\footnotetext{
General rights rights.

- You may freely distribute the URL identifying the publication in the public portal. please follow below link for the End User Agreement:

www.umlib.nl/taverne-license

Take down policy

If you believe that this document breaches copyright please contact us at:

repository@maastrichtuniversity.nl

providing details and we will investigate your claim.
}

Copyright and moral rights for the publications made accessible in the public portal are retained by the authors and/or other copyright owners and it is a condition of accessing publications that users recognise and abide by the legal requirements associated with these

- Users may download and print one copy of any publication from the public portal for the purpose of private study or research.

- You may not further distribute the material or use it for any profit-making activity or commercial gain

If the publication is distributed under the terms of Article $25 \mathrm{fa}$ of the Dutch Copyright Act, indicated by the "Taverne" license above, 


\section{Relocation, Mobility and Migration:}

The Dynamics of Workers and Firms in the Netherlands 
Relocation, Mobility and Migration: The Dynamics of Workers and Firms in the Netherlands (C) Kristin Kronenberg, Maastricht 2012 ISBN 978-94-6159-154-8

Printed by: Datawyse/Universitaire Pers Maastricht 


\title{
Relocation, Mobility and Migration:
}

\section{The Dynamics of Workers and Firms in the Netherlands}

\author{
Proefschrift \\ ter verkrijging van de graad van doctor \\ aan de Universiteit Maastricht, \\ op gezag van de Rector Magnificus, \\ Prof. mr. G. P. M. F. Mols \\ volgens het besluit van het College van Decanen, \\ in het openbaar te verdedigen op \\ vrijdag 8 juni 2012 om 10.00 uur \\ door
}

Kristin Kronenberg

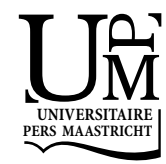




\section{Promotor}

Prof. dr. Martin A. Carree

\section{Beoordelingscommissie}

Prof. dr. A. de Grip (voorzitter)

Prof. dr. J. van Dijk (Rijksuniversiteit Groningen)

Dr. W. Letterie 


\section{Acknowledgements}

First of all, I would like to thank my supervisor, Martin Carree, for his guidance and support throughout the past four years. Martin, you gave me the freedom to pursue the questions I was most intrigued by, yet have always been there whenever I was looking for advice - I think I have been a very fortunate $\mathrm{PhD}$ candidate.

I am also grateful to the members of my reading committee, Andries de Grip, Jouke van Dijk, and Wilko Letterie, for taking the time to read my manuscript, and for their constructive and detailed feedback.

Furthermore, I would like to thank everyone at the Department of Organization and Strategy at Maastricht University for providing such an inspiring and pleasant work environment. Adela Buttolo, Anita Weijzen, Kitty van Straaten and Mieke van Zutphen, thank you very much for taking care of all administrative issues. I am also grateful to my colleagues at Statistics Netherlands (CBS) for making me feel welcome and sharing their knowledge concerning the various databases with me. Special thanks go to Fred Demollin, Hub Beunen, Rico Konen, and all other members of the former 'taakgroep ondernemingen en integratie'. Maarten Cuijpers (Maastricht University) and Ilse van der Lijf (CBS), you have been great company, and I very much enjoyed being your roommate.

My dear parents, I would like to thank you for your support and encouragement. You have helped me in numerous ways, and I am especially grateful for your enthusiasm whenever I wanted to discuss some new ideas.

Dear Tobias, do you remember what you wrote some years ago in your acknowledgements? We did it! I would like to thank you with all my heart for being there for me, for enduring my grumpiness, taking care of me when I was exhausted, proofreading my work, and for making me smile even after the hardest day. 

List of Tables

List of Figures

Chapter 1: Introduction

1.1 Relocation, mobility and migration - the dynamics of workers and firms

1.2 Description of the data 16

$\begin{array}{ll}1.3 & \text { Outline of the chapters } \\ 1.47\end{array}$

1.4 Dissemination of research 20

Chapter 2: On the move: determinants of job and residential mobility in different sectors

2.1 Introduction 24

2.2 Theoretical framework and hypotheses 26

$\begin{array}{lll}2.2 .1 & \text { Job mobility } & 26\end{array}$

2.2.2 Residential mobility 28

2.2.3 Job and residential mobility 31

$\begin{array}{lll}2.3 & \text { Data } & 32\end{array}$

2.3.1 Data sources 32

2.3.2 Data description 34

2.4 Model and variables $\quad 36$

2.4.1 Model 36

$\begin{array}{lll}2.4 .2 & \text { Variables } & 37\end{array}$

$\begin{array}{lll}2.5 & \text { Results and discussion } & 41\end{array}$

2.5.1 The determinants of job mobility 41

2.5.2 The determinants of residential mobility 43

2.5.3 The determinants of job and residential mobility 44

2.5.4 Limitations 46

$\begin{array}{lll}2.6 & \text { Conclusions } & 50\end{array}$ 
Chapter 3: Firm relocations in the Netherlands:

Why do firms move, and where do they go?

3.1 Introduction 54

3.2 Theoretical framework and hypotheses 56

3.2.1 The decision to relocate 56

3.2.1.1 General drivers of firm relocation $\quad 56$

3.2.1.2 Sector-specific drivers of firm relocation $\quad 58$

3.2.2 The choice of where to relocate 61

3.2.2.1 General regional characteristics 61

3.2.2.2 Sector-specific regional characteristics $\quad 62$

$\begin{array}{lll}3.3 & \text { Data } & 64\end{array}$

3.3.1 Data sources 64

3.3.2 Data description $\quad 65$

$\begin{array}{lll}3.4 & \text { Model } & 69\end{array}$

$\begin{array}{lll}3.5 & \text { Model specification } & 72\end{array}$

$\begin{array}{lll}\text { 3.5.1 Whether to relocate } & 72\end{array}$

$\begin{array}{lll}\text { 3.5.2 Where to relocate } & 75\end{array}$

$\begin{array}{lll}3.6 & \text { Results and discussion } & 76\end{array}$

$\begin{array}{ll}\text { 3.6.1 Why do firms relocate? } & 76\end{array}$

$\begin{array}{ll}\text { 3.6.2 Where do firms go? } & 79\end{array}$

$\begin{array}{lll}3.7 & \text { Conclusions } & 82\end{array}$

Chapter 4: Locational choices and the costs of distance: empirical evidence for Dutch graduates 93

4.1 Introduction 94

4.2 Theoretical framework and hypotheses 95

4.2.1 A model of graduates' locational choices $\quad 95$

4.2.2 The determinants of the distances between graduates' places of interest 96

$\begin{array}{lll}4.3 & \text { Data } & 101\end{array}$

$\begin{array}{lll}\text { 4.3.1 Data sources } & 101\end{array}$

$\begin{array}{lll}\text { 4.3.2 Data description } & 103\end{array}$ 
4.4 Methodology 104

$\begin{array}{lll}\text { 4.4.1 Theoretical model } & 104\end{array}$

4.4.2 Empirical specification 107

$\begin{array}{lll}4.4 .3 & \text { Variables } & 108\end{array}$

$\begin{array}{lll}4.5 & \text { Results and discussion } & 112\end{array}$

4.5.1 Determinants of the distance between place of study and place of work 112

4.5.2 Determinants of the commuting distance between place of residence and place or work $\quad 114$

4.5.3 Determinants of the distance between place of study and place of residence 115

$\begin{array}{lll}4.6 & \text { Conclusions } & 119\end{array}$

Chapter 5: The effects of workforce composition, labor turnover, and the qualities of entering and exiting workers on productivity growth 121

$\begin{array}{lll}5.1 & \text { Introduction } & 122\end{array}$

$\begin{array}{lll}5.2 & \text { Theoretical framework } & 124\end{array}$

5.2.1 Workforce composition and firm productivity 124

5.2.2 Labor turnover and firm productivity 125

5.2.3 The qualities of entering and exiting workers and firm productivity 126

$\begin{array}{lll}5.3 & \text { Data } & 129\end{array}$

5.3.1 Data sources 129

5.3.2 Data description 130

5.4 Methodology 131

$\begin{array}{lll}\text { 5.4.1 Model } & 131\end{array}$

5.4.2 Variables 133

$\begin{array}{lll}5.5 & \text { Results and discussion } & 138\end{array}$

5.5.1 The impact of workforce composition and firm characteristics on productivity growth $\quad 138$

5.5.2 The impact of labor turnover on productivity growth

5.5.3 The impact of the qualities of entering and exiting employees on productivity growth 139

$\begin{array}{lll}\text { 5.5.4 Limitations } & 145\end{array}$ 
5.6 Conclusions

Chapter 6: Conclusion

6.1 Concluding remarks 147

6.2 Summary of main findings 148

6.3 Limitations and future outlook 152

$\begin{array}{ll}\text { References } & 155\end{array}$

$\begin{array}{ll}\text { Samenvatting } & 169\end{array}$

$\begin{array}{ll}\text { About the author } & 175\end{array}$ 


\section{List of tables}

Table 2.1: Hypotheses 32

Table 2.2: Mobility 37

Table 2.3: Definitions of variables used in the analysis 39

Table 2.4: Descriptive statistics (all sectors) 41

Table 2.5: Multinomial logit regression model:

change job/keep residence $\quad 47$

Table 2.6: Multinomial logit regression model:

keep job/change residence $\quad 48$

Table 2.7: Multinomial logit regression model:

change job and residence $\quad 49$

Table 3.1: Classification of sectors $\quad 67$

Table 3.2: Mobility $\quad 68$

Table 3.3: Definitions of variables used in the analysis

$\begin{array}{ll}\text { (relocate or not) } & 74\end{array}$

Table 3.4: Descriptives (pooled) 75

Table 3.5: Definitions of variables used in the analysis $\begin{array}{ll}\text { (where to relocate) } & 76\end{array}$

Table 3.6: Logit regression - whether to relocate 86

Table 3.7: Conditional logit regression - where to relocate 88

Table 3.8: Conditional logit regression - where to relocate 90

Table 4.1: Graduates' college-to-work (D_SW), college-to-residence (D_WR) and commuting (D_SR) distances (in km) 96

Table 4.2: Definitions of variables 108

Table 4.3: Descriptive statistics 111

Table 4.4: Tobit regression, distance between place of study

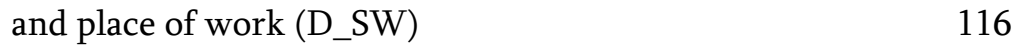

Table 4.5: Tobit regression, distance between place of work $\begin{array}{ll}\text { and place of residence (D_WR) } & 117\end{array}$

Table 4.6: Tobit regression, distance between place of study and place of residence (D_SR) 118

Table 5.1: Definitions of variables used in the analysis 134

Table 5.2: Descriptives (all firms) 136

Table 5.3: Descriptives (firms with entries from $\begin{array}{ll}\text { and exits to other firms) } & 137\end{array}$ 
Table 5.4: Ordinary least squares regression for change in firm productivity (D_LOGSPE), restricted model, all firms

Table 5.5: Ordinary least squares regression for change in firm productivity (D_LOGSPE), restricted model, firms with entries from and exits to other firms

Table 5.6: Ordinary least squares regression for change in firm productivity (D_LOGSPE), full model, firms with entries from and exits to other firms 


\section{List of figures}

Figure 3.1: Nesting structure of the two-level nested logit

(simultaneous decision-making process)

Figure 4.1: Graduates' locations of study, residence and work and the respective distances 



\section{CHAPTER 1}

\section{INTRODUCTION}

\subsection{Relocation, mobility and migration - the dynamics of workers and firms}

'If everything occurred at the same time there would be no development. If everything existed in the same place there could be no particularity. Only space makes possible the particular, which then unfolds in time' (Lösch, 1954, p. 508).

A country is shaped by the spatial behavior of individuals and organizations. Human beings settle in favorable locations, and seek work in places where they can put their skills to good use and are adequately compensated for their efforts. Firms may select a locality due to its proximity to other businesses in the same industry, or because of other beneficial conditions to be found in the region. Yet, the decisions of individuals and firms cannot be assumed to be taken autonomously, but may affect or even instigate each other. A firm may be set up in a specific area due to the known qualities of the local workforce, whereas workers might decide to find employment in a region where the needs of the local businesses match their own aptitudes and affinities.

Nevertheless, both workers and firms are free to (re)settle as they wish. Hence, along the lines of Lösch (1954), space and time appear to be intrinsically entwined. While the mere location of an individual or organization at a specific point in time may be the outcome of pure chance, relocation or migration to another location presumes the assessment of both the current and the potential future situations. Thus, it can be expected to lead to an informed decision which reflects the aspiration for improving particular current conditions. In line with this argument, Pellenbarg (2005) argues that 'relocation is interesting because it provides the best showcase of (...) decision-making with regard to location choice, and therefore the best source of knowledge upon which to build location choice theories' (p. 2).

This dissertation was motivated by the desire to understand the locational choices and spatial behavior of individuals and firms, to identify 
the interconnections between the decisions of these often seemingly disparate entities, and to investigate one's quest for betterment as apparent in the spatial dynamics of persons and organizations.

\subsection{Description of the data}

The recent availability of microdata on individuals, households and firms allows for intriguing research questions to be tackled. Especially with regard to issues bridging the fields of economic geography, labor economics, and industrial organization, their richness permits the creation and use of exciting datasets linking information on employees and their employers.

The data employed in this dissertation were provided by Statistics Netherlands. They consist of mainly register-based information regarding employees, households, housing, firms, and municipalities, covering virtually all workers and businesses in the Netherlands. These data originate from various sources and were merged specifically for the purposes of each analysis.

Information on employees and households originates from the Social Statistical Database (SSB), and is compiled on the basis of register and survey data from two main sources. Personal information (e.g. date of birth, gender, location of residence, number of households per address) stems from the municipal registration system, which also holds information regarding one's marital status, registered cohabitation, and (changes in) household composition. Information regarding employees' jobs (e.g. employer, duration of employment, salary, part-time factor, location of employment) originates from the Fibase, a database delivered by the Dutch Tax Administration.

Data concerning higher education (institution of higher education and its location, year of graduation, field of study) originate from the Dutch central student register (CRIHO), which is based on information derived from the Informatie Beheer Groep, a Dutch governmental institution.

Firm data (industrial sector, age, size, financial outcomes, location) are available on the level of the 'business unit' (BE). In the large majority of cases, the business unit is an independent firm, yet it sometimes constitutes a subunit of a larger company. The data originate from the SSB, the Dutch business register (ABR), the Survey on Employment and Wages (EWL), the 
Survey Production Statistics (SBS and STS), and data provided by the Dutch Tax Administration.

The locations of all residences, firms, and institutions of higher education are known on the municipal level. As Statistics Netherlands developed a coordinate system which puts the exact location of each municipality (its center) in relation to a point of origin, its distance to other municipalities respectively locations of interest could be established. This allows for various distances such as the distance covered in case of a job change, residential move, or the relocation of a firm, the commuting distance between one's place of residence and workplace, or the distance to the 'Heart of the Randstad' to be calculated.

Basic information regarding the Dutch municipalities (e.g. population, population density) originates from Statline, a publicly available database provided by Statistics Netherlands supplying aggregate regional information on the municipal level. Additional figures regarding the characteristics of the workforce, businesses and sectors present in each municipality could be established on the basis of the microdata on employees and firms at hand. Information regarding the attractiveness of the Dutch municipalities for individuals was obtained from www.elsevier.nl, where all Dutch municipalities are evaluated each year. Apart from a general ranking of the municipalities, separate rankings are also available with regard to specific topics such as recreational facilities, infrastructure, and accessibility.

\subsection{Outline of the chapters}

The main body of this thesis consists of four self-contained empirical chapters, unified in the common theme of 'relocation, mobility and migration', followed by a short conclusion. This section provides an overview regarding these chapters.

\subsubsection{Chapter 2}

Chapter 2 identifies and evaluates the determinants underlying the job and residential mobility of employees in different sectors. In the empirical 
analysis, a multinomial model of job and residential change is estimated. For the purpose of this study, data on individuals (e.g. age, firm tenure, educational level), households (e.g. marital status, number of children), dwellings (single- or multi-family unit), firms (e.g. sector, size) and municipalities (e.g. degree of urbanization, distances between any two municipalities) in two consecutive years were combined.

This study contributes to the body of literature on job and residential mobility in two key aspects: Firstly, it identifies sectoral differences and peculiarities regarding the mobility decisions of individuals. Since the dataset at hand covers the entire population of Dutch employees, not only including manufacturing and (private) services are included in the analysis, but also sectors such as public administration and healthcare. Next, it analyzes job and residential mobility in one integrated model, thereby also investigating in which respect job and residential mobility might complement respectively substitute for each other.

\subsubsection{Chapter 3}

Chapter 3 analyzes determinants of business relocation and identifies regional characteristics which attract relocating firms. The decisions taken by a firm regarding its relocation are estimated by means of a two-stage nested logit model. The dataset used in this study is based on register data covering virtually all businesses and workers in the Netherlands, and consists of information regarding the characteristics of Dutch firms, employees, and municipalities in the years 2002-2004.

The research contributes to the existing literature in several respects. Firstly, it analyzes both regional 'push'- and 'pull'-factors. Interestingly, while numerous studies acknowledge the relevance of both the characteristics of a firm's region of origin (which might push a firm from its present location, or keep it there), and the qualities of a firm's region of destination (which might pull a firm towards this location), most analyses either focus on reasons underlying the outmigration of firms, or concentrate on regional features which attract relocating businesses. Secondly, while previous work - supposedly mainly for reasons of data availability - often focuses on the migration behavior of manufacturing firms, this study 
differentiates between knowledge-intensive respectively high-tech and less knowledge-intensive respectively low-tech manufacturing and service industries, thereby taking into consideration probable intersectoral differences regarding firms' decision to relocate as well as their locational preferences. Thirdly, it analyzes the interregional relocation of firms on the very detailed level of the municipality, an approach which has rarely been employed for the Netherlands. Fourthly, it takes into account firm- and municipal sector-specific wages regarding their effect on firm mobility and their ability to attract businesses, analyzing the relevance of the wageinherent aspects 'cost' and 'quality' for different kinds of sectors.

\subsubsection{Chapter 4}

Chapter 4 identifies and analyzes the effects of graduates' personal, household and employment characteristics as well as the attributes of their study, work and home locations on their college-to-work, college-toresidence, and commuting distances. In the empirical analysis, Tobit regression models are employed. The dataset used in this study covers virtually all Dutch university/college graduates in 2003, and consists of information regarding graduates' personal, household and employment characteristics, their study, home and work locations, and the attributes of these localities.

Research on the locational decisions of individuals often distinguishes between areas considerably larger than the average Dutch municipality, and commonly assumes one's locations of work and residence to be identical. This study contributes to the existing body of literature on individuals' spatial behavior by analyzing the determinants of graduates' college-to-work, college-to-residence and commuting distances, and the relationships between these three locations of interest. By this means, it illustrates the manner in which individuals trade off locational benefits and the costs associated with the distances between relevant localities. 


\subsubsection{Chapter 5}

Chapter 5 analyzes the effects of firms' workforce composition, labor turnover, and the qualities of entering and exiting workers on productivity growth. In the empirical analysis, a least squares regression model is employed, assuming that changes regarding a firm's level of productivity depend on the composition of its current workforce, the share of entries and exits, and the qualities of workers entering and exiting the firm. A matched employer-employee dataset is used. It is based on register data, and consists of information regarding the characteristics of firms and their employees in the Dutch manufacturing sector between the years 2002 and 2005.

While numerous studies investigate how the qualities of a firm's current workforce or the entry and exit rates of employees are related to its productivity, the features of those workers who enter and exit the firm are rarely taken into account. Yet, it can be argued that especially when looking at changes regarding a firm's future performance, the characteristics of those employees who alter the composition of its workforce and add or subtract specific new qualities need to be considered. This study contributes to the existing work in this field by investigating the effects of workforce composition, labor turnover, and particularly the qualities of entering and exiting workers - especially in terms of the characteristics (industrial sector, level of productivity) of their previous respectively future employers - on firm productivity growth.

\subsection{Dissemination of research}

Each of the four empirical chapters of this dissertation is based on a selfcontained article. These papers (or earlier versions thereof) have been presented at various international conferences and workshops such as the Conference of the European Association of Labour Economists (EALE), Tallinn, Estonia (Chapter 2), the NIPE workshop on the Economic Analysis of Linked Employer and Employee Data, Braga, Portugal (Chapter 2), the Simposio de la Asociación Española de Economía, Valencia, Spain (Chapter 2), the DIME workshop 'Industrial Dynamics and Economic Geography', Utrecht, The Netherlands (Chapter 5), the KUL-UMA-DICE-ZEW PhD 
workshop, ZEW, Mannheim, Germany (Chapter 3), the International workshop on 'Regional Competitiveness and International Factor Movements', Orléans, France (Chapter 3), and the European Congress of the Regional Science Association International, Barcelona, Spain (Chapter 3). The papers have either been accepted for publication in, or have been submitted to international, peer-reviewed journals. Below, the corresponding articles or working papers are indicated.

Chapter 2: Kronenberg, K., \& Carree, M. (2012). On the move: determinants of job and residential mobility in different sectors. Forthcoming in Urban Studies.

Chapter 3: Kronenberg, K. (2012). Firm relocations in the Netherlands: Why do firms move, and where do they go? Forthcoming in Papers in Regional Science.

Chapter 4: Carree, M., \& Kronenberg, K. (2012). Locational choices and the costs of distance: empirical evidence for Dutch graduates. MPRA Paper 36221.

Chapter 5: Kronenberg, K., \& Carree, M. (2010). The effects of workforce composition, labor turnover, and the qualities of entering and exiting workers on productivity growth. MPRA Paper 25844. 



\title{
CHAPTER 2
}

\section{ON THE MOVE: DETERMINANTS OF JOB AND RESIDENTIAL MOBILITY IN DIFFERENT SECTORS ${ }^{1}$}

\begin{abstract}
This chapter identifies and evaluates determinants of employees' job and residential mobility. It examines mobility of fulltime employees in selected sectors in 2003/2004, using register data for the Netherlands. We estimate a multinomial model of job and residential change. The results illustrate how individuals decide upon changing jobs and/or relocating by taking into account the strength of family- and job-related ties, career opportunities within and outside the firm, and attachment to the present dwelling. A long commuting distance was found to encourage both job and housing mobility, often simultaneously. Employees living/working in large cities are more likely to either change jobs, or to relocate. The influence of human capital indicators on mobility was found to be highly sector-dependent.
\end{abstract}

\footnotetext{
${ }^{1}$ This chapter is based on the following article: Kronenberg, K., \& Carree, M. (2012). On the move: determinants of job and residential mobility in different sectors. Forthcoming in Urban Studies.
} 


\subsection{Introduction}

Mobility is generally assumed to be motivated by an expected gain in utility (e.g. Böheim \& Taylor, 2007; Ritsilä \& Ovaskainen, 2001). In this chapter, we investigate two different kinds of mobility, namely interfirm and residential mobility, their determinants, and their interrelationship. Individuals are expected to change employers in order to, for example, receive higher wages, to benefit from superior career opportunities, or to reduce their daily commuting time (Clark et al., 2003; Henneberger \& Sousa-Poza, 2002; Linneman \& Graves, 1983; Schneider, 2007). Regarding residential relocation, individuals may be induced to move, for example, in order to enjoy a more pleasant living environment (Knapp et al., 2001; Nivalainen, 2004), while they might be reluctant to migrate if other members of their family could be negatively affected by a residential move (Becker, 1981; Linneman \& Graves, 1983; Molho, 1987; Nivalainen, 2004; Sjaastad, 1962).

Job and residential mobility can be closely related, since relocation might require individuals to also switch jobs, or changing employers may bring about the need for migration (Bartel, 1979; Dieleman, 2001; Kan, 2003; Sjaastad, 1962). In these cases, job and residential mobility function as complements, since one kind of mobility induces the other. Alternatively, a long commuting distance between place of residence and workplace might trigger an employee to switch employers instead of moving geographically, or vice versa (Clark et al., 2003; Zax, 1991). Under these circumstances, job and residential mobility serve as substitutes, since, for example, changing jobs allows an employee to abstain from relocating.

Many studies on job mobility presume that individuals merely take personal characteristics such as their age, firm tenure, or level of education into consideration when deciding upon changing jobs or staying with their current employer. Nevertheless, as many employees belong to households consisting of more than one person, the presence of additional household members should not be ignored (Van Ommeren, 2000), especially since the composition of one's household has been found to affect decisions concerning residential relocation (Feijten \& Van Ham, 2007; Linneman \& Graves, 1983). We thus reason that a job change not involving migration is intrinsically different from interfirm mobility requiring the employee and possible further family members to move. Likewise, residential relocation not 
including a job change will be motivated by other aspects than joint job and housing mobility. We therefore explicitly differentiate between job mobility, residential mobility, and joint job and residential mobility.

We analyze job and residential mobility within one integrated model, an approach which previously has only been taken by a small number of studies (Bartel, 1979; Börsch-Supan, 1990; Kan, 2003; Linneman \& Graves, 1983). Our investigation benefits from the fact that we had access to data on the entire population of Dutch employees, including not only those working in manufacturing and services, but also in sectors such as public administration and healthcare. This allows for the exploration of sectoral differences and peculiarities. Besides analyzing the role of personal features (e.g. age, firm tenure, educational level) and household attributes (e.g. marital status, number of children, birth of a child), we investigate the importance of employer characteristics (sector and firm size) as determinants of interfirm and/or residential mobility. In addition, we consider the dwelling an employee resides in as well as the degree of urbanization of an employee's place of residence and workplace, and take into account the daily commuting distance between those two locations. This combination of explanatory variables is unique and, to our knowledge, has not been employed so far.

The Netherlands are a densely inhabited country, exhibiting a population density of 489 inhabitants $/ \mathrm{km}^{2}$ and a still growing population of more than 16 million inhabitants (source: Statistics Netherlands, 2010). With congestion being an increasingly critical concern in such a densely populated territory, it is crucial to comprehend human behavior regarding interfirm and/or housing mobility and commuting. Furthermore, there is a need to investigate the phenomena of job and residential mobility in order to understand the imbalances in labor supply and demand at the level of firms, sectors, or areas. There are districts and sectors facing many vacancies, while others are confronted with substantial unemployment rates. In case of a lack of mobility, it could be expected that these regional or sectoral imbalances will persist over time.

We employ a multinomial logit model (MNL) in order to investigate the determinants of job and residential mobility. This model is derived from a framework of utility maximization. We use a dataset provided by Statistics Netherlands, consisting of information regarding the individual characteristics, household composition, and employers of employees working 
fulltime (at least 0.8 FTE) in selected Dutch sectors, the degree of urbanization of their places of residence and workplaces, the commuting distances between those two locations, and the kind of dwelling they reside in.

The chapter is organized as follows. In section 2.2, we provide the theoretical background of the research. Section 2.3 outlines the characteristics of the data used in this study. In section 2.4, we present the model employed in the empirical analysis, and define the variables. In section 2.5, we outline the results of the multinomial regressions, discuss our findings, and indicate the limitations of the study. Section 2.6 concludes.

\subsection{Theoretical framework and hypotheses}

\subsubsection{Job mobility}

An employee will decide to change jobs if the expected net benefits derived from the new position (e.g. a friendlier working atmosphere, a higher salary, or superior career opportunities) exceed the net benefits derived from the present job. We hypothesize in this section that the utility which an employee derives from changing jobs depends on the strength of the employee's ties with the current employer, the existing internal as well as the expected external career opportunities, the financial remuneration which the employee receives, and the commuting distance between the employee's place of residence and workplace.

Human capital theory has increasingly been utilized in order to explain workers' motivations to change employers. One typically distinguishes between two different forms of human capital, namely firm- or job-specific, and general human capital. Firm- or job-specific human capital constitutes a person's expertise which can only be used within the organization or with respect to the job in which it has been obtained. General human capital, on the other hand, signifies a person's level of knowledge which can be transferred to and used with any employer (e.g. Acemoglu \& Pischke, 1999; Becker, 1962; Borghans \& Heijke, 2005; Henneberger \& Sousa-Poza, 2002).

It can be expected that the human capital acquired and held by an individual has an effect on this person's propensity to change jobs. The more 
an employee previously invested in the acquisition of specific human capital, the less likely this employee will be to change employers. As a consequence, it follows that the longer a person has been employed with a specific firm, the more likely this person is to stay with this firm, since a new employer would not reward the previously accumulated firm-specific knowledge (e.g. Bergin, 2009; Henneberger \& Sousa-Poza, 2002; Van Ham et al., 2001). We therefore hypothesize that the utility which an employee derives from changing jobs decreases with the strength of the employee's ties with the current employer, which is proxied by firm tenure.

The human capital approach also predicts that the size of a company influences an employee's tendency to change jobs, as bigger companies usually provide better career and training opportunities within the firm (Kalleberg \& Mastekaasa, 1998; Kalleberg \& Van Buren, 1996; Rebitzer, 1986; Stolzenberg, 1978). Within large organizations, employees can put their firm- and task-specific skills to use and have the chance to advance their careers without having to change employers. As Kalleberg and Mastekaasa (1998) demonstrate, job mobility is indeed lower for employees of larger organizations. We thus assume that the utility which an employee derives from changing jobs decreases with the internal career opportunities present in the employee's current organization, which are proxied by firm size.

While the career opportunities within an organization can be assumed to induce employees to stay with their current employer, external options will most likely have the opposite effect. We claim that for highly educated individuals as well as for those situated in urban areas, external career opportunities are relatively abundant. As argued by Börsch-Supan (1990) as well as Eliasson et al. (2003), a person with a higher level of education should be more capable of collecting and processing information regarding possible employment alternatives. Furthermore, highly educated individuals are supposed to be more proficient with respect to the utilization of their knowledge in different environments, hence job mobility may increase due to a heightened availability of external options (Bergin, 2009; Weiss, 1984). Moreover, residents of densely inhabited urban areas have been found to have more employment opportunities in close proximity (Finney \& Kohlhase, 2008; Nivalainen, 2004). These individuals may thus have a comparatively higher number of nearby alternative job matches which would not require the simultaneous change of one's residence (Van Ham et 
al., 2001). We therefore expect that the utility which an employee derives from changing jobs increases with the available external career opportunities, which are proxied by the employee's level of education, and by being situated in a large city.

The higher an employee's present salary is, however, the less likely the employee may be to find another job which is even better paid. Hence, job mobility could be lower for employees with higher wages (e.g. Bergin, 2009; Burdett, 1978; Henneberger \& Sousa-Poza, 2002), especially if one's salary exceeds one's level of productivity. We thus hypothesize that the utility which an employee derives from changing jobs decreases with the current financial remuneration ${ }^{2}$.

As illustrated by Zax (1991), (dis)utility is also derived from the distance between one's place of residence and workplace. Individuals facing long commuting distances should therefore be more likely to switch jobs, or to relocate (Van Ommeren et al., 2000) in order to decrease travel costs and/or time. This suggests that the utility which an employee derives from changing jobs increases with the commuting distance between the employee's place of residence and current workplace. See Table 1 for an overview regarding the expected effects of the variables introduced in this section on job mobility.

\subsubsection{Residential mobility}

Individuals will relocate if they expect the utility from migrating to be higher than the utility from staying in their present location (Ritsilä \& Ovaskainen, 2001). We hypothesize in this section that the utility which an employee derives from changing houses depends on the strength of the employee's family ties, changes regarding the composition of the employee's household, the attachment to the present dwelling, the employee's

\footnotetext{
${ }^{2}$ It may be argued that not so much the absolute, but the relative salary an employee receives in comparison to colleagues having the same level of education, or being employed in the same sector matters regarding the decision of whether to change jobs or not (Henneberger \& Sousa-Poza, 2002). By analyzing mobility separately for various sectors, we control for sectoral affiliation. The model also includes firm tenure and educational level as explanatory variables. In this sense, we condition the absolute salary level on several observable measures of human capital.
} 
opportunities on the housing market, and the commuting distance between the employee's place of residence and workplace.

With respect to household composition, Mincer (1978) argued that family ties discourage migration. Not only the pursuit of one's own happiness, but also the altruistic concern about the welfare of others constitute vital components of utility (Boswell, 2008). Hence, as the wellbeing of other family members who might be unwilling to leave familiar surroundings (Sjaastad, 1962) is taken into account, it follows that multiperson households will be less inclined to move than those consisting of only one person (Becker, 1981).

This notion was empirically verified by Helderman et al. (2004), Linneman and Graves (1983) and Molho (1987), who identified a lower propensity to relocate among employees who are married and have children. Likewise, employees with a partner also having a fulltime job will be less geographically mobile (Nivalainen, 2004; Helderman et al., 2006), since relocation might require the spouse to give up his/her job, or to accept a longer commuting distance ${ }^{3}$. We thus conclude that the utility which an employee derives from relocating decreases with the strength of his/her family ties, which are proxied by marital status, number of children, and employment status of the partner.

Moreover, changes regarding the composition of one's household may also have an impact on subsequent residential mobility (Clark et al., 1984; Feijten \& Van Ham, 2007; Helderman et al., 2004; Linneman \& Graves, 1983), as e.g. the birth of a child may induce a family to relocate to a larger dwelling. We therefore assume that the utility which an employee derives from relocating increases with the number of children added to the household in the previous year.

The higher a person's salary is, the more opportunities this person has on the housing market. This holds true both for renting, and for buying one's own home. Individuals with higher earnings might consequently be more likely to move, as they can afford the kind of residence they have envisioned (Helderman et al., 2004; Helderman et al, 2006). Furthermore, residents of

\footnotetext{
3 This argument especially applies to spouses whose workplace is close to the couple's place of residence. Results show, however, that having either 'partner with fulltime job' or 'partner with fulltime job within $10 \mathrm{~km}$ commuting distance' gives virtually identical results.
} 
densely inhabited neighborhoods (Kim et al., 2005) and large cities (Van Huis et al., 1999) have been found to have an increased likelihood to relocate. These findings may be attributed to the fact that in densely populated urban areas, individuals are able to relocate without having to change jobs. Moreover, the housing stock of large cities in the Netherlands has been found to consist predominantly of multi-family rental dwellings (Deurloo et al., 1990), so that residential mobility in these regions - and thus also the number of alternative housing opportunities which become vacant - will be higher than in areas where the share of privately owned dwellings prevails. We thus expect that the utility which an employee derives from relocating increases with the available alternative housing opportunities, which are proxied by the employee's current financial remuneration, and by being situated in a large city.

As previously argued, individuals also derive (dis)utility from the distance between their place of residence and workplace. Employees confronted with long commuting distances will be inclined to adjust their current situation by either changing jobs, or by relocating. Hence, we assume that the utility which an employee derives from relocating increases with the commuting distance between the employee's place of residence and current workplace.

As established by e.g. Clark et al. (1984), Clark and Huang (2004), Helderman et al. (2004), Helderman et al. (2006), and Van der Vlist et al. (2002), residential mobility is affected by home ownership, as owners - often residing in single-family units - are less likely to relocate than renters. It can be expected that the attachment - both psychological and financial - to the present dwelling is higher for residents of single-household units than for those living in multi-family dwellings (apartments). Thus, we expect that the utility which an employee derives from relocating decreases with the attachment to the current residence, which is proxied by a dummy variable indicating whether or not a person lives in a single-household unit. See Table 1 for an overview regarding the expected effects of the variables introduced in this section on residential mobility. 


\subsubsection{Job and residential mobility}

Interfirm mobility is likely to be primarily influenced by employees' personal characteristics (e.g. previously accumulated human capital), while residential mobility should predominantly be determined by the composition of their families (hence their family ties), and by the attachment to the present dwelling. It follows that a joint change of one's job and place of residence is affected by both employees' individual traits, and by the structure of the household they are part of as well as the current kind of residence. The hypotheses regarding the determinants of joint job and residential mobility should therefore in most cases constitute an 'aggregate' of those shaping job mobility, and those affecting relocation. However, three of these determinants merit additional discussion.

The combination of a hypothesized negative effect of salary on job mobility, and a hypothesized positive one on residential mobility implies that the sign of the effect of salary on joint job and residential mobility is unclear. An extra argument for an aggregate positive effect is that individuals with higher earnings often face a more geographically dispersed labor market, so that accepting a new job often requires simultaneous residential relocation. Nevertheless, joint job and residential mobility can be particularly costly, since both one's place of residence and workplace have to be adjusted.

Since we hypothesized that commuting distance will have a positive effect on job mobility as well as on residential mobility, this would imply a strong positive effect on joint job and residential mobility. Yet, this matter warrants further consideration. On the one hand, job and residential mobility might substitute for each other (Zax, 1991), as individuals who intend to reduce the time and money spent on their daily commute may either adjust their place of residence, or their workplace. On the other hand, employees with long commutes might search more intensively in both the job and the housing market, and may therefore be more likely to spot interesting 'offers'. Additionally, these individuals might not fully commit to both their social and professional environments, and could thus more willingly change jobs and relocate.

The abundance of dwellings and jobs in densely populated urban areas may lead to an overall high level of mobility. However, individuals living/working in those regions may not need to change houses in order to 
realize a job change (or vice versa). This would imply that job and residence changes may serve as substitutes, e.g. in order to decrease commuting time within, to, or from the highly congested municipality of a large city. See Table 2.1 for an overview regarding the expected effects of the variables introduced in this section on joint job and residential mobility.

Table 2.1: Hypotheses

\begin{tabular}{cccc}
\hline & \multicolumn{3}{c}{ Expected effects } \\
\hline Change job & $\begin{array}{c}\text { Change } \\
\text { residence }\end{array}$ & $\begin{array}{c}\text { Change job } \\
\text { and residence }\end{array}$ \\
\hline Firm tenure & - & $\mathrm{x}$ & - \\
Firm size & - & $\mathrm{x}$ & - \\
Educational level & + & $\mathrm{x}$ & + \\
Salary & - & + & $\mathrm{x}$ \\
Household composition & $\mathrm{x}$ & - & - \\
Changes in household composition & $\mathrm{x}$ & + & + \\
Commuting distance & + & + & - \\
Single-household residence & $\mathrm{x}$ & - & $\mathrm{x}$ \\
Level of urbanization & + & + &
\end{tabular}

+ indicates an expected positive effect, - indicates an expected negative effect, and $\mathrm{x}$ indicates that no clear hypothesis regarding the direction of the effect is established.

\subsection{Data}

\subsubsection{Data sources}

The data employed in this study were provided by Statistics Netherlands. Data on individuals, households, firms and municipalities originate from various sources and were merged for the purpose of this study.

Information on employees and households originates from the Social Statistical Database, which is compiled on the basis of register and survey data from two main sources. Personal information (e.g. date of birth, gender, address, number of households per address) stems from the municipal registration system, which also holds information regarding one's marital status, registered cohabitation, and (changes in) household composition. 
Information regarding employees' jobs (e.g. employer, duration of employment, salary) is provided by the Fibase, a database delivered by the Dutch Tax Administration. Furthermore, data concerning individuals' level of education originate from the Dutch central student register, which is based on information derived from the Informatie Beheer Groep, a Dutch governmental institution. As each individual is identified by a unique identification number, it was possible to merge employees' personal, employment-, household- and housing-related information from these sources.

Information regarding firms - on the level of the 'business unit' originates from the business register, the Survey on Employment and Wages, and the Survey Production Statistics. In the large majority of cases, the 'business unit' is an independent firm, yet it sometimes constitutes a subunit of a larger company. Since each employee can be linked to the respective employer, identified by a unique identification number, firm-related information (sector, size) is also known for each employee.

Furthermore, all personal and firm addresses can be linked to the municipalities $^{4}$ they are located in, hence the location of both place of residence and workplace is known for each employee on the municipal level. This allows for the distance between each employee's place of residence and workplace to be calculated, and to be employed as a measure of commuting distance ${ }^{5}$.

The publicly available database Statline, provided by Statistics Netherlands, comprises municipal-level information such as the number of inhabitants. Hence, it was possible to determine whether an employee lived and/or worked in the municipality of one of the four largest (in terms of population) Dutch cities (Amsterdam, Rotterdam, The Hague and Utrecht $)^{6}$ in 2003, and to construct a CITY dummy $(1=$ located in one of these four cities and $0=$ located elsewhere).

\footnotetext{
4 In 2003, the Netherlands consisted of 489 municipalities. The average number of residents within a municipality was 33,114 .

${ }^{5}$ For intra-municipal commutes, the commuting distance is thus zero.

6 The number of inhabitants for these municipialities in 2003 amounted to 736,562 (Amsterdam), 599,651 (Rotterdam), 463,826 (The Hague) and 265,151 (Utrecht).
} 


\subsubsection{Data description}

In order to analyze job and residential mobility between the years 2003 and 2004, we used the full dataset including all employees from all sectors (NACE7 15-85), and constructed samples of employees working in six selected sectors. These six sectors are Metals \& Machinery (NACE 28/29), Building (NACE 452), Retailing (NACE 52), Finance (NACE 65), Law \& Order (NACE 7523/7524), and Healthcare (NACE 851).

The above variety of sectors was selected in order to investigate possible variation in the determinants of mobility across different industries due to sector-specific characteristics of the labor market. We therefore chose one manufacturing sector (Metals \& Machinery), one construction sector (Building), one wholesale and retail sector (Retailing), one financial intermediation sector (Finance), one public administration and defense sector (Law \& Order), and one health and social work sector (Healthcare). As put forward by $\mathrm{Ng}$ et al. (2007) as well as Rosenfeld (1992), industries may differ with respect to the characteristics of the workforce employed in the sector (e.g. share of highly educated workers, average wage level). These qualities can be expected to have an effect on the mobility of workers employed in the sector (Bailey \& Cooke, 1998).

The data consist of information regarding personal characteristics, household composition and employment in the years 2003 and 2004. Information regarding employees' duration of employment is available with exact start and end dates, while individuals' personal characteristics and household composition are determined once a year (last Friday in September). We therefore limited our analysis to employees holding jobs in both September 2003 and September 2004, since only at those points in time, reliable information regarding all variables of interest is available.

We selected only fulltime workers (at least $0.8 \mathrm{FTE}$ ), as it is difficult to investigate job mobility if employees hold more than one job at the same time. Employees who quit their job between the reference dates in 2003 and 2004 without starting a new job were removed from the samples, as well as

\footnotetext{
${ }^{7}$ Nomenclature statistique des activités économiques dans la Communauté européenne, based on the International Standard Industrial Classification of all Economic Activities (ISIC).
} 
all records for which information on any of the relevant variables (e.g. age, number of children, address) was missing.

It became apparent that the information on salary for the year 2003 was not always fully reliable for those employees who changed jobs within that year, since bonus payments (e.g. compensation of unused hours of leave, 'golden handshake') might incorrectly suggest that job changers received higher salaries in their previous positions than it was actually the case $\mathrm{s}^{9}$ Hence, we selected only employees who had worked in the job which they held at the reference date in 2003 already for some time in 2002, and the information on salary for the year 2002 was used. Since the information on salary was found to be unreliable for jobs which had lasted only a few days in 2002, only employees who had held their job for at least 16 days in 2002 were selected ${ }^{10}$.

Since information regarding higher education (university/college degree) is only available and reliable for employees who were older than 21 and younger than 41 in 2003, we limited our analysis to employees aged 22-40 in order to allow for the inclusion of educational level as an explanatory variable. The full dataset consists of 1,550,249 records, and the samples of the selected industries range from 34,435 (Law \& Order) to 85,258 (Retailing) employees $^{11}$.

\footnotetext{
${ }^{8}$ Roughly $3 \%$ of the cases were removed due to missing information.

9 If salary information from 2003 was used, a positive bias regarding the effect of a person's salary on the propensity to change employers may result due to reverse causality. ${ }^{10}$ Due to this restriction, approximately $15 \%$ of the cases were removed.

${ }^{11}$ We also performed the analysis - excluding educational level as an explanatory variable - without imposing any restrictions on employees' age. The results of the analysis are very much in line with those discussed in section 5, and are available from the authors upon request.
} 


\subsection{Model and variables}

\subsubsection{Model}

We developed and estimated a multinomial logit model (MNL) in order to analyze the determinants of job and residential mobility ${ }^{12}$. The model assumes unordered outcomes and incorporates only individual-specific characteristics (e.g. age, gender, level of education), not choice-specific attributes. In the framework of utility maximization, one assumes that given a choice between $M$ alternatives (indexed, $j=1, \ldots, M$ ), the utility that the $i^{\text {th }}$ person $(i=1, \ldots, N)$ derives from the $j^{t h}$ alternative can be represented as $U_{i j}$ These alternatives do not signify possible available jobs and residences, but represent the four options 'keep job and residence', 'change job and keep residence', 'keep job and change residence', and 'change job and residence'.

Let $Y_{i}$ be a random variable whose value $(j=1, \ldots, 4)$ indicates the choice made by person $i$, then the probability that this person prefers to keep both his/her job and place of residence $(m=1)$, to change jobs $(m=2)$ or houses $(m=3)$, or to change both $(m=4)$ is

$$
\operatorname{Pr}\left(Y_{i}=m\right)=\operatorname{Pr}\left(U_{i m}>U_{i j}\right) \text { for all } j=1, \ldots, 4, j \neq m
$$

An individual logically chooses the option for which the expected utility will be highest. The utility is built up as $U_{i j}=V_{i j}+\varepsilon_{i j}$ where $V_{i j}$ is observable and measurable, while $\varepsilon_{i j}$ is a random term. In case $\varepsilon_{i j}$ is Gumbel distributed, we have the multinomial logit model.

\footnotetext{
12 We also tried a multinomial probit model (MNP), and obtained very similar results. The Hausman and Small-Hsiao tests of the IIA assumption suggest that MNL and MNP outcomes should be very close, as the null hypothesis of the odds being independent of other alternatives is either not rejected, or only marginally so.
} 


\subsubsection{Variables}

The dependent variable is MOBILITY. Table 2.2 displays the four alternatives as specified in the multinomial logit model, and their respective frequencies for the full dataset and the six selected sectors.

Table 2.2: Mobility

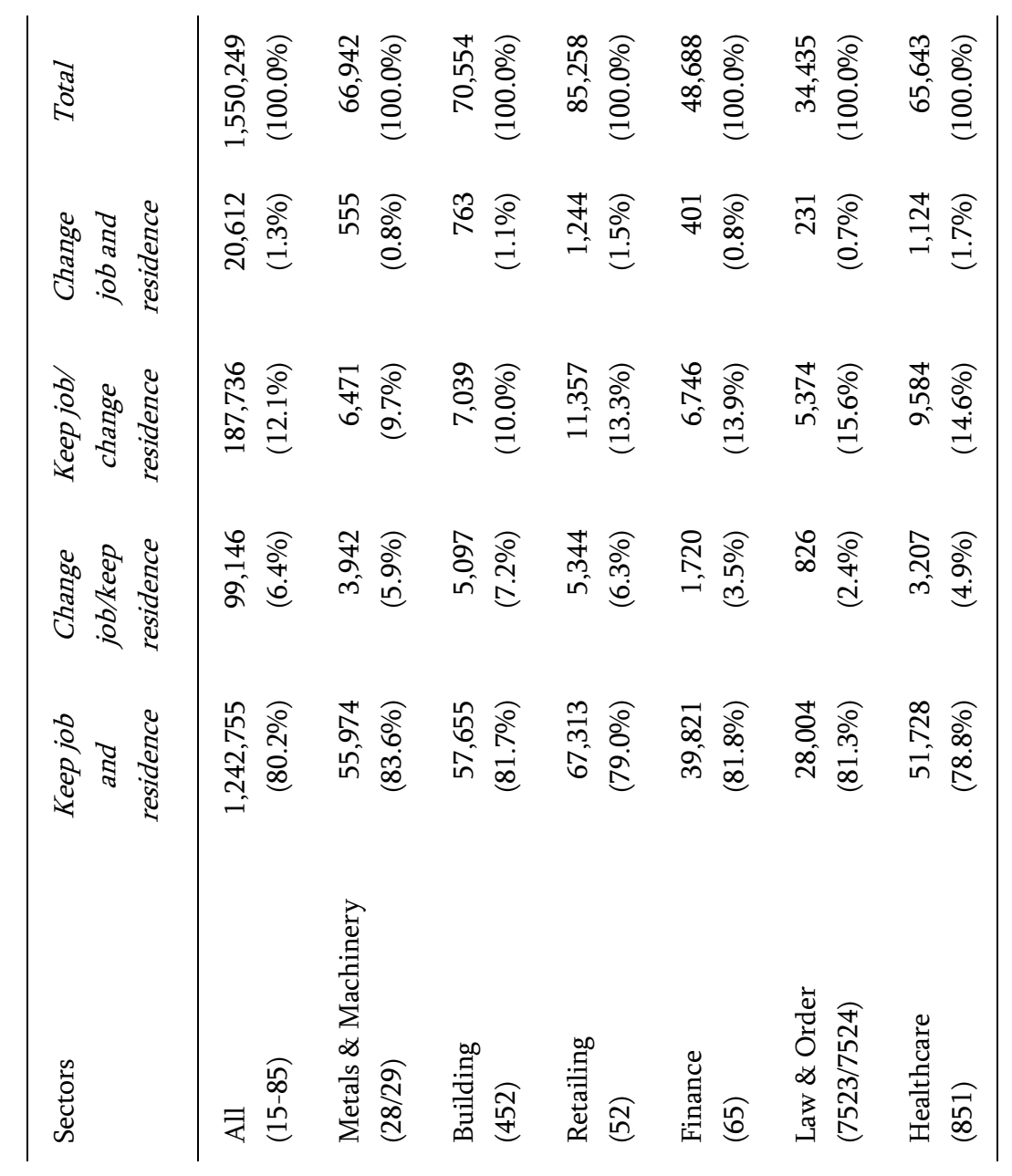

The first category is 'keep job and residence', consisting of individuals who changed neither their job, nor their place of residence between 
September 2003 and 2004. The next category, 'change job/keep residence', comprises job changers who did not migrate between the reference dates in 2003 and 2004. The third category - 'keep job/change residence' encompasses those who moved houses without changing employers, while the last category - 'change job and residence' - consists of those who changed employers and relocated. In total, 1,242,755 (80.2\%) individuals changed neither their job nor their place of residence, while 99,146 (6.4\%) changed their jobs without migrating. A total of 187,736 (12.1\%) persons moved houses without changing employers, and 20,612 (1.3\%) changed jobs and relocated. Regarding the six selected sectors, the highest share of job changers was observed in the Building sector (7.2\%), whereas job mobility is comparatively low for employees in Law \& Order (2.4\%). While the largest fraction of those having changed their place of residence was found in the Law \& Order sector (15.6\%), only $9.7 \%$ of the employees in Metals \& Machinery relocated. The highest percentage of employees having changed both their job and place of residence was observed in Healthcare (1.7\%), whereas only $0.7 \%$ of the employees in Law \& Order changed jobs and moved houses.

Table 2.3 presents the explanatory and control variables employed in the analysis. FIRM_TENURE - the proxy for the strength of the employee's ties with the current employer - is the number of years the employee had been employed with the same firm in 2003, while FIRM_SIZE - proxying internal opportunities - is the natural logarithm of the average number of employees working for the employee's employer in 2003. HIGH_EDUCATION - the proxy for external opportunities - denotes whether the employee holds a degree in higher education or not, and SALARY is the natural logarithm of the employee's daily salary in 2002. PARTNER - proxying the strength of the employee's family ties - measures whether the employee had a registered partner in 2003, CHILDREN - also a proxy for family ties - denotes the number of children in the employee's household in 2003, and PARTNER_JOB - likewise proxying the strength of the employee's family ties - indicates whether the employee had a partner with a fulltime job (at least 0.8 FTE) in 2003. Regarding changes in household composition, CHILDREN_GAIN denotes the change (between 2002 and 2003) in the number of children living in the employee's household. The variable DISTANCE measures the commuting distance (in 10 kilometers) between the 
employee's place of residence and workplace in $2003^{13}$, and SINGLE_UNIT denotes whether the employee was living in a single-household unit in 2003, thereby proxying attachment to the dwelling. CITY indicates whether the employee lived and/or worked in the municipality of one of the four largest Dutch cities - namely Amsterdam, Rotterdam, The Hague and Utrecht ${ }^{14}$ - in 2003. This variable proxies for both job and housing opportunities.

Table 2.3: Definitions of variables used in the analysis

\begin{tabular}{ll}
\hline Variable & Definition \\
\hline FIRM_TENURE & Firm tenure (in years) in 2003 \\
FIRM_SIZE & $\begin{array}{l}\text { Natural logarithm of firm size (average number of } \\
\text { employees) in } 2003\end{array}$ \\
& $1=$ university/college degree and $0=$ otherwise (in 2003) \\
HIGH_EDUCATION & Natural logarithm of daily salary (in $€$ ) in 2002 \\
SALARY & $1=$ registered partnership and $0=$ otherwise (in 2003) \\
PARTNER & Number of children in the household in 2003 \\
CHILDREN & $1=$ partner with fulltime job (at least 0.8 FTE) in 2003 and \\
PARTNER_JOB & $0=$ otherwise \\
CHILDREN_GAIN & Number of children added to household between 2002 and \\
& 2003 \\
DISTANCE & Distance between place of residence and place of work (in \\
& 2003 in 10 km) \\
SINGLE_UNIT & $1=$ living in single-household residence and $0=$ otherwise \\
& (in 2003) \\
CITY & $1=$ living and/or working in the municipality of one of the \\
four largest Dutch cities and $0=$ otherwise (in 2003) & Age (in years) of employee in 2003 \\
AGE & $1=$ female and $0=$ male \\
FEMALE &
\end{tabular}

${ }^{13}$ Especially in the case of larger organizations, a firm (BE) can have more than one location. If an employee was found to be employed with a firm having multiple establishments, the location closest to the employee's place of residence was selected as the most probable workplace.

14 These cities are located in the so-called 'Randstad', a densely populated region in the Western part of the Netherlands with about seven million inhabitants. More than $40 \%$ of the Dutch population live in this area, although it accounts for only about $20 \%$ of the country's surface. 
We control for age, since it is commonly found to impede both job and residential mobility (e.g. Bergin, 2009; Dieleman et al., 2000; Helderman et al., 2004; Helderman et al., 2006; Henneberger \& Sousa-Poza, 2002; Linneman \& Graves, 1983; Nivalainen, 2004; Ritsilä \& Ovaskainen, 2001; Schneider, 2007; Van Ham et al., 2001). The significance of locational ties has been argued to increase with age (Ritsilä \& Ovaskainen, 2001), and older individuals are assumed to have accumulated larger stocks of specific human capital, causing interfirm mobility to be progressively disadvantageous (e.g. Schneider, 2007). AGE indicates the age (in years) of the employee in 2003. We also control for gender, although it has been reasoned that the effect of gender on mobility may be ambiguous (Ritsilä \& Ovaskainen, 2001), or even absent (Bergin, 2009). FEMALE denotes the gender of the employee.

The descriptive statistics for the explanatory and control variables used in the study are displayed in Table 2.4. (Note: for all dummy variables, the value ' 1 ' signifies 'yes', while the value ' 0 ' denotes 'no'.) On average, employees had been employed with their current employer for 5.28 years. Some $22 \%$ of the workforce had a degree in higher education. Two thirds of the employees had a registered partner in 2003, on average 0.84 children were living in an employee's household, and about one third of the employees had a partner who was also working in a fulltime position. On average, households gained 0.09 children between 2002 and 2003. The average commuting distance was 12.7 kilometers (one-way), more than $90 \%$ of the employees were living in single-household units, and $21 \%$ were living and/or working in one of the four largest Dutch cities. Employees were on average 32.1 years old, and 29\% of the workforce were female ${ }^{15}$.

15 The relatively low share of females can be explained by the fact that many Dutch women have parttime jobs. 
Table 2.4: Descriptive statistics (all sectors)

\begin{tabular}{lrrrr}
\hline & Minimum & Maximum & Mean & Std. Deviation \\
\hline FIRM_TENURE & 1.00 & 26.00 & 5.28 & 4.350 \\
FIRM_SIZE & 0.00 & 11.02 & 5.59 & 2.559 \\
HIGH_EDUCATION & 0.00 & 1.00 & 0.22 & 0.413 \\
SALARY & 3.03 & 10.05 & 4.38 & 0.347 \\
PARTNER & 0.00 & 1.00 & 0.66 & 0.475 \\
CHILDREN & 0.00 & 16.00 & 0.84 & 1.052 \\
PARTNER_JOB & 0.00 & 1.00 & 0.31 & 0.461 \\
CHILDREN_GAIN & 0.00 & 10.00 & 0.09 & 0.309 \\
DISTANCE & 0.00 & 31.50 & 1.27 & 2.172 \\
SINGLE_UNIT & 0.00 & 1.00 & 0.94 & 0.240 \\
CITY & 0.00 & 1.00 & 0.21 & 0.407 \\
AGE & 22.00 & 40.00 & 32.09 & 5.091 \\
FEMALE & 0.00 & 1.00 & 0.29 & 0.456 \\
\hline
\end{tabular}

Number of observations: $1,550,249$

\subsection{Results and discussion}

\subsubsection{The determinants of job mobility}

Tables 2.5 to 2.7 present the results of the multinomial regressions. The explanatory power proved to be rather constant across sectors, with values for the Nagelkerke $\mathrm{R}^{2}$ ranging from 0.078 to 0.112 . The signs of the coefficients indicate the direction of change in the relative risk-ratio $-\operatorname{Pr}\left(Y_{i}\right.$ $=j) / \operatorname{Pr}\left(Y_{i}=1\right)-$ in response to a change in the value of the variable to which the coefficient is attached. The base category $\left(Y_{i}=1\right)$ is 'keep job and residence'.

We first discuss the determinants of job mobility (Table 2.5). The estimation results confirm our hypothesis regarding the negative effect of the strength of an employee's ties with the current employer on the propensity to change jobs, as job mobility indeed decreases with firm tenure. Interfirm mobility also tends to decrease with firm size, indicating that larger firms 
indeed offer better career opportunities within the firm. However, for employees in Law \& Order, job mobility becomes more likely with increasing firm size. A possible explanation might be that for employees in Law \& Order, a 'larger firm' equals a larger institution respectively an institution located in a densely populated area as employer, which may be perceived as an unpleasant work environment.

We further established that in general, employees having a degree in higher education and/or being situated in a large city are more likely to change jobs, hence our hypothesis with respect to the effect of employees' external opportunities - due to personal qualities or the abundance of alternative employment options - on their propensity to change employers was generally confirmed. Yet, the effect of employees' presumed chances of alternative employment on consequent interfirm mobility is evidently sector-dependent, as, for example, the mobility decisions of workers in Building and in Finance are not affected by the availability of external options. These findings suggest that employees in these sectors do not change employers in order to advance their careers, but may move forward internally.

Our findings regarding the effect of employees' current financial remuneration on their propensity to change jobs are mixed. For the full dataset, a person's salary was not found to have any significant effect on the propensity to change employers. Yet, the assumed negative impact of salary on interfirm mobility was established for employees in Building and in Finance, whereas we found this effect to be positive and significant for employees in Law \& Order and Healthcare. The positive effect of salary on the propensity to change jobs suggests that for well-paid, presumably ambitious employees in these sectors, changing employers is the usual way to advance one's career.

In line with our hypothesis, the distance ${ }^{16}$ between an employee's place of residence and workplace was found to be a significant determinant of a consequent job change, suggesting that employees benefit from a reduced commuting time.

\footnotetext{
${ }^{16}$ We also investigated the impact of distance_squared in order to check for non-linear effects of commuting distance on mobility, but did not find improved statistical fit.
} 
The propensity to change employers is, in general, lower for older employees. These findings suggest that older employees previously accumulated higher amounts of occupation-specific knowledge, and are therefore more inclined to stay with their current employer, especially since they have less time to recoup the costs associated with moving. Furthermore, female employees generally have a lower propensity to change employers.

\subsubsection{The determinants of residential mobility}

With respect to residential mobility (Table 2.6), the results illustrate that the propensity to relocate is indeed lower for married individuals, yet it does not decrease with the number of children. Hence, the results partly confirm our hypothesis regarding the negative effect of the strength of an employee's family ties (marital status, family size) on the propensity to move, and lend partial support to our assumption that individuals behave altruistically towards members of their families.

Having a partner with a fulltime job does not hamper residential mobility, but double-earners appear to be more likely to move houses. Since households with a double income are in general more affluent than those with a single income, we assume that residential mobility is facilitated by the financial means available, and may be motivated by the desire to relocate to a comparatively more agreeable place of residence and/or neighborhood.

We also established that previous changes regarding the composition of one's household do not affect the likelihood to move. This finding indicates that the birth of a child does not induce subsequent residential mobility, but suggests that couples who intend to be parents will plan ahead and move at an earlier point in time.

As hypothesized, we found that employees earning comparatively high salaries are generally more likely to migrate, indicating the precondition of having the necessary financial means in order to realize a residential move. Interestingly, the effect does not hold for employees in Finance, Law \& Order, and Healthcare, the latter two being (primarily) public service sectors. These results suggest that for employees working in the public service sector, the impact of one's salary on the likelihood of relocation is smaller than for employees in the private sector. 
The effect of commuting distance on residential mobility was found to be weak, indicating that employees in the Netherlands who face long journeys to and from work are more likely to change employers than to relocate. Employees living in single-household units were, as hypothesized, found to be less likely to relocate. Furthermore, as expected, individuals living and/or working in a large city are generally more likely to change their place of residence.

Age was found to inhibit residential mobility, suggesting that older individuals are aware of the shorter time period over which they are able to realize any adjustment benefits associated with residence site choice. Females, on the other hand, appear to have a tendency to be more residentially mobile than men.

\subsubsection{The determinants of job and residential mobility}

Table 2.7 indicates that the inclination to change both job and place of residence decreases across all industries with the strength of an employee's ties with the current employer and the attachment to the current residence. Generally, it also decreases with the existing internal career opportunities and the strength of the employee's family ties, while it increases with the assumed external career prospects.

Many of our findings are clearly sector-dependent. For employees in Law \& Order and in Healthcare, the propensity to change jobs and move houses increases (instead of decreases) with the size of the current employer. These findings correspond to those discussed in section 5.1, and again suggest that for employees in these sectors, a 'larger firm' equals a larger institution respectively an institution located in a densely populated area as employer, which may be perceived as an unpleasant work environment.

Overall, individuals with a high income and/or a degree in higher education are more likely to change both their workplace and place of residence. These findings - along the lines of Chen and Rosenthal (2008), who found that individuals with high human capital move to productive locations (...) in order to take advantage of their skills' (p. 520) - suggest that especially ambitious (highly-educated, already well-paid) individuals who aim to advance their careers are also willing to simultaneously relocate. In 
Finance, however, highly educated individuals have a lower propensity to change jobs and move houses, suggesting that employees in the financial sector do not use interfirm mobility in order to advance their careers, but ambitious individuals may have ample opportunities within the firm.

While employees with a partner who also works fulltime were found to be more likely to change houses, having a partner with a fulltime job does not necessarily promote joint job and residential mobility. These findings are in line with Clark and Davies Withers (2007), and may illustrate the expected altruistic behavior on the part of the employee, since residential relocation most likely reflects intraregional moves (e.g. to a nicer house or a more pleasant environment), while joint job and residential mobility is more likely to indicate a job-induced, interregional move which may require the partner to give up his or her job.

Changes regarding the composition of one's household encourage employees to change their job and place of residence to a much greater extent than to only change their place of residence. As changes regarding the number of children present in the household were measured between 2002 and 2003, this finding may indicate that after the birth of a child, parents again focus on advancing their careers before finally settling down when their children start going to school. Moreover, employees who recently became parents may modify their career path by switching to a more familyfriendly employer offering better childcare facilities or more flexible work arrangements.

We established that larger distances between one's place of residence and place of work not only encourage job changes or migration, but also joint job and residential mobility. These findings indicate that employees who have to commute long distances might indeed search more intensively in both the job and the housing market, thereby being more likely to come across interesting 'offers'. In addition, these individuals might more willingly change jobs and relocate because they feel comparatively less attached to both their social and professional environments. It also became evident that employees living in single-household units have a decreased propensity to change jobs and move houses, suggesting that one's attachment to the present dwelling also impedes presumably career-related residential moves.

We found that employees living and/or working in one of the four largest 
Dutch cities appear to either switch jobs, or to change houses, but not necessarily both. These findings suggest that in the highly congested areas of the four largest Dutch municipalities, job and residence changes often serve as substitutes.

\subsubsection{Limitations}

This study is not without limitations. First of all, an analysis of the determinants of job mobility would benefit from a differentiation between voluntary and involuntary job changes. Unfortunately, the data available do not provide information regarding the reasons underlying employees' job changes ${ }^{17}$. Next, we do not have information on individuals' character traits such as their averseness to risk. The omission of the variable 'risk-averseness' may bias our results.

Since changes between the reference dates in two consecutive years are used in the analysis, any information referring to the timespan in between (e.g. additional jobs held) gets lost. Furthermore, since the samples were restricted to fulltime employees, job changes to parttime jobs or the reduction of an existing job from fulltime to parttime were recorded as 'moveouts', and the records were deleted from the samples.

Given that the information on salary in 2002 was used, only employees with jobs already existing in 2002 could be selected. As, however, previous mobility is argued to induce further mobility (e.g. Linneman \& Graves, 1983; Nivalainen, 2004), this may lead to some sample selection bias, since the records of frequent job changers were more likely to be removed from the samples.

\footnotetext{
17 The share of voluntary job changes could be approximated by regarding those employees as voluntary movers whose period of unemployment between jobs did not exceed a specific timespan. We found that about $15-20 \%$ of the 'movers' had been unemployed for more than 90 days between jobs, indicating that probably less than $1 / 5$ of the moves could be considered unintended.
} 
Table 2.5: Multinomial logit regression model: change job/keep residence

\begin{tabular}{|c|c|c|c|c|c|c|c|c|}
\hline 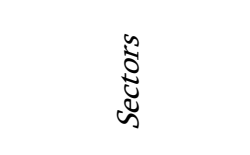 & $\nexists$ & 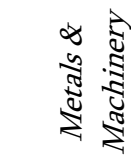 & $\begin{array}{l}\text { : } \\
: \mathbb{I} \\
: \mathbb{I} \\
0\end{array}$ & 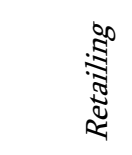 & 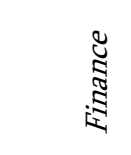 & 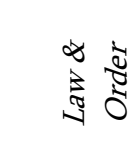 & 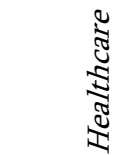 & \\
\hline & Coeff. & Coeff. & Coeff. & Coeff. & Coeff. & Coeff. & Coeff. & \\
\hline \multirow[t]{2}{*}{ FIRM_TENURE } & -0.115 & * $\quad-0.107$ & * $\quad-0.111$ & * $\quad-0.110$ & * $\quad-0.125$ & * $\quad-0.041$ & * $\quad-0.163$ & 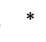 \\
\hline & $(0.001)$ & $(0.005)$ & $(0.005)$ & $(0.005)$ & $(0.010)$ & $(0.012)$ & $(0.007)$ & \\
\hline \multirow[t]{2}{*}{ FIRM_SIZE } & -0.050 & * $\quad-0.136$ & * $\quad-0.061$ & $* \quad-0.035$ & * $\quad-0.062$ & * $\quad 0.106$ & * $\quad-0.047$ & 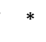 \\
\hline & $(0.002)$ & $(0.012)$ & $(0.009)$ & $(0.005)$ & $(0.008)$ & $(0.027)$ & $(0.010)$ & \\
\hline \multirow[t]{2}{*}{ HIGH_EDUCATION } & 0.125 & * $\quad 0.126$ & * $\quad 0.034$ & 0.326 & * -0.010 & 0.304 & * $\quad 0.376$ & 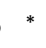 \\
\hline & $(0.009)$ & $(0.054)$ & $(0.056)$ & $(0.056)$ & $(0.055)$ & $(0.093)$ & $(0.041)$ & \\
\hline \multirow[t]{2}{*}{ SALARY } & -0.009 & -0.052 & -0.424 & * -0.012 & -0.176 & * $\quad 0.936$ & * $\quad 0.582$ & 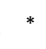 \\
\hline & $(0.012)$ & $(0.075)$ & $(0.071)$ & $(0.059)$ & $(0.080)$ & $(0.187)$ & $(0.070)$ & \\
\hline \multirow[t]{2}{*}{ PARTNER } & -0.006 & 0.033 & 0.086 & $* \quad 0.025$ & -0.128 & -0.174 & -0.054 & \\
\hline & $(0.009)$ & $(0.045)$ & $(0.040)$ & $(0.039)$ & $(0.072)$ & $(0.103)$ & $(0.055)$ & \\
\hline \multirow[t]{2}{*}{ CHILDREN } & -0.041 & $* \quad-0.052$ & * -0.053 & * $\quad-0.074$ & * $\quad-0.029$ & -0.003 & -0.077 & 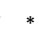 \\
\hline & $(0.004)$ & $(0.018)$ & $(0.015)$ & $(0.016)$ & $(0.031)$ & $(0.043)$ & $(0.024)$ & \\
\hline \multirow[t]{2}{*}{ PARTNER_JOB } & -0.054 & * $\quad-0.017$ & -0.091 & * $\quad-0.139$ & * -0.046 & 0.046 & -0.019 & \\
\hline & $(0.009)$ & $(0.047)$ & $(0.043)$ & $(0.042)$ & $(0.070)$ & $(0.102)$ & $(0.054)$ & \\
\hline \multirow[t]{2}{*}{ CHILDREN_GAIN } & 0.035 & * $\quad 0.055$ & 0.041 & -0.022 & 0.110 & -0.117 & 0.237 & 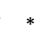 \\
\hline & $(0.011)$ & $(0.052)$ & $(0.045)$ & (0.053) & $(0.085)$ & $(0.130)$ & $(0.065)$ & \\
\hline \multirow[t]{2}{*}{ DISTANCE } & 0.056 & * $\quad 0.040$ & * $\quad 0.034$ & * $\quad 0.070$ & * $\quad 0.120$ & * $\quad 0.160$ & * $\quad 0.125$ & 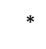 \\
\hline & $(0.001)$ & $(0.007)$ & $(0.006)$ & $(0.007)$ & $(0.013)$ & $(0.023)$ & $(0.009)$ & \\
\hline \multirow[t]{2}{*}{ SINGLE_UNIT } & 0.001 & 0.025 & -0.039 & 0.072 & -0.064 & -0.104 & 0.001 & \\
\hline & $(0.015)$ & $(0.085)$ & $(0.079)$ & $(0.066)$ & $(0.113)$ & $(0.156)$ & $(0.080)$ & \\
\hline \multirow[t]{2}{*}{ CITY } & 0.154 & * $\quad 0.215$ & * $\quad 0.080$ & 0.023 & 0.081 & -0.044 & 0.192 & ? \\
\hline & $(0.008)$ & $(0.063)$ & $(0.048)$ & $(0.040)$ & $(0.058)$ & $(0.087)$ & $(0.039)$ & \\
\hline \multirow[t]{2}{*}{ AGE } & -0.025 & * $\quad-0.012$ & * $\quad-0.006$ & -0.037 & * $\quad-0.037$ & $* \quad-0.075$ & $\begin{array}{ll}* & -0.007\end{array}$ & \\
\hline & $(0.001)$ & $(0.004)$ & $(0.003)$ & $(0.004)$ & $(0.007)$ & $(0.010)$ & $(0.005)$ & \\
\hline \multirow[t]{2}{*}{ FEMALE } & -0.134 & * $\quad-0.180$ & * -0.322 & * $\quad-0.329$ & * $\quad-0.075$ & -0.236 & $* \quad-0.152$ & \\
\hline & (0.009) & (0.069) & $(0.074)$ & $(0.033)$ & $(0.056)$ & $(0.080)$ & $(0.042)$ & \\
\hline
\end{tabular}

The reference category is 'keep job and residence'. * indicates significance at the 5\%-level.

For the full dataset, we employ industry dummies (2-digit). Standard errors are shown in parentheses. 
Table 2.6: Multinomial logit regression model: keep job/change residence

\begin{tabular}{|c|c|c|c|c|c|c|c|c|}
\hline \multirow[t]{2}{*}{$\begin{array}{l}\tilde{\Xi} \\
\tilde{\Xi} \\
\tilde{\Xi}\end{array}$} & ₹ & 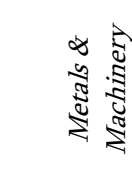 & $\begin{array}{l}\text { : } \\
: \mathbb{I} \\
\mathbb{I} \\
\infty\end{array}$ & 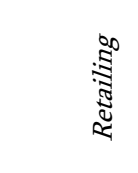 & 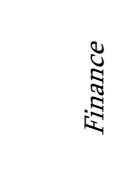 & $\begin{array}{l}\tilde{\Xi} \\
\tilde{J} \\
\infty \\
\infty \\
\vec{J}\end{array}$ & 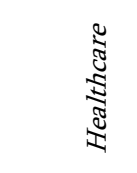 & \\
\hline & Coeff. & Coeff. & Coeff. & Coeff. & Coeff. & Coeff. & Coeff. & \\
\hline \multirow[t]{2}{*}{ FIRM_TENURE } & -0.032 & * $\quad-0.035$ & * $\quad-0.028$ & * -0.033 & $* \quad-0.022$ & * $\quad-0.027$ & * $\quad-0.030$ & * \\
\hline & $(0.001)$ & $(0.004)$ & $(0.004)$ & $(0.003)$ & $(0.004)$ & $(0.005)$ & $(0.004)$ & \\
\hline \multirow[t]{2}{*}{ FIRM_SIZE } & 0.010 & * $\quad 0.017$ & 0.017 & * $\quad 0.009$ & * $\quad 0.020$ & * -0.017 & -0.002 & \\
\hline & $(0.001)$ & $(0.010)$ & $(0.008)$ & $(0.004)$ & $(0.006)$ & $(0.011)$ & $(0.007)$ & \\
\hline \multirow[t]{2}{*}{ HIGH_EDUCATION } & 0.066 & * 0.110 & * $\quad 0.210$ & * $\quad 0.048$ & 0.073 & * -0.040 & 0.087 & * \\
\hline & $(0.007)$ & $(0.043)$ & $(0.045)$ & $(0.045)$ & $(0.030)$ & $(0.044)$ & $(0.026)$ & \\
\hline \multirow[t]{2}{*}{ SALARY } & 0.135 & * $\quad 0.290$ & * $\quad 0.226$ & * 0.306 & $* \quad 0.059$ & 0.014 & 0.008 & \\
\hline & $(0.010)$ & $(0.062)$ & $(0.063)$ & $(0.043)$ & $(0.045)$ & $(0.084)$ & $(0.049)$ & \\
\hline \multirow[t]{2}{*}{ PARTNER } & -0.507 & $* \quad-0.503$ & $* \quad-0.650$ & $* \quad-0.506$ & * $\quad-0.491$ & * -0.472 & * $\quad-0.541$ & * \\
\hline & $(0.007)$ & $(0.035)$ & $(0.035)$ & $(0.030)$ & $(0.040)$ & $(0.046)$ & $(0.036)$ & \\
\hline \multirow[t]{2}{*}{ CHILDREN } & -0.003 & -0.027 & -0.003 & 0.000 & 0.033 & 0.012 & 0.070 & * \\
\hline & $(0.003)$ & $(0.014)$ & $(0.013)$ & $(0.011)$ & $(0.017)$ & $(0.019)$ & $(0.013)$ & \\
\hline \multirow[t]{2}{*}{ PARTNER_JOB } & 0.143 & * $\quad 0.114$ & * $\quad 0.130$ & * $\quad 0.080$ & * $\quad 0.103$ & $\begin{array}{ll}* & 0.227\end{array}$ & * $\quad 0.088$ & * \\
\hline & $(0.008)$ & $(0.041)$ & $(0.041)$ & $(0.033)$ & $(0.040)$ & $(0.047)$ & $(0.038)$ & \\
\hline \multirow[t]{2}{*}{ CHILDREN_GAIN } & 0.060 & * -0.001 & 0.019 & 0.044 & 0.055 & 0.040 & 0.072 & \\
\hline & $(0.009)$ & $(0.045)$ & $(0.043)$ & $(0.037)$ & $(0.048)$ & $(0.054)$ & $(0.045)$ & \\
\hline \multirow[t]{2}{*}{ DISTANCE } & 0.015 & * $\quad 0.013$ & * $\quad-0.003$ & 0.008 & 0.010 & 0.008 & 0.022 & * \\
\hline & $(0.001)$ & $(0.006)$ & $(0.006)$ & $(0.007)$ & $(0.012)$ & $(0.015)$ & $(0.008)$ & \\
\hline \multirow[t]{2}{*}{ SINGLE_UNIT } & -1.083 & * -1.133 & * $\quad-1,059$ & $* \quad-1.060$ & * -1.050 & * -1.116 & * -1.026 & * \\
\hline & $(0.008)$ & $(0.045)$ & $(0.047)$ & $(0.034)$ & $(0.047)$ & $(0.050)$ & $(0.036)$ & \\
\hline \multirow[t]{2}{*}{ CITY } & 0.055 & * $\quad 0.161$ & * 0.142 & * $\quad-0.036$ & 0.064 & 0.095 & * $\quad 0.042$ & \\
\hline & $(0.006)$ & $(0.051)$ & $(0.040)$ & $(0.029)$ & $(0.033)$ & $(0.037)$ & $(0.026)$ & \\
\hline \multirow[t]{2}{*}{ AGE } & -0.065 & * $\quad-0.066$ & * $\quad-0.066$ & $* \quad-0.071$ & * $\quad-0.067$ & * $\quad-0.063$ & $\begin{array}{ll}* & -0.073\end{array}$ & * \\
\hline & $(0.001)$ & $(0.003)$ & $(0.003)$ & $(0.003)$ & $(0.004)$ & $(0.004)$ & $(0.003)$ & \\
\hline \multirow[t]{2}{*}{ FEMALE } & 0.031 & * 0.152 & * $\quad 0.167$ & * $\quad 0.056$ & * $\quad-0.013$ & -0.041 & -0.031 & \\
\hline & $(0.006)$ & $(0.049)$ & $(0.055)$ & $(0.023)$ & $(0.030)$ & $(0.034)$ & $(0.027)$ & \\
\hline
\end{tabular}

The reference category is 'keep job and residence'. * indicates significance at the 5\%-level.

For the full dataset, we employ industry dummies (2-digit). Standard errors are shown in parentheses. 
Table 2.7: Multinomial logit regression model: change job and residence

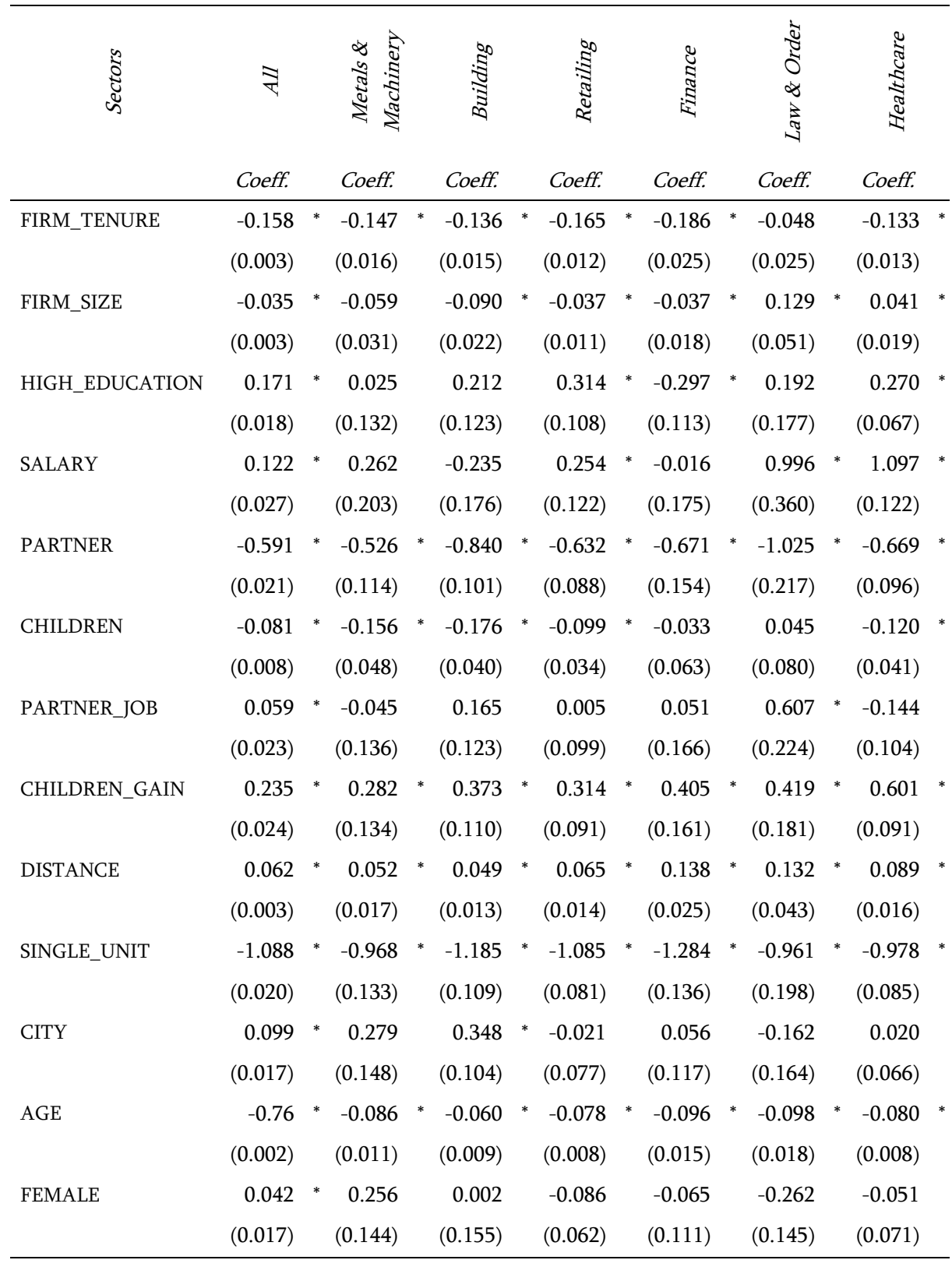

The reference category is 'keep job and residence'. * indicates significance at the 5\%-level.

For the full dataset, we employ industry dummies (2-digit). Standard errors are shown in parentheses. 


\subsection{Conclusions}

The results of the empirical analysis illustrate that individuals assess the advantages and disadvantages of changing one's job and/or place of residence by taking into account the strength of their family- and job-related ties as well as their attachment to the present residence. Furthermore, the presence of internal career opportunities impedes job changes, while mobility is promoted by the existence of external options.

A high salary was found to facilitate relocation, however, our findings regarding the effect of salary on interfirm mobility were mixed. We further established that a high salary generally encourages joint job and residential mobility, suggesting that skilled, ambitious individuals already in advantageous positions decide to switch employers in order to further advance their careers.

Long commuting distances encourage employees to change jobs, or to relocate. Our findings also indicate that employees who have to commute long distances not necessarily view job and residential moves as substitutes, since long commuting distances also have a positive impact on joint job and residential mobility. As these employees can be assumed to search more intensively in both the job and the housing market, they might be more likely to spot attractive vacancies. Furthermore, it may be the case that these individuals feel comparatively less attached to both their social and professional environments, and might therefore more willingly change jobs and relocate.

Individuals living and/or working in one of the four largest Dutch cities have an increased likelihood to change jobs or houses. These findings suggest that in the highly congested areas of the four largest Dutch municipalities, individuals make use of the abundance of nearby alternative offers on the job and housing markets.

Our findings illustrate the need to differentiate between interfirm mobility not involving migration, and job changes requiring the residential relocation of the employee and possible additional family members. While job mobility not including geographical relocation is to a great extent determined by a worker's personal characteristics (e.g. the accumulated human capital, or the strength of one's ties with the current employer), joint interfirm and residential mobility is also influenced by the structure of the 
household the employee is part of. Accordingly, since migration affects all members of the household, a prospective job changer is presumed to take the welfare of these into consideration when assessing the benefits and shortcomings of a possible job change including residential relocation. Furthermore, the results illustrate the importance of locational characteristics such as commuting distance or urbanization on the propensity to change jobs and/or houses.

The study uncovered sector-specific effects. We found differences between employees in the public and the private sectors, mainly with regard to residential mobility. Internal and external job opportunities also appear to play different roles across different sectors of the economy. 



\title{
CHAPTER 3
}

\section{FIRM RELOCATIONS IN THE NETHERLANDS: WHY DO FIRMS MOVE, AND WHERE DO THEY GO? ${ }^{18}$}

\begin{abstract}
This chapter analyzes determinants of business relocation and identifies regional characteristics which attract relocating firms. Results indicate that the relocation decisions of firms are sector-dependent, and the migratory behavior of firms in knowledge-intensive sectors notably differs from that in less knowledge-intensive sectors. Predominantly low-tech manufacturing and less knowledge-intensive service firms paying high average salaries have a higher probability to move out of their present location. For less knowledge-intensive service firms, the average municipal wage negatively affects their propensity to relocate, while those located in municipalities with high sector-specific wages have an increased likelihood to move. Relocating firms are generally attracted by densely populated municipalities with high wage levels, and primarily service firms are drawn to municipalities which are specialized in the firm's own sector and appeal to individuals. Sectorspecific wages may either attract, or deter firms, suggesting that this variable may capture both the cost and the quality of the locally available workforce.
\end{abstract}

\footnotetext{
18 This chapter is based on the following article: Kronenberg, K. (2012). Firm relocations in the Netherlands: Why do firms move, and where do they go? Forthcoming in Papers in Regional Science.
} 


\subsection{Introduction}

The economic landscape of a country is shaped by the formation of new enterprises, the growth and decline of existing businesses, and the spatial redistribution of economic activity due to the relocation of firms. Yet, while numerous studies analyze determinants of new firm formation, or reasons underlying the growth of existing companies, the issue of firm relocation has remained comparatively uninvestigated.

Previous studies found that a firm's decision to relocate is motivated by firm- and location-specific factors which 'push' the firm from its present location (e.g. Brouwer et al., 2004; Van Dijk \& Pellenbarg, 2000; Van Wissen, 2000), and that firms which relocate are likely to be 'pulled' to regions which are attractive to them (e.g. Capasso et al., 2010; Erickson \& Wasylenko, 1980; Holl, 2004a; Van Dijk \& Pellenbarg, 2000; Van Wissen, 2000).

This study analyzes determinants of business relocation, and identifies regional characteristics which attract relocating firms. A firm's decision to move is expected to depend upon characteristics of the firm, and of the region it is located in. The decision of where to locate is assumed to be motivated by the characteristics of the regions the firm can choose between. The dataset used in this study was provided by Statistics Netherlands (CBS). It is based on register data covering virtually all businesses and workers in the Netherlands, and consists of information regarding the characteristics of Dutch firms, employees, and municipalities in the years 2002-2004.

The research contributes to the existing literature in several respects. Firstly, it analyzes both regional 'push'- and 'pull'-factors. Interestingly, while numerous studies acknowledge the relevance of both the characteristics of a firm's region of origin (which might push a firm from its present location, or keep it there), and the qualities of a firm's region of destination (which might pull a firm towards this location), most analyses either focus on reasons underlying the outmigration of firms, or concentrate on regional features which attract relocating businesses. A notable exception is Van Wissen (2000), who explicitly argues for a two-step decision model.

Secondly, while previous work - supposedly mainly for reasons of data availability - often focuses on the migration behavior of manufacturing firms, this study differentiates between firms in knowledge-intensive respectively high-tech and less knowledge-intensive respectively low-tech 
manufacturing and service sectors, thereby taking into consideration probable intersectoral differences regarding firms' decisions to relocate as well as their locational preferences.

Thirdly, it analyzes the interregional relocation of firms on the very detailed level of the municipality, an approach which has been found to be well-suited for the analysis of firms' relocation decisions (Arauzo-Carod, 2005; Holl, 2004a; Rosenthal \& Strange, 2003), yet has rarely been employed for the Netherlands ${ }^{19}$. Fourthly, it takes into account firm- and municipal sector-specific wages regarding their effect on firm mobility and their ability to attract businesses, analyzing the relevance of the wage-inherent aspects 'cost' and 'quality' for different kinds of sectors.

Results indicate that the relocation decisions of firms are sectordependent, and the migratory behavior of firms in knowledge-intensive sectors notably differs from that in less knowledge-intensive sectors. Predominantly low-tech manufacturing and less knowledge-intensive service firms paying high average salaries have a higher probability to move out of their present location. For less knowledge-intensive service firms, the average municipal wage negatively affects their propensity to relocate, while those located in municipalities with high sector-specific wages have an increased likelihood to move. Relocating firms are generally attracted by densely populated municipalities with high wage levels, and primarily service firms are drawn to municipalities which are specialized in the firm's own sector and appeal to individuals. Sector-specific wages may either attract, or deter firms, suggesting that this variable may capture both the cost and the quality of the locally available workforce.

The chapter is organized as follows: Section 3.2 provides an overview regarding the theoretical background of the research. Section 3.3 outlines the characteristics of the data used in this study. Section 3.4 introduces the model employed in the empirical analysis, and Section 3.5 specifies the model and defines the variables which are used. Section 3.6 presents and discusses the results, and Section 3.7 concludes.

${ }^{19}$ To my knowledge, only Van Oort et al. (2007) have yet analyzed firm relocations in the Netherlands on the municipal level. 


\subsection{Theoretical framework and hypotheses}

Thousands of firms are set up each year all across the Netherlands. Practically, this implies that many of those businesses select their location for non-economic motives such as familiarity with the area, recreational opportunities, or lack of information about alternative options (Holl, 2004a; Van Dijk \& Pellenbarg, 2000). However, firms need to be profitable in order to survive, hence being in a non-optimal situation which generates low profits may trigger the decision to relocate. Furthermore, even a location which had been optimal when the firm was founded may have become less advantageous with time, as the firm itself, and/or the economic environment may have changed. Firms which currently find themselves in a sub-optimal situation may thus be 'pushed' to relocate to a more favorable location which better fits their present needs in order to increase their profits. On the other hand, a firm may be 'pulled' to another location due to the attractiveness either compared to the firm's present location (Van Dijk \& Pellenbarg, 2000), or to other alternatives (Van Wissen, 2000) - of this site.

\subsubsection{The decision to relocate}

A firm's decision to relocate can be influenced by various sets of factors, two prominent ones being the characteristics of the firm, and the qualities of the region it is located in. Section 2.1.1 presents (general) firm- and regionspecific drivers of firm relocation which have been established in the literature and are employed as control variables, whereas section 2.1.2 introduces the (sector-specific) explanatory variables employed in the analysis, as well as the corresponding hypotheses.

\subsubsection{General drivers of firm relocation}

The effects of various firm-specific characteristics on the propensity to relocate have been established in the literature. Older firms, for example, will be more embedded in their environment, and may have established long-term trust-based relationships in the vicinity. It can therefore be 
expected that the likelihood to relocate to another municipality decreases with the age of the firm (Brouwer et al., 2004). Regarding firm size, as moving costs will be considerably higher for larger firms (Brouwer et al., 2004; Knoben \& Oerlemans, 2008; Van Dijk \& Pellenbarg, 2000), the propensity to relocate to another municipality can be assumed to decrease with the size of the firm.

Firms which experienced growth or decline regarding the size of their workforce may have to relocate to other premises (Brouwer et al., 2004; Cooke, 1983; Pellenbarg \& Van Steen, 2003; Van Oort et al., 2007) which might be located outside the municipality the firm is currently located in. It can thus be assumed that firms growing or declining in size will have an increased likelihood to move to another municipality.

If located in sectorally diverse regions, firms can benefit from complementary services and the intersectoral transfer of knowledge and information (Holl, 2004a; Holl, 2004b). The 'cross-fertilization of ideas across different lines of work' (Glaeser et al., 1992, p. 1131) will give rise to Jacobs externalities, the 'external economies available to all local firms stemming from a variety of sectors' (Frenken et al., 2007, p. 687). It can thus be expected that firms being located in a municipality which is sectorally diverse will be less likely to relocate to another municipality.

The Netherlands exhibit some peculiarities regarding the demographic and economic landscape of the country. Its four biggest cities - Amsterdam, Rotterdam, The Hague and Utrecht - are located in the so-called 'Randstad', a densely populated region in the Western part of the Netherlands with about 7 million inhabitants. Although the Randstad accounts for only about $20 \%$ of the country's surface, more than $40 \%$ of the Dutch population live in this area, where also a large number of firms is located. Firms situated in (or close to) the Randstad have been found to be more likely to relocate (Capasso et al., 2010), either due to the large quantity of potentially attractive nearby alternatives (locating to which would not necessarily require a firm's workforce to move), or leaving towards the less densely populated semiperiphery or periphery of the country, where space is amply available and land prices (and also house prices, which may be of interest for the firm's employees) are considerably lower (Pellenbarg \& Kemper, 1999; Van Dijk \& Pellenbarg, 2000). 


\subsubsection{Sector-specific drivers of firm relocation}

The average daily salary received by a firm's employees may have an effect on the firm's propensity to move. On the one hand, firms paying high average salaries may be required to do so in their present location due to e.g. specific regional conditions, and might therefore be triggered to relocate in order to save costs. This might especially hold for less knowledge-intensive respectively low-tech firms which may be confident to quickly find, instruct and train an equally competent workforce at another location. Conversely, high salaries may indicate that a firm employs a large fraction of qualified and specialized workers whom it wants to retain, hence relocation would be less likely for firms paying high wages. This effect may especially apply to knowledge-intensive respectively high-tech firms which largely depend on the specific qualities of their workforce. Based on these considerations, the following hypothesis has been formulated:

H1: For low-tech manufacturing and less knowledge-intensive service firms, the propensity to relocate to another municipality increases with the average salary received by the firm's employees, whereas it decreases for high-tech manufacturing and knowledge-intensive service firms.

As put forward by Arauzo-Carod (2005), the population density of a municipality may operate in two ways. On the one hand, it may serve as a proxy for urbanization economies respectively the market conditions in the area (Arauzo-Carod, 2005; Arauzo-Carod \& Viladecans-Marsal, 2009; List, 2001; Wasylenko, 1980; Erickson \& Wasylenko, 1980), and can therefore be expected to have a negative impact on a firm's propensity to relocate. We assume this effect to be particularly strong for firms in the service sector, as these depend profoundly on local demand. On the other hand, it may capture land prices (Arauzo-Carod, 2005; Arauzo-Carod \& Viladecans-Marsal, 2009; Bartik, 1985; Figueiredo et al., 2002), thus pushing firms out of the region towards areas where the costs of buying or leasing property are lower. This effect may especially apply to manufacturing firms, as these are on average larger in size than service firms. Based on the above, the following hypothesis is proposed: 
H2a: For manufacturing firms, the propensity to relocate to another municipality increases with the population density of the municipality the firm is located in, whereas it decreases for service firms.

Firms generally benefit from the agglomeration of firms in their own sector, since firms located in such 'clusters' can take advantage of localization economies arising from the exchange of knowledge and workers, or from the nearby existence of specialized suppliers (Arauzo-Carod, 2009; Figueiredo et al., 2002; Frenken et al, 2007; Holl, 2004a; Holl, 2004b). This would imply that a firm being located in a municipality in which its own industry is compared to other regions - underrepresented will be more likely to relocate to another municipality. We expect this effect to be particularly strong for high-tech manufacturing firms and knowledge-intensive service firms, as these might specifically benefit from interfirm knowledge flows, and therefore hypothesize:

H3a: The propensity to relocate to another municipality decreases with the own-sector specialization of the municipality the firm is located in, and this effect is particularly strong for high-tech manufacturing and knowledgeintensive service firms .

Firms located in amenity-rich regions may save labor costs, as employees in regions which are attractive to individuals might be inclined to accept lower wages (Gottlieb, 1995; Kohler, 1997). It can thus be expected that firms being situated in a municipality which appeals to individuals will have a decreased propensity to relocate, and this effect will be particularly strong for service firms, as these are generally more labor-intensive than firms in the manufacturing sector. Hence:

H4a: The propensity to relocate to another municipality decreases with the residential amenities of the municipality the firm is located in, and this effect is particularly strong for service firms.

It has been argued that the average income in an area captures regional market conditions (Erickson \& Wasylenko; Wasylenko, 1980), hence firms in service sectors depending on local demand (e.g. retailing, hotels and 
restaurants) which are located in a municipality with high average wages should have a decreased propensity to move out of the area. Based on these considerations, it is hypothesized:

H5a: For service firms depending on local demand, the propensity to relocate to another municipality decreases with the average salary in the municipality the firm is located in.

Average wages in a specific sector in a municipality may differ significantly from its average general wage level. Yet, the municipal wage level in a firm's own sector may operate in two directions. On the one hand, own-sector wages in the area - more than general wages - indicate costs, as firms need to match the wage levels of neighboring firms in order to be able to attract employees. On the other hand, the municipal own-sector wage level may indicate the quality of the local workforce, and it might therefore be beneficial for firms to be located in regions with high sector-specific wages. This might apply particularly to knowledge-intensive respectively high-tech firms which may depend relatively more than less knowledge-intensive respectively low-tech firms on local interfirm knowledge flows as well as access to a pool of talented workers. It can thus be expected that less knowledge-intensive respectively low-tech firms located in a municipality with high wages in their own sector will be more likely to relocate, presumably in order to save costs, whereas high own-sector wages may be a 'keep'-factor for knowledge-intensive respectively high-tech firms which depend on and benefit from the quality of the local workforce, thus:

H6a: For low-tech manufacturing and less knowledge-intensive service firms, the propensity to relocate to another municipality increases with the average salary in the firm's sector in the municipality the firm is located in, whereas it decreases for high-tech manufacturing and knowledge-intensive service firms. 


\subsubsection{The choice of where to relocate}

The firm's decision of where to locate is assumed to be motivated by the characteristics of the municipalities it can choose between. Since firms may be pushed out of their present location due to the presence of specific regional qualities (or the lack thereof), the absence of these qualities (respectively their existence) may pull a firm to a specific location. Section 2.2.1 presents (general) region-specific characteristics which have been found to attract or deter firms, and are employed as control variables, whereas section 2.2.2 introduces the (sector-specific) explanatory variables employed in the analysis, as well as the corresponding hypotheses.

\subsubsection{General regional characteristics}

Since firms can be assumed to benefit from the externalities arising from the cross-sectoral exchange of ideas, knowledge and information (Frenken et al., 2007; Glaeser et al., 1992; Holl, 2004a; Holl, 2004b), it can be expected that firms in all sectors will be drawn to diverse municipalities.

Regarding the distance of the municipality to the 'Center of the Randstad', opposite forces may be at play: On the one hand, as the Randstad is the economic center of the Netherlands, it might be essential for specific industries to be located in (or locate to) this area. On the other hand, mature firms might prefer to move to the periphery where land is cheaper (Pellenbarg \& Kemper, 1999; Van Dijk \& Pellenbarg, 2000; Wasylenko, 1980), and employees can afford nicer homes while at the same time saving commuting time (Van Dijk \& Pellenbarg, 2000).

Most firm relocations are realized across small distances, presumably since it may be in a firm's interest to be able to retain its current workforce, and to remain in close proximity to its suppliers and/or customers. Furthermore, information on possible nearby locations is considerably easier to come by than on distant locations (Knoben \& Weterings, 2010; Van Dijk \& Pellenbarg, 2000; Van Wissen, 2000). It can thus be assumed that firms will be drawn to municipalities which are situated close to their present location. 


\subsubsection{Sector-specific regional characteristics}

We expect service firms to be drawn to densely populated municipalities in order to profit from local market conditions, whereas manufacturing firms may be deterred by the density of a municipality due to the associated higher costs of buying or leasing property. Based on these considerations, we hypothesize:

H2b: Densely populated municipalities attract relocating firms in the service sector, whereas they deter relocating manufacturing firms.

The concentration of an industry at a specific locality facilitates knowledge spillovers and the transfer of workers and information, thus giving rise to Marshallian externalities (Arauzo-Carod, 2009; Figueiredo et al., 2002; Frenken et al, 2007; Glaeser et al., 1992; Holl, 2004a; Holl, 2004b). Due to these localization economies, municipalities with high sectoral specialization in a firm's own industry can be assumed to appeal to firms in all sectors, and this effect is expected to be particularly strong for knowledge-intensive service and high-tech manufacturing firms, thus:

H3b: Municipalities with high own-sector specialization attract relocating firms, and this effect is particularly strong for high-tech manufacturing and knowledge-intensive service firms.

Residential amenities were found to be most important to firms moving into a specific region which were small in size, concerned about attracting professional personnel, and relatively footloose (Love \& Crompton, 1999). Furthermore, firms located in attractive regions may be able to save labor costs, as workers may accept lower wages (Gottlieb, 1995; Kohler, 1997). Hence, while it can be expected that firms are generally drawn to municipalities which appeal to individuals, we presume this effect to be specifically strong for firms in the service sector, as these are generally more labor-intensive than manufacturing firms, generally smaller in size, and can be assumed to be more footloose, hence: 
H4b: Municipalities which appeal to individuals attract relocating firms, and this effect is particularly strong for firms in the service sector.

As the municipal wage level captures market conditions in the area, municipalities with high average wages should appeal to service firms depending on local demand (Erickson \& Wasylenko, 1980; Wasylenko, 1980), therefore:

H5b: Municipalities with high average salaries attract relocating service firms which depend on local demand.

Regarding the effect of municipal sector-specific wages on the inflow of firms, we expect two counteracting effects. On the one hand, predominantly low-tech respectively less knowledge-intensive firms may relocate to regions where own-sector wages are low, as this allows them to save labor costs. Yet, the literature on firm relocation does not provide any empirical evidence which would unequivocally support this assumption, although findings on the locational preferences of service firms (Schmenner, 1993) suggest that predominantly firms in the less knowledge-intensive service sectors consider low own-sector wages in the region to have a substantial impact on their choice of location.

On the other hand, as the local own-sector wage level may indicate the quality of the workforce employed in the municipality, firms which depend on high-quality labor may be drawn to municipalities where wages in their own sector are high in order to benefit from interfirm knowledge and worker flows. Schmenner (1993) correspondingly finds knowledge-intensive service firms to be attracted by regions in which they have access to qualified labor, while regional labor costs have a remarkably weak impact on the locational choices of these firms. In line with this, Pellenbarg (2002) argues that in the 1990s, a shift regarding the importance of firm location factors took place, away from primary (e.g. transportation and labor costs) and secondary (e.g. agglomeration economies) factors towards tertiary factors such as living conditions, environmental aspects, and also the quality of labor. It can thus be assumed that less knowledge-intensive respectively lowtech firms may be drawn to municipalities where own-sector wages are low, as they will aim to save labor costs. Knowledge-intensive respectively high- 
tech firms, on the other hand, may be attracted by regions where wages in their own sector are high, as this will allow them to gain access to the qualified workforce present in the area. It is thus hypothesized:

H6b: High average salaries in a firm's own sector attract relocating high-tech manufacturing and knowledge-intensive service firms, whereas they deter low-tech manufacturing and less knowledge-intensive service firms.

\subsection{Data}

\subsubsection{Data sources}

The data employed in this study were provided by Statistics Netherlands (CBS). Information regarding firms (location, industrial sector, age, size) is available on the level of the 'business unit'. The data originate from the Social Statistical Database (SSB), the Dutch business register, the Survey on Employment and Wages, the Survey Production Statistics, and information provided by the Dutch Tax Administration.

Information on employees stems from the SSB, which is compiled on the basis of register data from two main sources. Personal information (e.g. date of birth, gender, address) within the SSB originates from the municipal registration system, while data concerning employees' jobs (e.g. employer, duration of employment, salary) is provided by the Dutch Tax Administration.

Basic data on Dutch municipalities originates from Statline, a publicly available database provided by Statistics Netherlands providing aggregate regional information such as population or population density on the municipal level. Further information regarding the characteristics of the labor force, businesses and industries present in each municipality was established on the basis of the microdata on employees and firms at hand.

As the exact location of each municipality (its center) is known, its distance to other municipalities/locations can be established. After determining the 'Center of the Randstad', the central point between Amsterdam, Rotterdam, The Hague and Utrecht (near Alphen aan den Rijn in the province South-Holland), the distance between each municipality and 
this locality could be calculated. Similarly, the distance to the firm's location in 2003 was determined.

Information regarding the attractiveness of the Dutch municipalities for individuals was obtained from www.elsevier.nl, where the 50 so-called 'best municipalities' (regarding e.g. economic position, health, education, infrastructure, and accessibility) of the Netherlands are ranked each year.

\subsubsection{Data description}

Two distinct datasets were constructed. The first dataset consists of all Dutch manufacturing (NACE ${ }^{20}$ 15-37) and services (NACE 50-74) firms (on the level of the business unit) which were active with employees in 2002, 2003 and 2004, remained located in the Netherlands throughout these years, and for which information regarding all relevant variables was available. In the large majority of cases, a business unit is an independent firm with only one location ${ }^{21}$. As this study aims to identify the determinants of complete (as opposed to partial) intermunicipal firm relocation, only single-site firms were selected. Furthermore, the dataset only consists of firms which did not change sectors between 2003 and 2004.

Firm-level information (e.g. number of employees, industrial sector) is available on a yearly basis. Variables which take into account the characteristics of its workforce, however, are slightly more difficult to come by, since employees can hold multiple jobs with different employers at the same time. We decided to select the job with the highest number of hours per week worked, the most recent start date, and the highest salary. After matching these employees/jobs to their employers, we determined the average salary a firm paid its employees in 2003.

In 2003/2004, the Netherlands consisted of roughly 485 municipalities (due to reorganizations, the exact number varies slightly from year to year,

\footnotetext{
${ }^{20}$ Nomenclature statistique des activités économiques dans la Communauté européenne, based on the International Standard Industrial Classification of all Economic Activities (ISIC).

${ }^{21}$ About $98 \%$ of the firms in 2003 had one location. Interestingly, firms with two or more locations are progressively rare, while there is a certain number of very large firms having five or more locations.
} 
and has generally been decreasing over the years). Since the location of a firm is known for each year on the municipal level, the characteristics of the municipality the firm was located in in 2003 were determined. These include municipal-level features such as population density and, due to the availability of detailed microdata on employees and firms, characteristics such as sectoral diversity, specialization in specific industries, and both average general and sector-specific wages.

The dataset thus entails information regarding characteristics of the firm in 2003 (including changes regarding its size between 2002 and 2003), features of the region (on the level of the municipality) the firm was located in in 2003, and the location (on the level of the municipality) of the firm in 2004. In total, the dataset consists of 179,913 firms, of which 4,241 firms (2.4 $\%)$ relocated to another municipality between 2003 and 2004. The analyses are also carried out separately for firms in high-tech/medium-high-tech manufacturing (HT + MHT), medium-low-tech manufacturing (MLT), lowtech manufacturing (LT), knowledge-intensive high-tech services (KIHTS), knowledge-intensive market services (KIMS), knowledge-intensive financial services (KIFS), and less knowledge-intensive services (LKIS). Table 3.1 provides detailed information on the classification of the two-digit NACE sectors into these categories. The sectors of medium-low-tech manufacturing and low-tech manufacturing had the smallest shares of relocating businesses (1.7\%), while the largest share $(4.7 \%)$ of firms moving to another municipality was found in the knowledge-intensive high-tech service sector. Table 3.2 gives a complete overview of firms' relocational behavior, both for the complete dataset, and for each subsample as previously specified.

The second dataset is based on those 4,241 firms which actually relocated between 2003 and 2004. For those firms, the characteristics of the (at most 482) municipalities they could choose between were determined for the year 2004. Basically, these variables are analogous to those presented in the previous paragraph, including e.g. population density, sectoral diversity and specialization in specific sectors, and average general and sector-specific wages. The analysis is carried out for the complete dataset, and for each subsample as previously specified. 
Table 3.1: Classification of sectors

\begin{tabular}{|l|l|l|l|}
\hline \multicolumn{1}{|c|}{ Classification $^{22,23}$} & $\begin{array}{l}\text { Labor intensity/ } \\
\text { capital intensity }\end{array}$ & \multicolumn{1}{|c|}{$\begin{array}{c}\text { Knowledge } \\
\text { intensity }\end{array}$} & NACE Sectors \\
\hline $\begin{array}{l}\text { High-tech and medium- } \\
\text { high-tech manufacturing }\end{array}$ & Capital-intensive & $\begin{array}{l}\text { Knowledge- } \\
\text { intensive }\end{array}$ & 24 and 29-35 \\
\hline $\begin{array}{l}\text { Medium-low-tech } \\
\text { manufacturing }\end{array}$ & Capital-intensive & $\begin{array}{l}\text { Less knowledge- } \\
\text { intensive }\end{array}$ & 23 and 25-28 \\
\hline $\begin{array}{l}\text { Low-tech } \\
\text { manufacturing }\end{array}$ & Capital-intensive & $\begin{array}{l}\text { Less knowledge- } \\
\text { intensive }\end{array}$ & $15-22$ and 36-37 \\
\hline $\begin{array}{l}\text { Knowledge-intensive } \\
\text { high-tech services }\end{array}$ & Labor-intensive & $\begin{array}{l}\text { Knowledge- } \\
\text { intensive }\end{array}$ & $64,72,73$ \\
\hline $\begin{array}{l}\text { Knowledge-intensive } \\
\text { market services }\end{array}$ & Labor-intensive & $\begin{array}{l}\text { Knowledge- } \\
\text { intensive }\end{array}$ & $61-62,70-71,74$ \\
\hline $\begin{array}{l}\text { Knowledge-intensive } \\
\text { financial services }\end{array}$ & Labor-intensive & $\begin{array}{l}\text { Knowledge- } \\
\text { intensive }\end{array}$ & $65-67$ \\
\hline $\begin{array}{l}\text { Less knowledge-intensive } \\
\text { services }\end{array}$ & Labor-intensive & $\begin{array}{l}\text { Less knowledge- } \\
\text { intensive }\end{array}$ & $\begin{array}{l}50-52,55,60, \\
63\end{array}$ \\
\hline
\end{tabular}

22 Technology classification of manufacturing industries: OECD Science, Technology and Industry Scoreboard 2009 (with NACE 35 reclassified as medium-high-tech)

${ }^{23}$ Classification of service industries: EUROSTAT Statistics in Focus 4/2005 
Table 3.2: Mobility

\begin{tabular}{|l|r|r|r|r|}
\hline & $\begin{array}{c}\text { Non- } \\
\text { relocating } \\
\text { firms }\end{array}$ & Percent & \multicolumn{1}{|c|}{$\begin{array}{c}\text { Relocating } \\
\text { firms }\end{array}$} & Percent \\
\hline All & 175,672 & 97.64 & 4,241 & 2.36 \\
\hline $\begin{array}{l}\text { High-tech and medium- } \\
\text { high-tech manufacturing }\end{array}$ & 5,664 & 97.93 & 120 & 2.07 \\
\hline $\begin{array}{l}\text { Medium-low-tech } \\
\text { manufacturing }\end{array}$ & 5,471 & 98.28 & 96 & 1.72 \\
\hline $\begin{array}{l}\text { Low-tech } \\
\text { manufacturing }\end{array}$ & 10,429 & 98.28 & 182 & 1.72 \\
\hline $\begin{array}{l}\text { Knowledge-intensive } \\
\text { high-tech services }\end{array}$ & 3,334 & 95.34 & 163 & 4.66 \\
\hline $\begin{array}{l}\text { Knowledge-intensive } \\
\text { market services }\end{array}$ & 43,018 & 96.64 & 1,495 & 3.36 \\
\hline $\begin{array}{l}\text { Knowledge-intensive } \\
\text { market services }\end{array}$ & 10,453 & 96.72 & 354 & 3.28 \\
\hline $\begin{array}{l}\text { Less knowledge-intensive } \\
\text { services }\end{array}$ & 97,303 & 98.15 & 1,831 & 1.85 \\
\hline
\end{tabular}




\subsection{Model}

The decisions taken by a firm regarding its relocation are estimated by means of a two-stage nested logit model. The alternatives a firm can choose between are illustrated in Figure 1. Regarding the decision of whether to relocate or not, firms can decide to either stay in their present location, or to move to another municipality. With respect to the decision of where to relocate, firms which relocate to another municipality can choose between a maximum of 482 alternatives (483 municipalities in 2004, excluding the municipality of origin $)^{24}$.

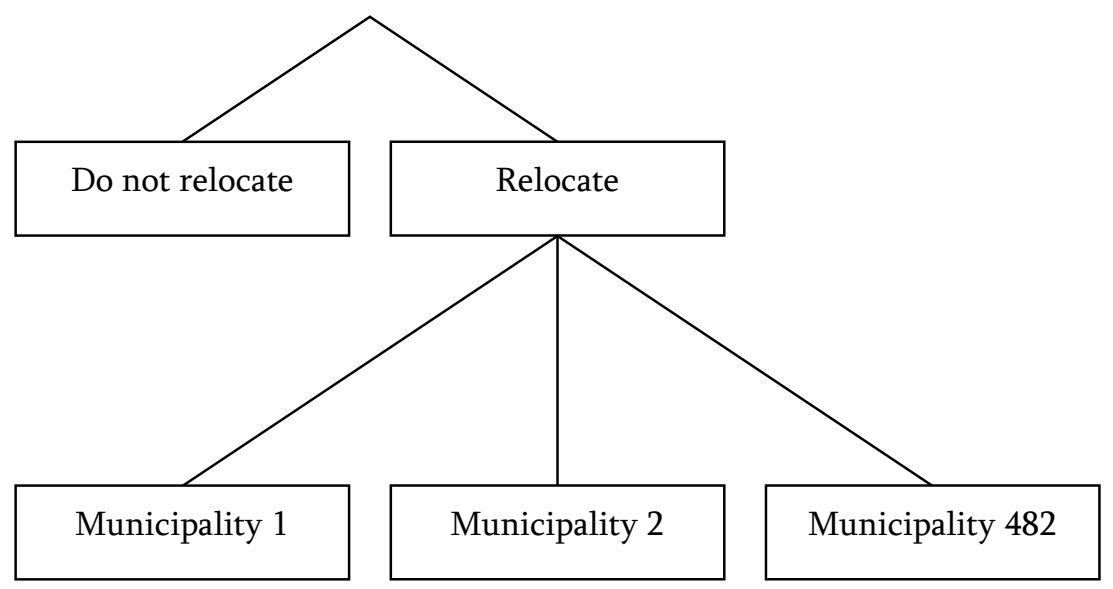

Figure 3.1: Nesting structure of the two-level nested logit (simultaneous decision-making process)

We assume that firms choose the location which is most beneficial to them. This implies that firms decide upon relocating by taking into account the attractiveness of moving to another municipality. If a firm decides to stay in its present location, it assumes this location to be most advantageous. If it

\footnotetext{
${ }^{24}$ Not all industries are present in all municipalities. We assume that firms only choose between those municipalities in which their industry is already present, as municipalities in which a specific sector is not yet present are likely to possess certain unobserved characteristics which discourage firms in those industries from locating there. Yet, we also carried out the analysis with 482 choices for each firm, and generally did not find different results. Results are available from the author upon request.
} 
relocates to another municipality, its location is chosen by comparing the characteristics of all municipalities it could possibly relocate to.

The value $v_{m}$ derived from locating at $m$ can be partitioned into attributes that are observed at the upper nest level (whether to relocate or not), and those which are observed at the lower nest level (where to relocate). Hence,

$$
v_{m}=\alpha B_{r}+\beta Y_{m}+\varepsilon_{m}
$$

where $B_{Y}$ is a vector of explanatory variables which determine whether to relocate or not, $Y_{m}$ is a vector of explanatory variables which determine whether to relocate to municipality $m$, conditional on relocating, and $\varepsilon_{m}$ is the error term (see Strauss-Kahn and Vives (2009) for a corresponding analysis of headquarter mobility between Metropolitan Statistical Areas in the US). $B_{r}$ and $Y_{m}$ incorporate firm- and region-specific characteristics, the latter being observed at the locations of origin for the upper nest level, and at the locations of destination for the lower nest level.

The probability of moving to municipality $m, P_{m}$, can be written as the product of the conditional probabilities of the two choices:

$$
P_{m}=P_{r} \cdot P_{m \mid r}
$$

where $P_{r}$ denotes the probability of choosing to relocate to another municipality, and $P_{m} \mid r$ is the probability of choosing municipality $m$ conditional on having decided to relocate, and depends on the characteristics of the municipalities the firm can choose between:

$$
P_{m \mid r}=\frac{\exp \left(\beta Y_{m}\right)}{\sum_{k=1}^{M} \exp \left(\beta Y_{k}\right)}
$$


where $M$ is the number of municipalities the firm can choose between ${ }^{25}$.

$P_{r}$ depends on characteristics of the firm, of the municipality the firm is currently located in $\left(B_{r}\right)$, and on the industry-specific ${ }^{26}$ value of relocating by means of the inclusive value $I=\ln \left(\sum_{k=1}^{M} \exp \left(\beta Y_{k}\right)\right){ }^{27}$ :

$$
P_{r}=\frac{\exp \left(\delta I+\alpha B_{r}\right)}{1+\exp \left(\delta I+\alpha B_{r}\right)}
$$

A simultaneous (as opposed to a sequential) decision-making process is assumed. Due to the fact that the inclusive value which is obtained at the lower level (where to relocate) enters the analysis at the upper level (whether to relocate), the nested logit specification is estimated in reversed order: First, a conditional logit model is estimated which assumes a firm's decision of where to relocate to depend upon characteristics of the municipalities it can choose between (lower nest level). Next, a binary logit model is estimated ${ }^{28}$ which presumes a firm's decision of whether to move to

\footnotetext{
${ }^{25}$ For convenience, subscripts for firms and sectors have been suppressed throughout the text.

${ }^{26}$ If only location-specific characteristics which are similar for all firms (e.g. population density) were part of the model, the inclusive value would be a constant (and could thus be omitted). Since we add sector-specific variables (e.g. average wage in the firm's own sector), the inclusive value is sector-specific. Taking into account the distance of each municipality to a firm's region of origin, an industry- and origin-specific inclusive value could have been determined. Yet, it would then have been necessary to have at least one relocating firm from each municipality and sector (and thus a total of almost 20,000 relocating firms) in order to determine the inclusive value for all firms in the analysis based on their sector and their location of origin. As this could not be realized, distance to origin was excluded from the analysis. Results for the analysis including this variable are presented in Table 3.8; the model was found to be generally insensitive to the in- or exclusion of the variable.

27 The inclusive value reflects the industry-specific value of moving. It is expected to be positive and significant, since firms in sectors in which the value of relocating is high should have an increased propensity to relocate.

${ }^{28}$ As the percentage of firms which relocate is rather small, it may be argued that a rare event logit could be employed. We also carried out the analysis using a rare event logit, and generally found comparable results. This can possibly be attributed to the fact that although the shares of relocating firms are not too large, the two logit models come up with comparable results due to the size of the samples (see e.g. King and Zeng, 2001a;
} 
another municipality to depend upon characteristics of the firm, the municipality the firm is currently located in, and on the inclusive value $I$ which reflects the industry-specific value of moving (upper nest level). Yet, for convenience, we will discuss both the model specifications and the results as presented in Figure 3.1.

\subsection{Model specification}

\subsubsection{Whether to relocate}

We use the first dataset as presented in section 3.2, consisting of those firms which either relocated, or stayed in their present location between the years 2003 and 2004. A binary logit model is estimated $(1=$ firm relocates between 2003 and 2004, 0 = firm does not relocate). The variables employed in the analysis consist of firm-specific characteristics, characteristics of the municipality the firm is located in, and the inclusive value $I$ which reflects the industry-specific value of moving.

All variables are measured in 2003 (or, in the case of GROWTH_FIRM_POS and GROWTH_FIRM_NEG, between 2002 and 2003), prior to the firm's potential relocation. Industries are identified on the 2-digit level. For the variables SIZE_FIRM, SALARY_FIRM, SALARY, $S A L A R Y \_I N D, G R O W T H \_F I R M \_P O S$ and GROWTH_FIRM_NEG, the natural logarithm is used. See Table 3.3 for an overview of the variables used in the analysis. Descriptive statistics (pooled) are presented in Table 3.4.

$A G E \_F I R M$ measures the age (in years) of the firm, and SIZE_FIRM denotes its size (number of employees). GROWTH_FIRM_POS indicates the positive change in the natural logarithm of a firm's number of employees from 2002 to 2003, and GROWTH_FIRM_NEG measures the negative change, also from 2002 to 2003. SALARY_FIRM indicates the average daily salary (in $€$ ) a firm's employees receive.

HERFINDAHL indicates the degree of specialization in the municipality the firm is located in. It is measured using the Herfindahl employment

King and Zeng, 2001b). As the rare event logit appears to be more sensitive to outliers, we decided to present the results for the binary logit. The results for the rare event logit are available from the author upon request. 
specialization index, exhibiting values which lie between zero and one. A smaller value indicates sectoral diversity in the municipality, whereas a larger value denotes that employment is concentrated in fewer sectors. The value ' 1 ' would thus indicate that only one sector is present in the municipality. DISTANCE_CENTER measures the firm's distance (in $\mathrm{km}$ ) to the 'Center of the Randstad', defined as the central point between The Hague, Amsterdam, Rotterdam and Utrecht, located near Alphen aan den Rijn in the province South-Holland.

POPDENS denotes the population density (inhabitants per square kilometer/100) of the municipality the firm is located in. SPECIALIZATION is the sectoral specialization regarding the firm's own industry (2-digit level) in the municipality. It is measured as the number of employees in the firm's industrial sector in the municipality divided by the number of employees in the municipality, divided by the number of employees in the firm's industrial sector divided by the total number of employees in the Netherlands. A value of 1 indicates that in the firm's municipality, its industry is as present as in the rest of the Netherlands, a value smaller than 1 indicates that in the firm's municipality, its industry is less present, and a value greater than 1 indicates that in the firm's municipality, its industry is more present than in the rest of the country.

The variable TOP_50 (dummy variable) indicates whether the municipality the firm is located in has been ranked as one of the 50 most attractive Dutch municipalities for individuals. $S A L A R Y$ is the average daily salary (in $€$ ) in the municipality the firm is located in, and $S A L A R Y_{-} I N D$ denotes the average daily salary (in $€$ ) in the municipality in the firm's own sector (2-digit level). 
Table 3.3: Definitions of variables used in the analysis (relocate or not)

\begin{tabular}{|l|l|}
\hline \multicolumn{1}{|c|}{ Variable } & \multicolumn{1}{c|}{ Definition } \\
\hline AGE_FIRM & Age of the firm (in years) in 2003 \\
\hline SIZE_FIRM & $\begin{array}{l}\text { Natural logarithm of firm size (average number of } \\
\text { employees) }\end{array}$ \\
\hline GROWTH_FIRM_POS & $\begin{array}{l}\text { Positive change in natural logarithm of a firm's number of } \\
\text { employees from 2002 to 2003 }\end{array}$ \\
\hline GROWTH_FIRM_NEG & $\begin{array}{l}\text { Negative change in natural logarithm of a firm's number of } \\
\text { employees from 2002 to 2003 }\end{array}$ \\
\hline SALARY_FIRM & $\begin{array}{l}\text { Natural logarithm of a firm's employees' average daily } \\
\text { salary (in } € \text { ) }\end{array}$ \\
\hline POPDENS & $\begin{array}{l}\text { Population density (inhabitants per km }{ }^{2} \text { ) of the } \\
\text { municipality the firm is located in }\end{array}$ \\
\hline SPECIALIZATION & $\begin{array}{l}\text { Specialization in the firm's own sector (2-digit NACE level) } \\
\text { in the municipality the firm is located in }\end{array}$ \\
\hline HERFINDAHL & $\begin{array}{l}\text { Sectoral concentration in the municipality the firm is } \\
\text { located in }\end{array}$ \\
\hline DISTANCE_CENTER & $\begin{array}{l}\text { Distance between the 'Center of the Randstad' and the } \\
\text { municipality the firm is located in }\end{array}$ \\
\hline TOP_50 & $\begin{array}{l}\text { Municipality the firm is located in is attractive for } \\
\text { individuals (dummy) }\end{array}$ \\
\hline SALARY & $\begin{array}{l}\text { Natural logarithm of the average daily salary in the } \\
\text { municipality the firm is located in }\end{array}$ \\
\hline SALARY_IND & $\begin{array}{l}\text { Natural logarithm of the average daily salary in the firm's } \\
\text { sector (2-digit NACE level) in the municipality the firm is } \\
\text { located in }\end{array}$ \\
\hline
\end{tabular}

Variables refer to the year 2003, GROWTH_FIRM_POS and GROWTH_FIRM_NEG refer to the years 2002/2003. 
Table 3.4: Descriptives (pooled)

\begin{tabular}{|l|r|r|r|r|}
\hline & \multicolumn{1}{|c|}{ Minimum } & Maximum & \multicolumn{1}{c|}{ Mean } & \multicolumn{1}{c|}{$S D$} \\
\hline AGE_FIRM & 1.00 & 40.00 & 14.72 & 11.155 \\
\hline SIZE_FIRM & 0.00 & 9.13 & 1.54 & 1.189 \\
\hline GROWTH_FIRM_POS & 0.00 & 6.92 & 0.11 & 0.274 \\
\hline GROWTH_FIRM_NEG & -4.90 & 0.00 & -0.08 & 0.225 \\
\hline SALARY_FIRM & 2.17 & 11.00 & 4.28 & 0.501 \\
\hline POPDENS & 0.25 & 56.10 & 15.23 & 14.740 \\
\hline SPECIALIZATION & 0.00 & 183.49 & 1.37 & 2.322 \\
\hline HERFINDAHL & 0.06 & 0.45 & 0.09 & 0.030 \\
\hline DISTANCE_CENTER & 2.12 & 208.45 & 72.59 & 47.044 \\
\hline TOP_50 & 0.00 & 1.00 & 0.25 & 0.432 \\
\hline SALARY & 4.12 & 5.18 & 4.48 & 0.153 \\
\hline SALARY_IND & 2.80 & 7.13 & 4.37 & 0.288 \\
\hline
\end{tabular}

Number of observations: 179,913

\subsubsection{Where to relocate}

The second dataset as presented in section 3.2 is employed. A conditional logit model is estimated ( 1 = municipality is chosen by relocating firm, $0=$ municipality is not chosen). The variables employed in the analysis consist of characteristics of the (at most 482) municipalities a relocating firm can choose between. The number of observations for each sample is based on the number of relocating firms multiplied by the number of municipalities (on average 457) it could choose between ${ }^{29}$. All variables refer to the year 2004. Industries are identified on the 2-digit level. For the variables $S A L A R Y$ and $S A L A R Y_{-} I N D$, the natural logarithm is used. The regional characteristics of the municipalities a firm can choose between refer to the year 2004 and are otherwise specified as illustrated in section 5.1. Additionally, DISTANCE_2003 denotes the distance between a relocating firm's previous location and the municipalities it can choose between. Table 3.5 provides an overview of the variables.

${ }^{29}$ Recall that municipalities in which the firm's sector is not present were excluded from the analysis. 
Table 3.5: Definitions of variables used in the analysis (where to relocate)

\begin{tabular}{|l|l|}
\hline \multicolumn{1}{|c|}{ Variable } & \multicolumn{1}{c|}{ Definition } \\
\hline POPDENS & $\begin{array}{l}\text { Population density (inhabitants per } \mathrm{km}^{2} \text { ) of the } \\
\text { municipalities the relocating firm can choose between }\end{array}$ \\
\hline SPECIALIZATION & $\begin{array}{l}\text { Specialization in the firm's own sector (2-digit NACE level) } \\
\text { in the municipalities the relocating firm can choose } \\
\text { between }\end{array}$ \\
\hline HERFINDAHL & $\begin{array}{l}\text { Sectoral concentration in the municipalities } \\
\text { the relocating firm can choose between }\end{array}$ \\
\hline DISTANCE_CENTER & $\begin{array}{l}\text { Distance between the 'Center of the Randstad' and the } \\
\text { municipalities the relocating firm can choose between }\end{array}$ \\
\hline TOP_50 & $\begin{array}{l}\text { Attractiveness for individuals of the municipalities } \\
\text { the relocating firm can choose between (dummy) }\end{array}$ \\
\hline SALARY & $\begin{array}{l}\text { Natural logarithm of the average daily salary in the } \\
\text { municipalities the relocating firm can choose between }\end{array}$ \\
\hline SALARY_IND & $\begin{array}{l}\text { Natural logarithm of the average daily salary in the firm's } \\
\text { sector (2-digit NACE level) in the municipalities } \\
\text { the relocating firm can choose between }\end{array}$ \\
\hline DISTANCE_2003 & $\begin{array}{l}\text { Distance between a relocating firm's previous location } \\
\text { and the municipalities the firm can choose between }\end{array}$ \\
\hline
\end{tabular}

All variables refer to the year 2004 .

\subsection{Results and Discussion}

\subsubsection{Why do firms relocate?}

Results are presented in Table 3.6. We find that predominantly low-tech respectively less knowledge-intensive firms paying high average salaries have an increased propensity to move, suggesting that these firms may indeed relocate in order to save costs, and may be confident about finding an equivalently competent workforce elsewhere. The relocation decisions of high-tech manufacturing respectively knowledge-intensive service firms, on the other hand, are generally not affected by firm-specific labor costs. Partially supporting Hypothesis 1, these findings suggest that while employees' salaries unquestionably represent costs which a profit- 
maximizing firm intends to minimize, they may also denote the quality of a firm's workforce.

The proposed negative effect of population density on the likelihood to relocate is confirmed for firms in the knowledge-intensive market service sectors, whereas the expected positive effect is found for (comparatively large) medium-low-tech manufacturing firms. These findings generally support Hypothesis 2a, and - in line with Arauzo-Carod (2005) - illustrate the differences in the valuation of densely populated regions between firms in the manufacturing and service sectors.

Although firms are expected to value being located among other firms in the same sector, a negative effect of sectoral specialization in the firm's current municipality on the propensity to relocate can not be observed. These findings indicate that sectoral specialization (or rather the lack of it) does not push firms out of their present location. Hypothesis 3a is thus not supported.

In partial support of Hypothesis 4a, being located in an area which appeals to individuals induces knowledge-intensive high-tech service firms to stay in their present location. This suggests that labor-intensive firms may be situated in attractive localities in order to be capable of paying lower wages. Furthermore, these comparatively small firms have to spend comparatively less than firms in other sectors on rents or machinery, and may therefore be able to 'afford' being located in appealing regions.

Less knowledge-intensive service firms (including e.g. retailing, hotels and restaurants) which are located in a municipality with high average wages tend to be less likely to relocate. Supporting hypothesis $5 \mathrm{a}$, this indicates that the general municipal wage level indeed captures local market conditions and will keep firms which benefit from or even depend upon high local demand within the municipality.

Sector-specific wages, on the other hand, appear to stimulate relocation, since less knowledge-intensive service firms located in municipalities with high own-sector wages have an increased likelihood to relocate. This finding suggests that these firms - depending comparatively less than firms in other, more knowledge-intensive sectors on the knowledge and skills of their workforce - may consider relocating from areas with high industry-specific wages in order to save labor costs. Supporting this line of argument, the coefficient for industry-specific wages for high-tech and medium-high tech 
manufacturing and knowledge-intensive high-tech services is negative (although not significant), suggesting that knowledge-intensive respectively high-tech firms, both in manufacturing and in services, acknowledge that high-quality labor comes at a price, and are willing to pay it. These results lend partial support to Hypothesis 6a.

Furthermore, across all sectors, older firms are indeed less likely to relocate, whereas the proposed negative effect of firm size on the propensity to move only holds true for firms in medium-low-tech manufacturing and in knowledge-intensive market services, while the probability for relocation increases with firm size for firms in less knowledge-intensive services. Yet, while both Brouwer et al. (2004) and Van Dijk and Pellenbarg (2000) find larger firms to be less likely to relocate, the study by Knoben and Oerlemans (2008) illustrates that firm size may proxy other, unobserved characteristics of the firm, since it loses is predictive power as soon as more explanatory variables are entered. As expected, firms which experienced changes in size, especially declining firms, have an increased likelihood to relocate.

For most knowledge-intensive service firms, the degree of sectoral diversity in the municipality has the proposed negative effect on relocation. These findings are in line with Carree et al. (2011), who found predominantly business service firms to be influenced by cross-sectoral effects, and suggest that specifically knowledge-intensive market and financial services firms value being located in municipalities which are sectorally diverse.

Generally, the further a service firm is located from the 'Center of the Randstad', the less likely it is to relocate to another municipality. These findings are in line with Capasso et al. (2010), and suggest that firms located in the Randstad may relocate within this region to more attractive premises, or may use the economic center of the Netherlands as a 'nursery' (Duranton and Puga, 2001) before moving to (possibly specialized) regions in the (semi-) periphery of the country where rents are lower.

Regarding the industry-specific inclusive value, coefficients are positive and significant for the sample including all firms, as well as for the subsamples consisting of knowledge-intensive market service, and of less knowledge-intensive service firms, indicating that firms in sectors for which the value of moving is high (due to the qualities of the alternative locations) indeed have a higher propensity to move. Especially for manufacturing firms, 
however, the inclusive value was found to be insignificant. Yet, these results are in line with Strauss-Kahn and Vives (2009), who found that manufacturing headquarters 'in different two-digit sectors (...) value moving in a similar fashion' (p. 179).

\subsubsection{Where do firms go?}

Results are presented in Table 3.7. Across all sectors, firms are drawn to densely populated municipalities, suggesting that the size of local demand is a relevant pull factor which attracts relocating businesses. Yet, while these findings confirm our expectations regarding firms in the service sector, one may have expected manufacturing firms to stay away from densely populated areas in order to avoid higher land prices and rents. Hypothesis $2 \mathrm{~b}$ is thus only partially supported.

Municipalities in which firms in the firm's own sector are overrepresented appeal to service firms, and to firms in low-tech manufacturing. This suggests that firms in these sectors are indeed pulled to their new location by agglomeration forces, wishing to benefit from the locally constrained exchange of knowledge and flows of workers taking place. Not surprisingly, the effect is noticeably strong for firms in knowledge-intensive high-tech services, in which all $R \& D$ activities are comprised. Regarding the manufacturing sector, one would have expected especially firms in high-tech manufacturing to be drawn to municipalities which are specialized in the firm's own sector, however, no significant effect could be observed. Yet, the results obtained in the analysis correspond to those established by Arauzo-Carod (2009), who recently found Catalan hightech manufacturing firms to deconcentrate and 'move away from traditional high-tech locations to new ones' (p. 28). These results therefore lend partial support to Hypothesis $3 \mathrm{~b}$.

Firms in the service sectors are drawn to attractive municipalities. These results suggest that relocating firms in these sectors - which are laborintensive and comparatively small in size - may indeed relocate to municipalities which appeal to individuals, supposedly in order to benefit from higher prices in the area due to the attractiveness of the region (e.g. in the case of hotels and restaurants), to take advantage of the opportunity to 
pay lower wages (Gottlieb, 1995; Kohler, 1997), or to directly enjoy the amenities provided. Furthermore, these municipalities also appeal to firms in low-tech manufacturing. Hypothesis $4 \mathrm{~b}$ is thus generally supported.

Service firms are also drawn to municipalities with high average wages. Moreover, although the size of the effect is less prominent, high-wage regions also appeal to high-tech and medium-high-tech as well as low-tech manufacturing firms. Since high average wages do not only attract service firms which depend on local demand, these findings lend only partial support to Hypothesis $5 b$.

Regarding high sector-specific wages, some interesting patterns can be observed. For high-tech and medium-high-tech as well as medium-low tech manufacturing firms, the appeal of locating in a region with high wages in the firm's own sector, and thus in a region with a supposedly highly qualified and skilled workforce, is apparently offset by the inclination to save labor costs, and no effect can be observed. Furthermore, since high-tech and medium-high-tech manufacturing are sectors which are present in a comparatively small number of regions (on average in 324 municipalities, compared to a total average of 457), and the willingness to move for jobrelated reasons has been found to be higher among highly educated workers, these firms might expect (or hope for) their workforce to relocate with them. In the case of low-tech manufacturing, firms are attracted by regions with high sector-specific wages. This suggests that in these sectors, high regional wages in a firm's sector are not seen as a deterrent to inmigration, but may indicate the quality of the local workforce, and therefore draw firms in. Additionally, since firms in these manufacturing sectors are both located in and drawn to regions with the highest own-sector specialization, paying high wages might be comparatively difficult to avoid, as firms which are clustered in close proximity might 'bid' for the most excellent employees.

For service firms, labor costs represent the better part of their operating costs. Surprisingly, less knowledge-intensive service firms are drawn to regions with high sector-specific wages. Yet, for firms in these sectors, ownsector wages are highly correlated with general wages. This suggests that the profits from locating in these comparatively prosperous regions more than offset the additional labor costs. With respect to knowledge-intensive services, firms face higher labor costs per person, yet might also require a qualified, capable workforce which naturally comes at a price. In the case of 
knowledge-intensive high-tech and financial services, firms are attracted by regions with high own-sector wages, supposedly since this may indicate the quality of the local workforce. High-tech market services, on the other hand, prefer regions with low sector-specific wages. The reasons for this may be twofold: Firstly, these firms might relocate to lower-wage areas in order to save labor costs. In addition, locating to a region where own-sector wages are low might enable a firm to poach their competitors' best employees by offering them comparatively higher salaries. These findings lend partial support to Hypothesis 6b, illustrating that depending on a firm's sector, sector-specific wages may capture the cost and/or the quality of the local workforce.

Furthermore, confirming our expectations, we find that relocating service firms as well as medium-low-tech and low-tech manufacturing firms are generally drawn to municipalities in which firms from a variety of different sectors are present, indicating that municipalities with sectoral diversity attract both manufacturing and service firms.

The larger the distance of a municipality to the economic center of the Netherlands, the less it appeals to firms in knowledge-intensive market and financial services, and in less knowledge-intensive services, whereas the location choices of manufacturing firms are not affected by the distance to the Randstad. These findings illustrate the diverse preferences of firms in services and manufacturing: firms which depend upon centrality and closeness to their customers will prefer to be located close to the center, whereas firms which do not require to be situated in a central location may opt for the 'periphery' of the country offering lower rents and land prices.

The larger the distance of a municipality to a firm's previous location (Table 3.8), the less the firm is drawn to $i^{30}$. This suggests that it may indeed be important for relocating firms to retain their current workforce, and to remain in close proximity to customers and/or suppliers. Furthermore, even in a small country such as the Netherlands, firms may be imperfectly

${ }^{30}$ Generally, the model is insensitive with respect to the in- or exclusion of this variable. Yet, when controlling for distance to previous location, the variable indicating the distance to the economic center of the Netherlands generally turns positive. These findings indicate that when controlling for a relocating firm's previous location (which is likely to have been close to the economic center with its high number of firms as well as its high mobility rates), relocating - possibly growing - firms have a tendency to move away from the densely populated, expensive and congested center. 
informed regarding all possible locations they might choose from, and might therefore select a locality which is 'close to home'.

\subsection{Conclusions}

Results indicate that both the determinants of firm relocation, and the regional characteristics which attract relocating firms differ between firms in the manufacturing and service sector, and also between high-tech respectively knowledge-intensive and low-tech respectively less knowledgeintensive firms.

Low-tech manufacturing and less knowledge-intensive service firms paying higher average salaries are generally more likely to relocate, whereas the relocation decisions of high-tech manufacturing respectively knowledgeintensive service firms are generally not affected by firm-specific labor costs. This suggests that firms depending less on a specifically qualified (and correspondingly expensive) workforce may intend to save labor costs by relocating, while in high-tech/knowledge-intensive sectors, salaries reflect the qualities and capacities of a firm's employees whom it supposedly wants to retain.

Population density positively affects the likelihood to move for firms in medium-low-tech manufacturing, as these (comparatively large) firms can be assumed to relocate to less densely populated regions where land is cheaper. Knowledge-intensive market service firms, on the other hand, refrain from moving if they are currently located in a densely populated region, indicating that for those firms, the gains from being close to potential customers more than offsets the higher costs associated with buying or renting land or office space. Correspondingly, relocating firms in all service sectors move to densely populated municipalities, possibly in order to benefit from closeness and concentration of demand. Somewhat surprisingly, yet, manufacturing firms are also drawn to densely inhabited municipalities despite the expected deterring effect of land prices.

Own-sector specialization (or rather the lack of it) does not have an effect on firms' propensity to move out of the region, yet specialization in the firm's own sector appeals to relocating firms in all service sectors as well as in low-tech manufacturing selecting a new locality. These findings suggest that 
the exchange of knowledge due to physical proximity may be more relevant in the service than in the manufacturing sector, and, unexpectedly, matters more to firms in low- than in high-tech manufacturing. As the results with regard to high-tech manufacturing correspond to those obtained for regions in Catalonia, the 'urban-rural shift' (Arauzo-Carod, 2009, p. 28) of high-tech manufacturing firms leaving traditional locations for new ones may indeed have started to take place across Europe, challenging the universal relevance of localization economies.

The attractiveness of a municipality for individuals only has an effect on the mobility of knowledge-intensive high-tech service firms, since those located in one of the 50 'best' Dutch municipalities are less likely to relocate. Yet, relocating firms in all service sectors and also in low-tech manufacturing are drawn to municipalities which appeal to individuals. These findings suggest that firms may initially be located in a specific region irrespective of the amenities present in this particular location (e.g. a firm may be established in the founder's hometown), yet in the case of relocation, the attractiveness of a region is indeed taken into account by firms which due to their relative 'footlooseness' can afford to do so.

For less knowledge-intensive service firms, the general average wage level in the municipality the firm is located in negatively affects the firm's propensity to relocate, whereas the local average wage level in the firm's own sector has a positive effect on its likelihood to move. These findings illustrate that general demand conditions keep these firms within the region, while they are pushed out by high sector-specific labor costs.

The effect of sector-specific wage levels on firms' relocational behavior is evidently sector-dependent. For most manufacturing firms, the attractiveness of relocating to a high-wage region with a supposedly highly qualified labor force appears to be counterbalanced by the inclination to save labor costs, hence no effect can be observed. Yet, relocating low-tech manufacturing firms are drawn to regions with high sector-specific wages, possibly since these firms have to 'bid' for the most excellent workers when located within agglomerations of firms active in the same industry.

For service firms, labor costs represent the better part of their operating costs. In contrast to our assumptions, less knowledge-intensive service firms are drawn to regions with high sector-specific wages. Yet, since for these firms, own-sector wages are highly correlated with general wages, the profits 
from locating in these comparatively affluent regions can be assumed to more than compensate the additional labor costs.

Regarding knowledge-intensive services, relocating knowledge-intensive high-tech and financial service firms are drawn to regions with high ownsector wages, supposedly in order to gain access to a highly competent and qualified workforce. Knowledge-intensive market service firms, on the other hand, prefer regions where own-sector wages are low, presumably in order to save labor costs, or possibly due to the fact that being situated in close proximity to firms in the same sector paying low wages enables them to poach their competitors' employees by offering them comparatively higher salaries.

Generally, and confirming an observation made by Van Dijk and Pellenbarg (2000), the results of this study suggest that a firm's decision to relocate is rather determined by firm-specific factors than by the characteristics of the region the firm is located in. This effect is even more pronounced for manufacturing than for service firms, which are to some extent sensitive to general and sector-specific regional wage levels, the degree of sectoral diversity, and the distance to the economic center of the Netherlands. These results underline the relevance of additional factors such as individual preferences (Figueiredo et al., 2002), characteristics of the business site (Van Dijk \& Pellenbarg, 2000), or inter-organizational relationships (Knoben \& Oerlemans, 2008) possibly influencing firms' relocational behavior which this study unfortunately cannot account for.

Regional characteristics do, on the other hand, profoundly affect the choice of where to move, as relocating firms are 'pulled' into densely populated municipalities with high wage levels and, in the case of services and low-tech manufacturing, into municipalities which are specialized in the firm's own sector and appeal to individuals, whereas sectoral concentration generally deters the inflow of migrating firms. Results for the effect of sectorspecific wages on the inmigration of firms are mixed, suggesting that possibly contingent on sectoral specificities - local sector-specific wage levels may be perceived as indicators of labor costs and/or labor quality.

The findings presented in this chapter are relevant with respect to matters of regional development and planning. As firms in different sectors diverge in their preferences regarding the characteristics of their environment, efforts directed at spatial development and regional planning 
should take these sectoral differences into account in order to be effective. Furthermore, the results of this study indicate that firms' immediate surroundings matter with respect to their locational choices, encouraging spatial planners to employ data aggregated at the detailed level of the municipality. 


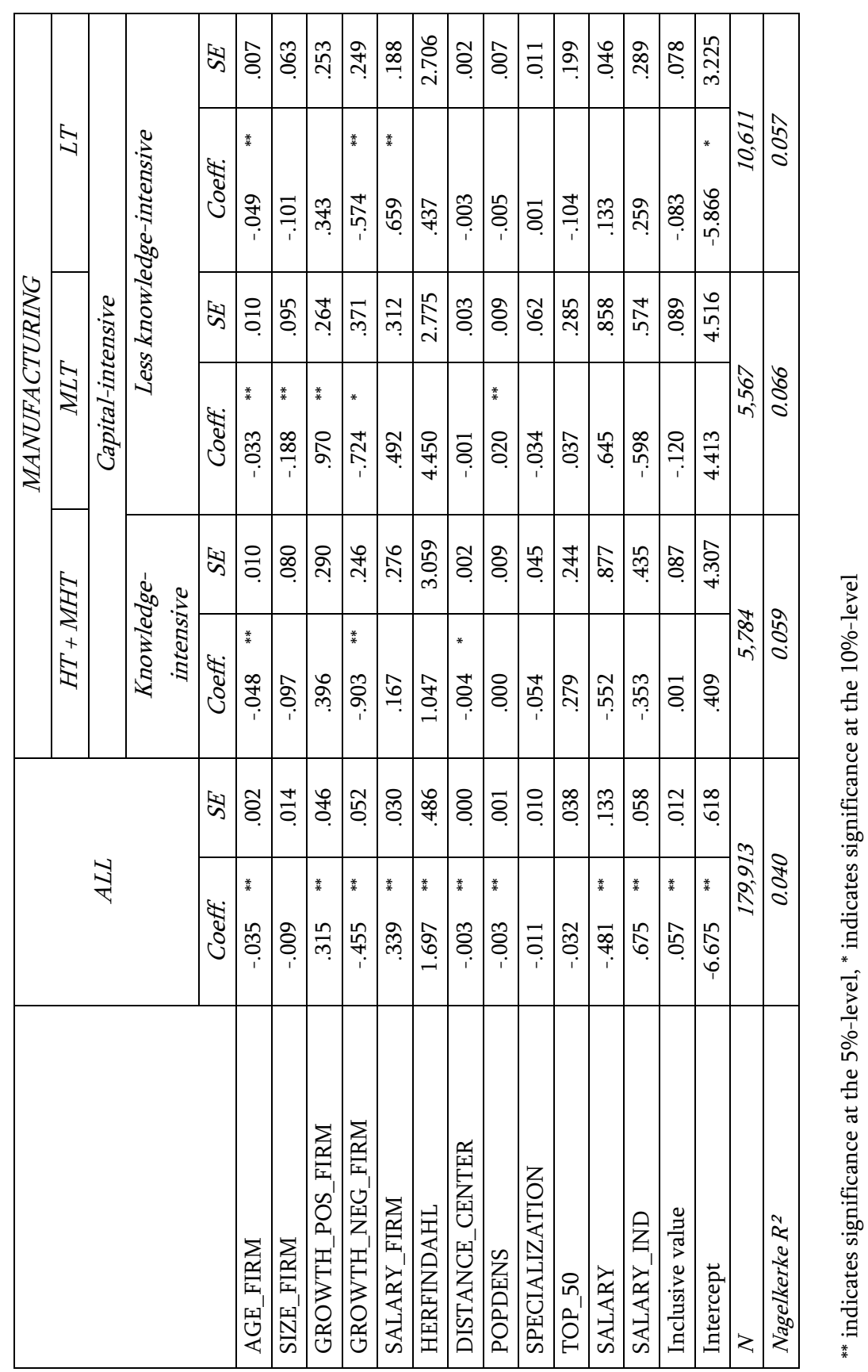




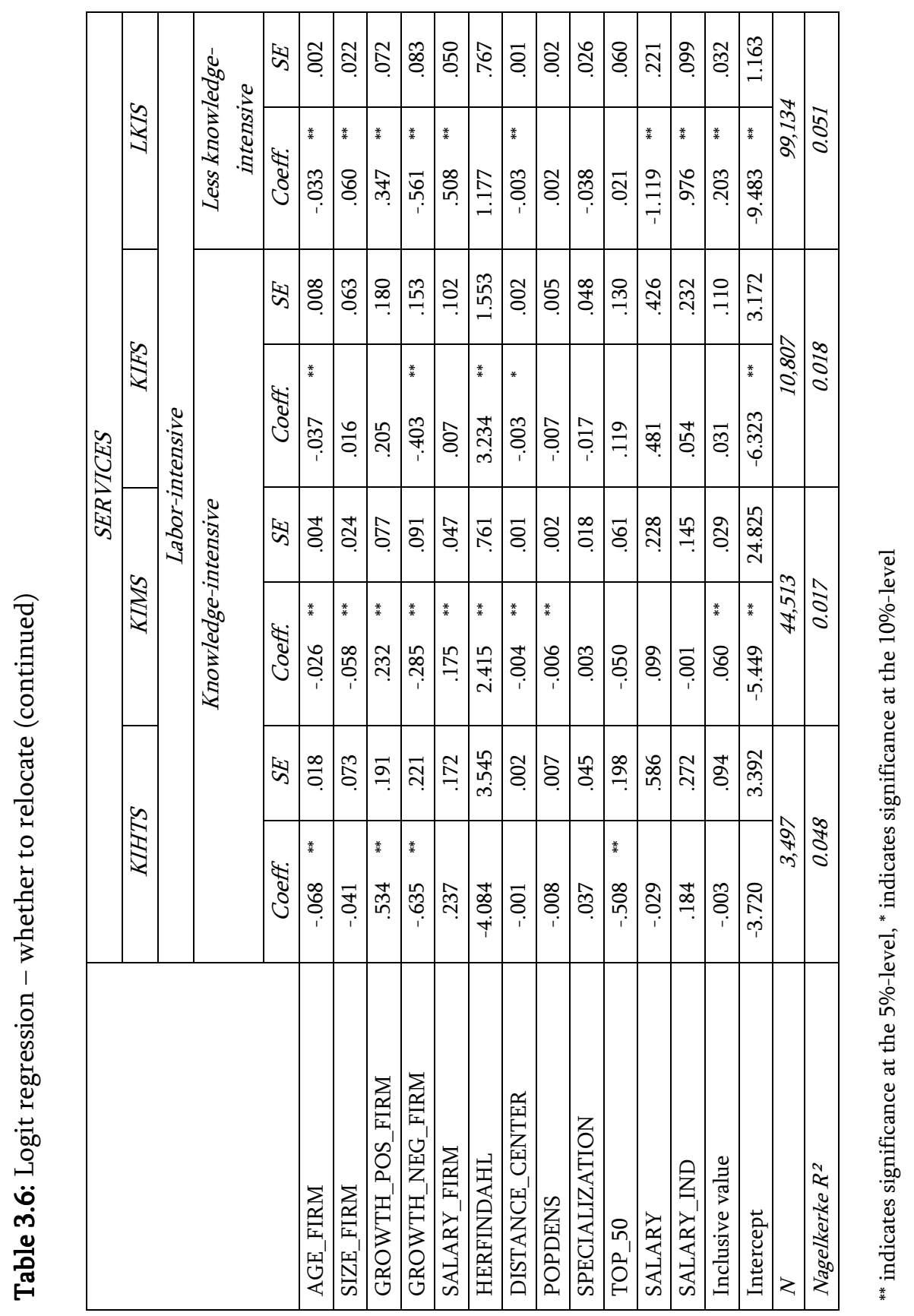




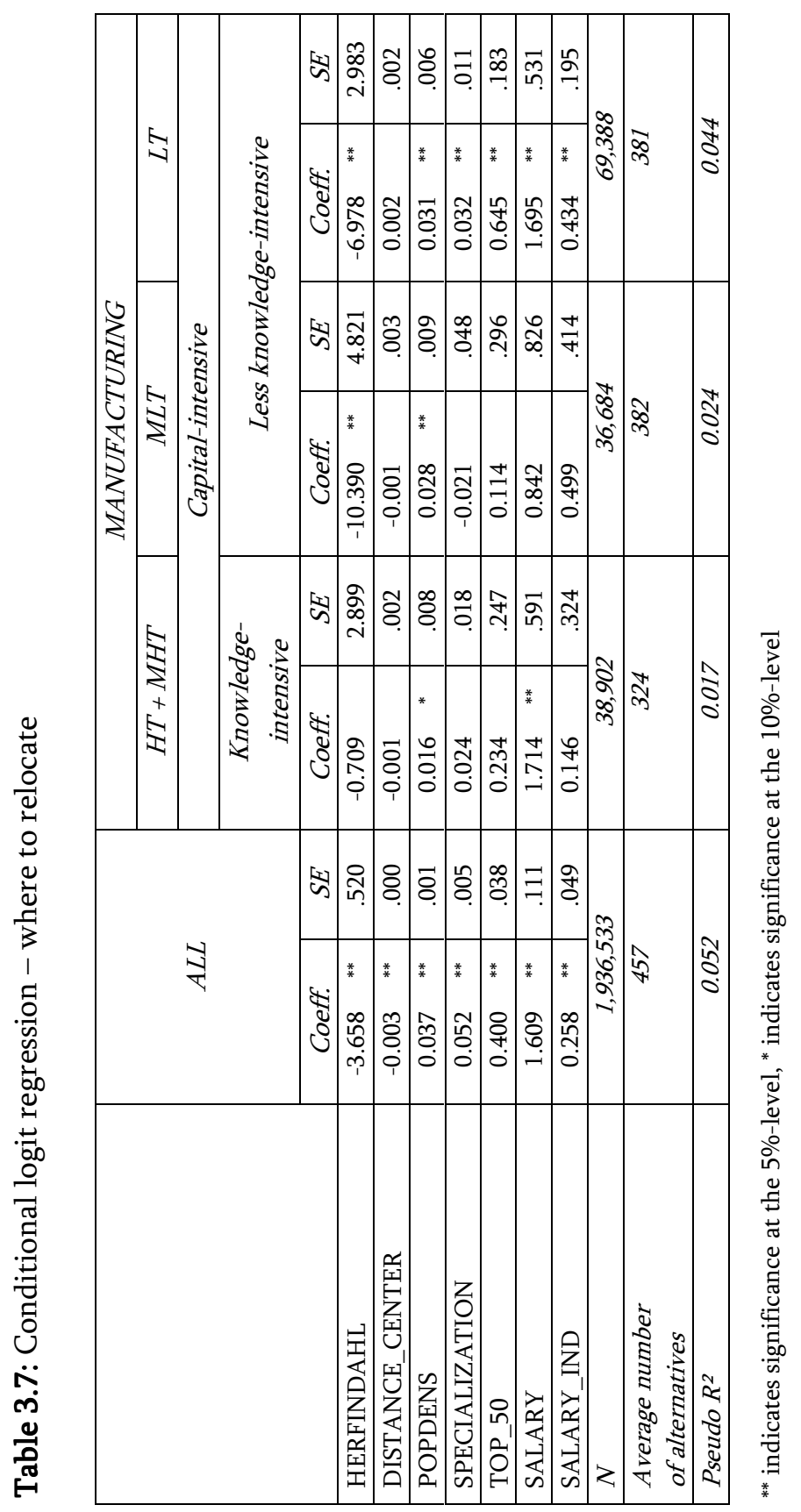




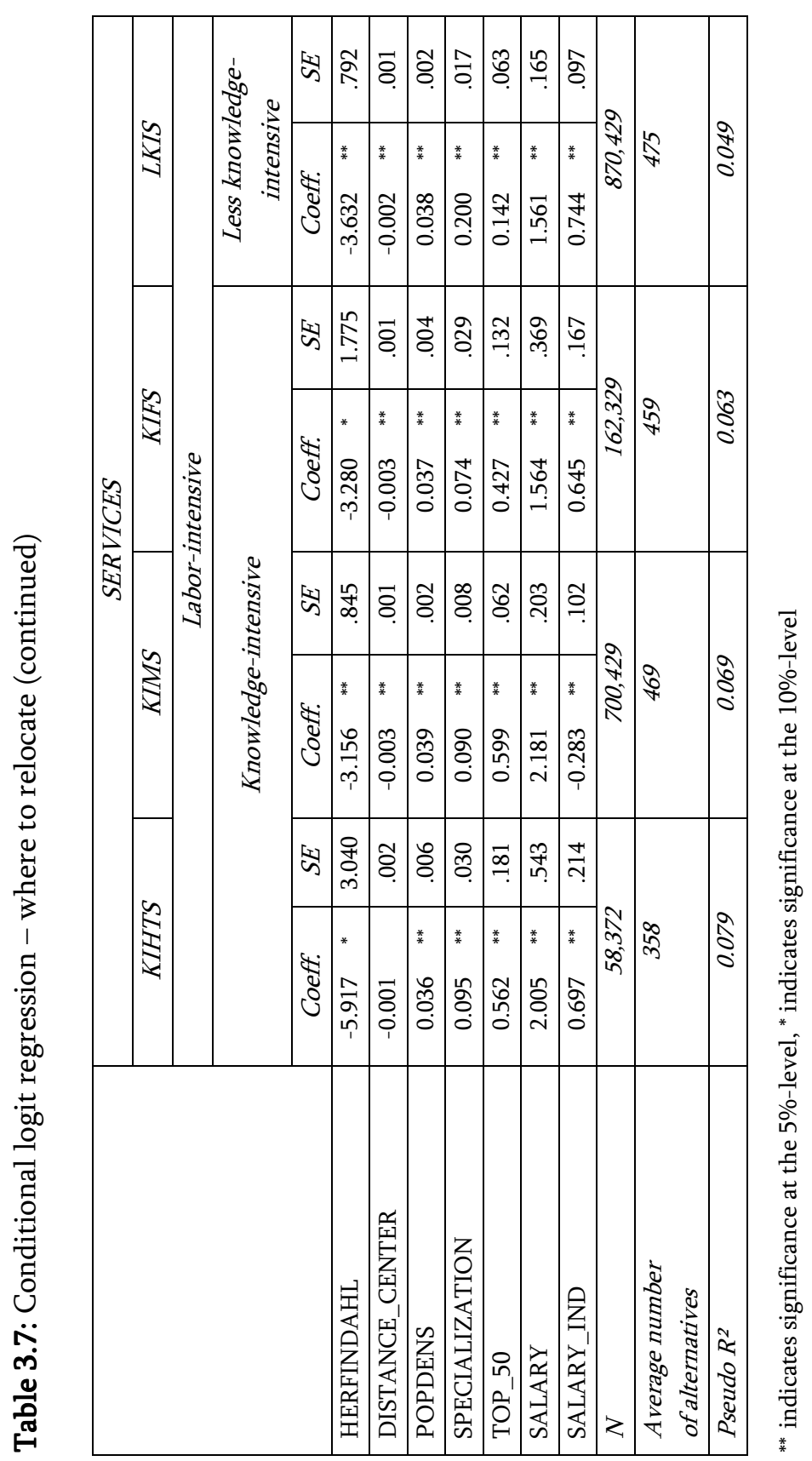




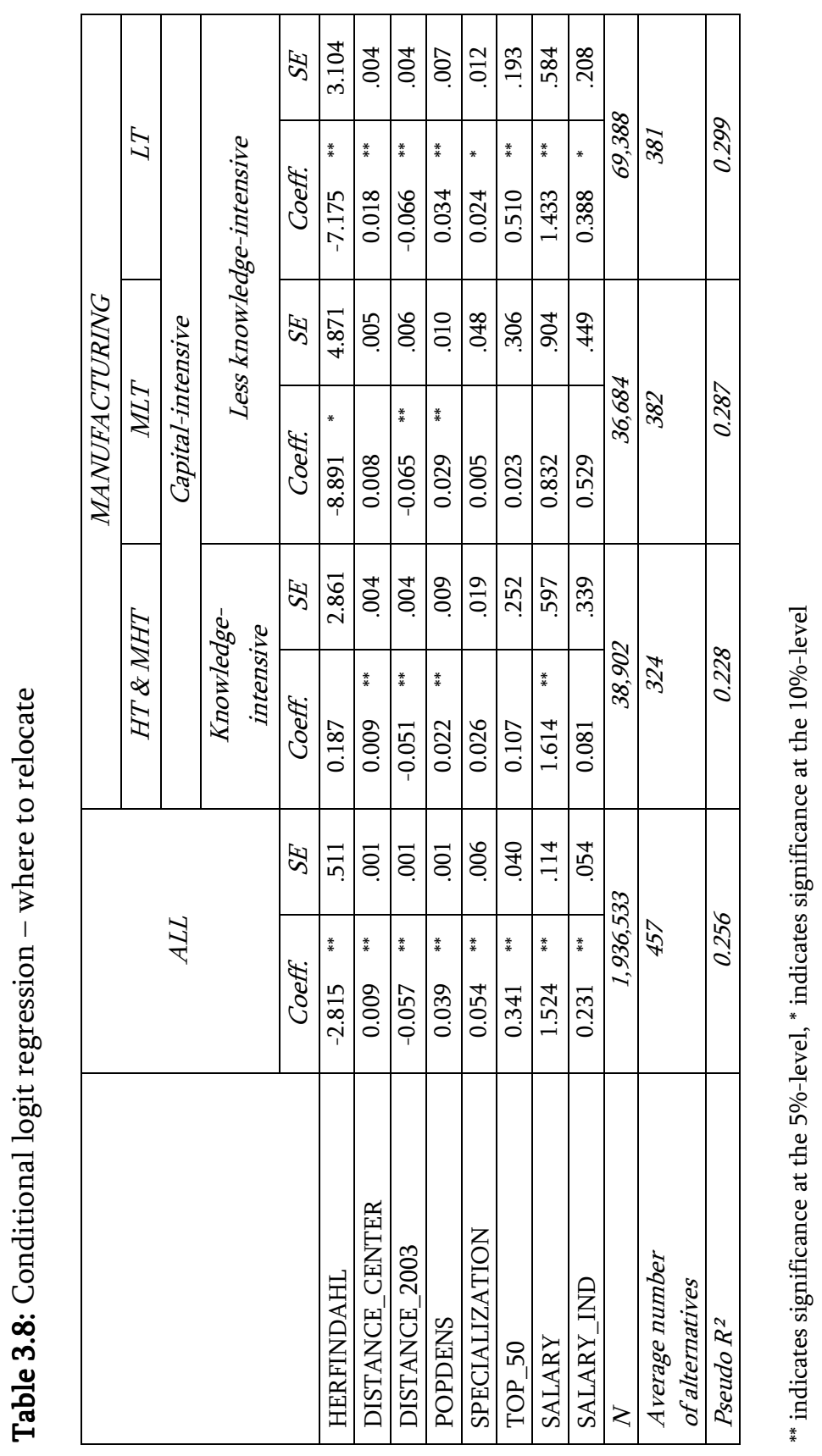




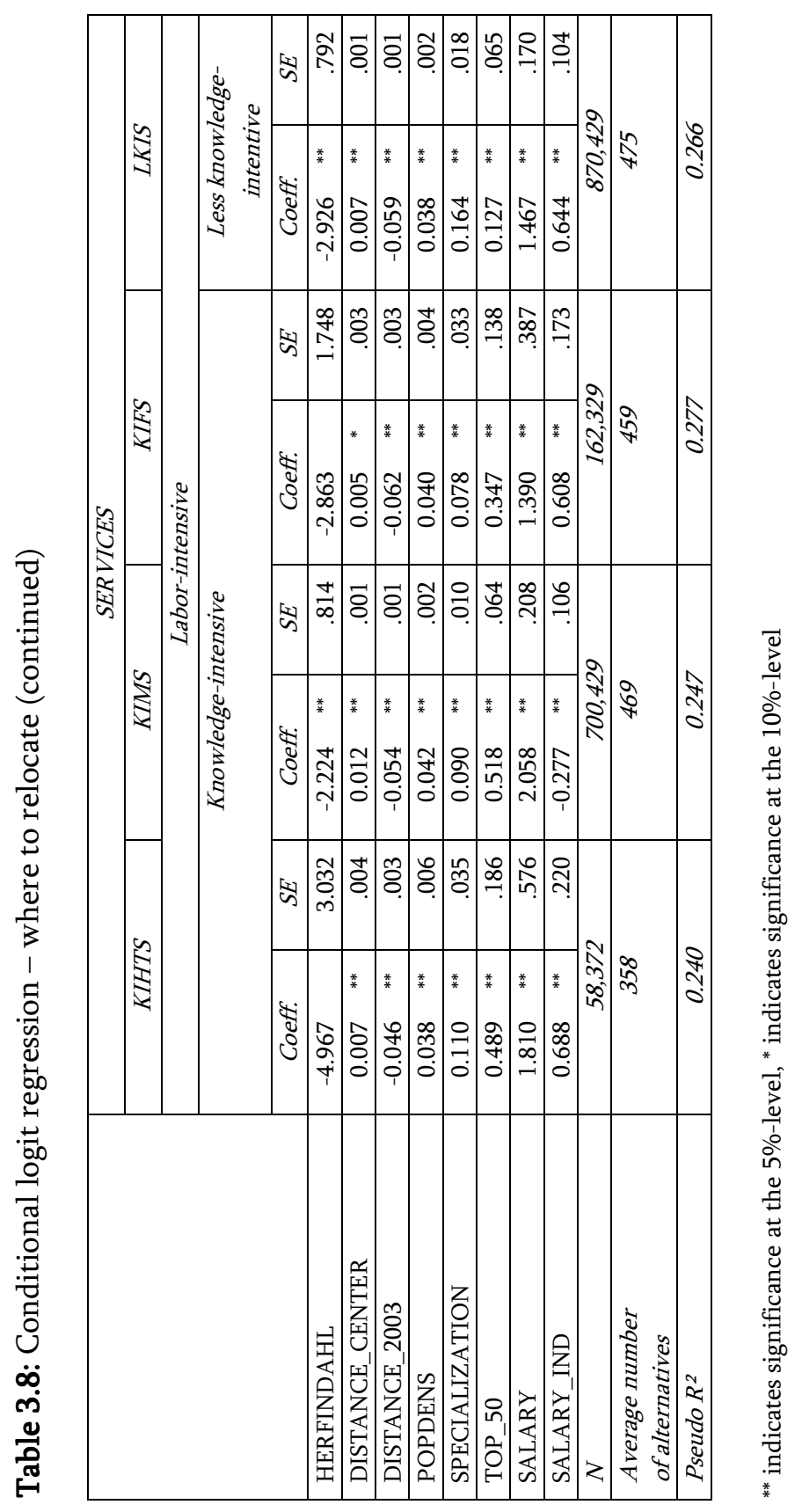



CHAPTER 4

LOCATIONAL CHOICES AND THE COSTS OF DISTANCE: EMPIRICAL EVIDENCE FOR DUTCH GRADUATES

\begin{abstract}
This chapter identifies and analyzes the effects of university/college graduates' personal, household and employment characteristics as well as the attributes of their study, work and home locations on their college-to-work, college-to-residence, and commuting distances. The results illustrate that graduates are drawn to prospering regions with ample job opportunities, supposedly in order to advance their careers. They choose their places of residence so as to balance their commuting distances and the distances to their previous places of study. Residential amenities have a comparatively small effect on graduates' locational choices, whereas they appear to value accessibility of the place of residence.
\end{abstract}




\subsection{Introduction}

The locational choices of graduates can be expected to have a substantial impact on the economic performance of regions experiencing the in- and/or outflow of highly educated individuals (e.g. Venhorst et al., 2010). Yet, while a vast body of literature exists on the migratory decisions of individuals in general, comparatively little is known about the locational preferences of recent university/college graduates, both regarding their choices of workplace and place of residence, and how these decisions depend on their location of study.

Recent university and college graduates, being young and highly educated, can be expected to display comparatively high levels of spatial mobility (Clark \& Cosgrove, 1991; Kodrzycki, 2001; Ritsilä \& Ovaskainen, 2001) as well as a high commuting tolerance (Schwanen et al., 2002). Yet, while the locational choices of these graduates may profit those areas which experience the inflow of qualified and affluent individuals, they might harm those regions which are confronted with the loss of a talented workforce, or have to bear the consequences of excessive commuting and the congestion associated with it.

This study contributes to the existing literature on individuals' spatial behavior by analyzing the determinants of graduates' college-to-work, college-to-residence and commuting distances. It takes into account the influence of graduates' personal, household and employment characteristics, the attributes of the regions of origin and destination, and the distances between the regions of origin and destination and other locations of interest, thereby illustrating the trade-offs individuals have to make between locational benefits and the costs associated with the distances between relevant localities. The study makes a valuable addition to the literature on individuals' locational choices which often distinguishes between areas considerably larger than the average Dutch municipality, and commonly assumes one's locations of work and residence to be identical.

The dataset used in the empirical analysis was provided by Statistics Netherlands. It is based on register data covering virtually all Dutch university/college graduates in 2003, and consists of information regarding graduates' personal, household and employment characteristics, their study, home and work locations, and the attributes of these localities. The 
Netherlands are a comparatively small country with a surface area of only $41.528 \mathrm{~km}^{2}$, and with the maximum distance between two municipalities amounting to just slightly more than 300 kilometers. Thus, a person living and working in the Netherlands can easily reach any location of interest within a reasonable period of time, and may virtually commute between any given workplace and place of residence. Yet, as the Netherlands are also a densely inhabited country with a population density of more than 490 inhabitants $/ \mathrm{km}^{2}$, congestion is a critical issue (e.g. Camstra, 1996; Kronenberg \& Carree, 2012; Rouwendal \& Meijer, 2001), asking for the understanding of the determinants of long-distance journeys and commutes.

Results illustrate that graduates appear to be drawn to prospering regions with ample job opportunities, supposedly in order to advance their careers, yet try to balance their commuting distances and the distances to their previous place of study by locating their place of residence accordingly. Residential amenities have a negligible effect on graduates' locational choices, whereas they appear to value accessibility of the place of residence, possibly in order to be prepared for future job changes.

The chapter is organized as follows: Section 4.2 provides an overview regarding the theoretical background of the research, and section 4.3 outlines the characteristics of the data used in the study. Section 4.4 introduces the theoretical model employed in the analysis as well as the empirical specification, and defines the variables which are used. Section 4.5 presents and discusses the results, and section 4.6 concludes.

\subsection{Theoretical framework and hypotheses}

\subsubsection{A model of graduates' locational choices}

For each graduate, we discuss three locations of interest, namely the place of study, which is assumed to also constitute the place of residence until graduation, and both the place of work and the place of residence in the year following graduation, and determine the respective distances (Figure 4.1). 


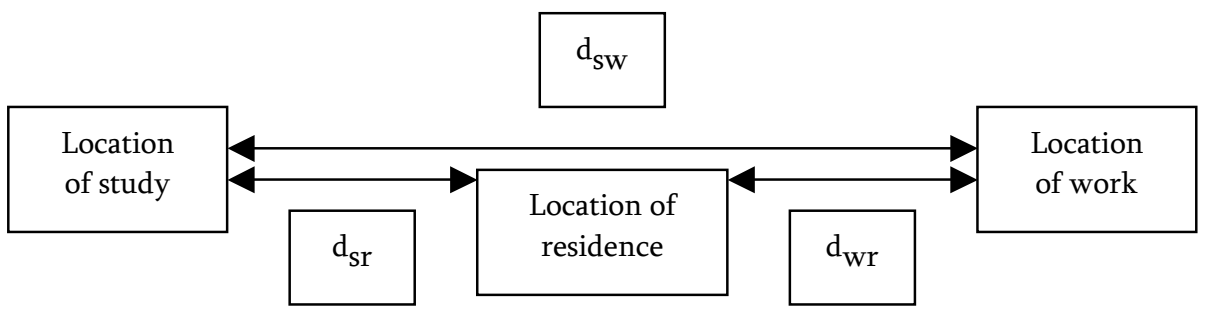

Figure 4.1: Graduates' locations of study, residence and work and the respective distances.

It is assumed that graduates first decide on a workplace, and then choose a place of residence by taking into consideration the distances to the locations of study and work. This model is supported by our Dutch data showing that the average college-to-work distance between a graduate's place of study and place of work amounts to $42.58 \mathrm{~km}$, while the average distances between the place of residence and the place of study and that of work equal $34.02 \mathrm{~km}$ and $25.13 \mathrm{~km}$, respectively (see Table 4.1). This suggests that graduates attempt to locate their place of residence in close proximity to both their workplace and place of study, so as to minimize the distances traveled when commuting and realizing return visits.

Table 4.1: Graduates' college-to-work (D_SW), college-to-residence (D_WR) and commuting (D_SR) distances (in $\mathrm{km}$ )

\begin{tabular}{|l|r|r|r|r|}
\hline & \multicolumn{1}{|c|}{ Mean } & \multicolumn{1}{c|}{ SD } & \multicolumn{1}{c|}{ Minimum } & \multicolumn{1}{c|}{ Maximum } \\
\hline D_SW & 42.584 & 47.31 & 0.00 & 314.48 \\
\hline D_WR & 25.134 & 36.06 & 0.00 & 314.47 \\
\hline D_SR & 34.018 & 43.69 & 0.00 & 275.55 \\
\hline
\end{tabular}

\subsubsection{The determinants of the distances between graduates' places of interest}

We assume the distances between a graduate's place of study, workplace and place of residence to be influenced by the individual's personal, household and employment characteristics, career opportunities and residential 
amenities at the locations of interest, and their accessibility. One's commuting distance is also expected to be affected by the distances between the place of study and the place of residence respectively work, as is the distance between the place of study and the place of residence assumed to be influenced by the commuting distance as well as the distance between the place of study and the workplace.

The costs of moving can be assumed to increase with age (Sandell, 1977), as older individuals can be expected to have developed stronger ties with their environment, and might thus be less willing to leave their familiar surroundings (Kronenberg \& Carree, 2012; Pekkala, 2003; Ritsilä \& Ovaskainen, 2001). At the same time, the commuting distances of older individuals are generally shorter than those of younger persons (Manaugh et al., 2010; Plaut, 2006; Schwanen et al., 2004; Susilo \& Maat, 2007), supposedly since younger workers are more likely to have the energy required to realize lengthy, time-consuming commutes (So et al., 2001). Since accepting a job at a large distance from one's place of study and current residence entails either simultaneous relocation, or the realization of long commutes, we hypothesize the distance between a graduate's place of study and workplace to decrease with the age of the graduate, resulting in both shorter commutes, and shorter distances between the place of study and the place of residence.

Female graduates have been found to be more migratory than males, as they may aim to counterbalance gender bias in the labor market by extending their search radius when looking for employment (Faggian et al., 2007). Correspondingly, Venhorst et al. (2011) established that female college graduates are more likely than their male equivalents to cover large collegeto-work distances when starting their first job after graduation. At the same time, females generally have shorter commutes than males (Crane, 2007; Manaugh et al., 2010; Plaut, 2006; Sang et al., 2011; Shuttleworth \& Gould, 2010; Susilo \& Maat, 2007), possibly due to the gender-specific allocation of domestic responsibilities (Rouwendal \& Nijkamp, 2004; Schwanen et al., 2002; Schwanen et al., 2004), or because women tend to attach a larger value on the disutility of commuting than men (So et al., 2001). We thus hypothesize that the distance between a graduate's place of study and workplace will be larger for female graduates and, since we expect women to 
have shorter commutes, we assume their college-to-residence distances to be longer than those of men.

Family ties have been found to discourage residential mobility (Mincer, 1978), as other members of the household might be unwilling to leave their familiar surroundings, or might even suffer from a residential move, since relocation might entail losing nearby friends, giving up one's job, or accepting a longer daily commute. Hence, it follows that multi-person households will be less inclined to move than those consisting of only one person (Becker, 1981; Eliasson et al., 2003; Kan, 2003; Kronenberg \& Carree, 2012; Linneman \& Graves, 1983; Pekkala, 2003). Accordingly, Clark and Cosgrove (1991) found that singles migrate across larger distances than individuals having a partner. Furthermore, commuting distances have been found to decrease with the number of persons in a worker's household (Manaugh et al., 2010; Schwanen et al., 2002), and are lower for employees with dependent children (Manaugh et al., 2010; Susilo \& Maat, 2007), supposedly since the coordination of domestic and professional responsibilities becomes more difficult with distance (So et al., 2001). We therefore hypothesize the distance between a graduate's place of study and workplace to be smaller for married graduates, and for those having children, bringing about shorter commutes as well as a shorter distances between the place of study and the place of residence.

Hensen et al. (2008) find that the probability of finding a full-time job increases with the distance covered between one's location of study and location of work, and graduates who are geographically mobile also have an increased propensity to find jobs which generate above-average pay. Correspondingly, employees working part-time have been found to have shorter commutes than those in full-time positions (Camstra, 1996; Kwan, 1999; Manaugh et al., 2010; Sang et al., 2011), presumably since their commuting costs relative to the total salary earned are comparatively high. Furthermore, commuting distances were found to be larger for individuals with higher incomes (Kim et al., 2005; Manaugh et al., 2010; Mulalic et al., 2010; Plaut, 2006; Schwanen et al., 2004; So et al., 2001; and Susilo \& Maat, 2007). There are two related explanations for this phenomenon. Workers might bargain for higher wages in order to compensate for longer commutes (Mulalic et al., 2010), or those being offered high salaries might attach a comparatively lower importance to commuting distance and the associated 
costs (Kim et al., 2005), especially if they can realize living in their preferred location. We thus hypothesize that both the distance between a graduate's place of study and workplace, and the commuting distance between the place of residence and the workplace increase with the salary earned, and with the part-time factor of the job.

Career opportunities have been found to have a considerable impact on the spatial behavior of individuals. Employees have been found to be generally drawn to high-wage regions (e.g. Davies et al., 2001; Greenwood \& Hunt, 1989; Kodrzycki, 2001; Molho, 1984; Pekkala, 2003), to locations which had been subject to employment growth (e.g. Clark \& Hunter, 1992; Greenwood \& Hunt, 1989; Davies et al., 2001; Gottlieb \& Joseph, 2006), or to highly populated areas with generally favorable economic circumstances (e.g. Berry \& Glaeser, 2005; Davies et al., 2001; Gottlieb \& Joseph, 2006; Kodrzycki, 2001; Pekkala, 2003). Conversely, being located in a sparsely populated, low-wage area with unfavorable employment conditions can be expected to push individuals towards seeking employment elsewhere (e.g. Hansen et al., 2003; Nakosteen \& Zimmer, 1982; Pekkala, 2003; Ritsilä \& Ovaskainen, 2001; Venhorst et al., 2011; Whisler et al., 2008; Yousefi \& Rives, 1987). We thus assume that the distance between a graduate's place of study and workplace decreases with the career opportunities present at the location of study, and increases with the job opportunities present at the location of work. Career opportunities are proxied by population, employment growth, the average salary earned, the share of highly educated workers, and the degree of specialization in the graduate's sector of employment.

While the career opportunities present in an area attract workers seeking employment (e.g. Berry \& Glaeser, 2005; Clark \& Hunter, 1992; Davies et al., 2001; Gottlieb \& Joseph, 2006; Greenwood \& Hunt, 1989; Kodrzycki, 2001; Molho, 1984; Pekkala, 2003), individuals may not be able to find (or afford) their preferred type of accomodation in these areas. When selecting the location of residence, individuals may therefore face a trade-off between housing attributes (e.g. size of the dwelling and the surrounding premises, qualities of the building, availability of a garden) and commuting distance (Clark \& Burt, 1980; Kain, 1962; Kim et al., 2005; Rouwendal \& Meijer, 2001; So et al., 2001), possibly encouraging workers to live and work in different locations. We therefore hypothesize that the distance between a graduate's 
place of residence and workplace increases with the career opportunities present at the location of work, and decreases with the career opportunities present at the location of residence.

The choice of one's residential location can be expected to be influenced by the presence of residential amenities such as favorable climatic conditions, low crime rates, and good educational and recreational facilities. Amenityrich locations have been found to experience larger inflows of migrants than those lacking characteristics which appeal to individuals (e.g. Clark \& Hunter, 1992; Davies et al., 2001; Graves, 1983; Rappaport, 2007). Conversely, regions which are perceived as unattractive are more likely to be subject to the outmigration of residents (e.g. Clark et al., 1996; Herzog \& Schlottmann, 1986). In case the location of work is not endowed with the desired locational attributes, individuals may decide to locate elsewhere, thus trading off residential amenities and commuting distance. We thus expect that the distance between a graduate's place of residence and workplace increases with the amenities present at the location of residence, and decreases with the amenities present at the location of work. Amenities are proxied by dummy variables indicating whether the municipalities of residence and work have been ranked as one of the 50 most attractive Dutch municipalities for individuals to live in. Correspondingly, as illustrated by Clark and Cosgrove (1991), the distance moved by migrants increases with the differences in amenity levels between the region of origin and the region of destination. In case the location of study provides the desired locational attributes, graduates may decide to remain in their place of study, whereas knowledge about alternative residential locations which appeal to individuals might induce them to relocate. We thus expect that the distance between a graduate's place of study and place of residence increases with the amenities present at the location of residence, and decreases with the amenities present at the location of study.

The better one's place of study and workplace can be reached, the larger the distance between those two locations can be without necessarily requiring concurrent relocation, as access to good transport infrastructure at both the locations of residence and work enables employees to realize longer commutes (Manaugh et al., 2010). Alternatively, better accessibility of the place of study implies that in the case of a residential move, it will be easier to return for visits and short-term stays, the psychic and actual costs of 
which will be diminished by the presence of good transportation facilities connecting the locations of origin and destination (Clark \& Cosgrove, 1991). We therefore hypothesize that the distance between a graduate's place of study and workplace increases with the accessibility of both locations, as both longer commutes, and longer college-to-residence distances are facilitated.

Individuals can be expected to keep the distances between all locations of interest as short as possible, e.g. by relocating to a place which is located between the place of study and the workplace. The decision of where to relocate thus entails a trade-off between remaining located in close proximity to the place of study, and minimizing the commuting distance between the place of residence and the workplace. Naturally, however, the larger the college-to-work distance, the larger the combined college-to-residence and commuting distances will be. We thus hypothesize that the commuting distance between a graduate's place of residence and workplace increases with the distance between the place of study and the workplace, and decreases with the distance between the place of residence and the place of study. Likewise, we expect the distance between a graduate's place of residence and place of study to increase with the distance between the place of study and the workplace, and to decrease with the commuting distance between the place of residence and the workplace.

\subsection{Data}

\subsubsection{Data sources}

The data used in this study were provided by Statistics Netherlands (CBS). Data on graduates, universities, households, firms and municipalities originate from various sources and were merged for the purpose of this study.

Education-related information on graduates (year of graduation, institution of higher education, field of study) stems from the Dutch central student register (CRIHO), which is based on information derived from the Informatie Beheer Groep, a Dutch governmental institution. For 57 institutions (13 universities and 44 colleges) of higher education, the location (municipality) could be determined. 
Personal, household- and job-related information on graduates originates from the Social Statistical Database (SSB) which is compiled on the basis of register and survey data from two main sources. Personal and householdrelated data (e.g. date of birth, gender, partner, children, residential location on the municipal level) stem from the municipal registration system, while information regarding a person's job (e.g. employer, duration of employment, salary, part-time factor) is provided by the Fibase, a database delivered by the Dutch Tax Administration. As each graduate is identified by a unique identification number, personal-, employment- and household-related information from these different sources could be merged.

Data regarding firms (e.g. industrial sector, location on the municipal level) are available on the level of the 'business unit'. The information originates from the SSB, the Dutch business register (ABR), the Survey on Employment and Wages (EWL), the Survey Production Statistics (SBS and STS), and data provided by the Dutch Tax Administration. As each employee can be linked to the respective employer, identified by a unique identification number, employer-related information is available for each employed graduate.

Basic information regarding the Dutch municipalities (e.g. population) originates from Statline, a publicly available database provided by Statistics Netherlands which supplies aggregate regional information on the municipal level. Further data regarding the characteristics of the workforce, firms and sectors present in each municipality were established on the basis of the microdata on employees and firms at hand. Information regarding the attractiveness of the Dutch municipalities for individuals was obtained from www.elsevier.nl, where all Dutch municipalities are evaluated each year. Apart from a general ranking (regarding e.g. economic position, health, education, infrastructure, and accessibility) of the municipalities, separate rankings are also available with regard to specific topics such as 'accessibility by car'. Since the locations of the university/college, workplace, and place of residence are known for each graduate, municipal-level characteristics of all three locations are available.

As the exact location of each municipality (its center) is known, the distances between municipalities/locations can be calculated. For each graduate, the respective distances between their place of study, workplace, and place of residence could be determined on the municipal level. 


\subsubsection{Data description}

The dataset consists of 5,665 individuals who graduated from a Dutch university or college in 2003, held a job (at least $0.6 \mathrm{FTE}^{31}$ ) at a single-site ${ }^{32}$ firm on March 24, 2004 which did not start before January 1, 200333, and had a registered place of residence at the reference date ${ }^{34}$ (September 24) in 2004. For these 5,665 graduates, the respective distances between the university/college they graduated from in 2003, their workplace in 2004, and their place of residence in 2004 were calculated.

The dataset further consists of information regarding graduates' personal characteristics (e.g. age, gender, field of study), household composition (e.g. partner, children), employment (e.g. salary, part-time factor), and the characteristics of the municipalities in which their university/college, workplace and place of residence were situated ${ }^{35}$.

These characteristics were determined for the year 2004 for the 475 Dutch municipalities for which information was complete ${ }^{36}$. They include general municipal features (population), employment-related characteristics (previous employment growth, average salary, share of employees aged 22-40 with degree in higher education, sectoral specialization ${ }^{37}$ ), and indicators of regional attractiveness and accessibility.

\footnotetext{
${ }^{31}$ Many Dutch students work parttime while studying, often even having more than one 'small' job, all of which may be unrelated to one's field of study. By only selecting graduates who work in the same job at least three days per week, we expect to limit the dataset to those with degree-related post-graduation jobs.

${ }^{32}$ More than $95 \%$ of the firms are single-site firms. Since the exact location of a person's workplace cannot be determined for those working in firms with subsidiaries in various locations, the latter had to be excluded from the analysis.

${ }^{33}$ Again, by imposing this restriction, we expect to exclude pre-graduation student jobs.

${ }^{34}$ In the dataset at hand, a person's place of residence as well as all other personal and household characteristics are only established once a year (last Friday in September).

35 Regrettably, the data at hand did not provide any information regarding a student's place of residence before attending university/college.

36 In 2004, the Netherlands consisted of 483 municipalities. Since information on employment growth and accessibility was not available for all municipalities, eight municipalities had to be excluded from the analysis. Graduates who were working and/or living in one of these municipalities were consequently excluded as well.

37 The values for sectoral specialization depend on the sector (2-digit NACE level) the graduate is employed in.
} 


\subsection{Methodology}

\subsubsection{Theoretical model}

There are 475 potential locations $(w=1, \ldots, 475)$ where graduates may enter employment, and they can choose between the same 475 locations $(r=1, \ldots$, $475)$ when selecting their place of residence. Since individuals will aim to maximize utility, they can be expected to select the locations at which they expect to obtain the highest net benefits, e.g. by choosing their job in a region with ample career opportunities, and selecting their residence in an area where residential amenities are abundant. At the same time, individuals derive disutility from the distances between locations of interest, as daily commutes and frequent return visits become increasingly costly and timeconsuming with distance. The utility function of graduate $i$ selecting a job at $w$ and a place to live at $r$ can thus be written as

$$
U=U(B, T)
$$

with $B$ signifying the benefits of choosing locations $w$ and $r$, and $T$ denoting the (travel) costs associated with these decisions. More specifically, we assume that

$$
U_{i W r}=\alpha_{i} X_{i W r}-\beta_{i}\left(d_{i W r}\right)^{2}-\gamma_{i}\left(d_{i s r}\right)^{2}
$$

where $X_{i w r}$ is a vector of the benefits which graduate $i$ selecting a job at $w$ and a place to live at $r$ attains, and $d_{i W r}$ and $d_{i s r}$ refer to the costs associated with the commuting distance between the place of residence and the workplace, and with the distance between the place of residence and the place of study ${ }^{38}$.

As graduates will aim to minimize the distances between all locations of interest, we assume that their place of residence is located on a straight line

\footnotetext{
${ }^{38} \mathrm{We}$ assume utility to be a negative quadratic function of distance, as the travel time between two locations will be subject to higher variance. Counterbalancing efforts (e.g. leaving earlier to be at work on time) thus generate a convex loss function (Juster \& Stafford, 1991). For convenience, the subscript $i$ will be omitted throughout the remainder of the text.
} 
between their places of study and work ${ }^{39}$, so that the college-to-work distance $d_{s W}=d_{w r}+d_{s r}$, hence $d_{s r}=d_{s W}-d_{w r}$. A graduate, having chosen a job at a specific location, will attempt to solve the following optimization problem:

$$
\text { Min } T=\beta\left(d_{w r}\right)^{2}+\gamma\left(d_{s W}-d_{w r}\right)^{2} \text { with respect to } d_{w r}
$$

The first order condition is:

$$
2 \beta d_{W r}-2 \gamma\left(d_{s W}-d_{w r}\right)=0
$$

Solving this for $d_{w r}$ yields:

$$
d_{w r}=\frac{\gamma}{\beta+\gamma} d_{s w}
$$

It thus follows that:

$$
d_{s r}=\frac{\beta}{\beta+\gamma} d_{s W}
$$

Hence:

$$
U_{w r}=\alpha X_{w r}-\beta\left(\frac{\gamma}{\beta+\gamma} d_{s W}\right)^{2}-\gamma\left(\frac{\beta}{\beta+\gamma} d_{s W}\right)^{2}
$$

In case two jobs, $\mathrm{J}_{1}$ and $\mathrm{J}_{2}$, offer the same benefits $X_{w r}$, but are located at dissimilar distances from the place of study, the graduate will prefer the job which is located closer to the place of study so as to minimize $d_{s w}$ and the associated costs $T$. Only if the benefits offered by $\mathrm{J}_{2}$, located at a greater distance to the place of study than $\mathrm{J}_{1}$, are sufficiently large to compensate for

\footnotetext{
39 Evidently, this constitutes only an approximation, yet Table 1 suggests that students indeed aim to minimize the distances between all relevant localities by choosing their place of residence so as to minimize the distances to both their places of work and study.
} 
the greater distance, the graduate will prefer $\mathrm{J}_{2}$ to $\mathrm{J}_{1}$. Graduates will only be tempted to move away from their place of study in case $X_{w r}$ is a (locally) increasing function of $d_{s W}$, say $\delta d_{s W}$. If $\delta$ was equal to zero, then graduates would always remain at their place of study. A reason for $\delta$ to be positive is that the number of alternative jobs increases with distance.

Thus:

$$
U_{w r}=\alpha \delta d_{s W}-\beta\left(\frac{\gamma}{\beta+\gamma} d_{s w}\right)^{2}-\gamma\left(\frac{\beta}{\beta+\gamma} d_{s w}\right)^{2}
$$

A graduate will attempt to solve the following optimization problem:

$$
\operatorname{Max} U_{w r}=\alpha \delta d_{s W}-\beta\left(\frac{\gamma}{\beta+\gamma} d_{s W}\right)^{2}-\gamma\left(\frac{\beta}{\beta+\gamma} d_{s W}\right)^{2}
$$

with respect to $d_{s W}$

The first order condition is:

$$
\alpha \delta-2 \beta\left[\left(\frac{\gamma}{\beta+\gamma}\right)^{2} d_{s W}\right]-2 \gamma\left[\left(\frac{\beta}{\beta+\gamma}\right)^{2} d_{s W}\right]=0
$$

Solving this for $d_{s W}$ yields:

$$
d_{s w}=\frac{\alpha \delta}{\left(2 \beta\left(\frac{\gamma}{\beta+\gamma}\right)^{2}\right)+\left(2 \gamma\left(\frac{\beta}{\beta+\gamma}\right)^{2}\right)}
$$

Hence, (11) illustrates that a graduate's college-to-work distance increases as the attractiveness $(\delta)$ of employment increases with distance from the place of study, but decreases with the unpleasantness $(\beta$ and $\gamma)$ the graduate associates with the distances between relevant localities. 


\subsubsection{Empirical Specification}

We assume that a graduate chooses his or her first post-graduation job by taking into account personal, household and employment characteristics, attributes of the locations of study and work, and the distance between the location of study and the location of the workplace. The distance between a graduate's place of study and workplace will thus be determined by the graduate's personal features, characteristics of the household, qualities of the job obtained after graduation, and attributes of the municipalities of study and work.

Having decided on a specific job in a particular location, the graduate selects a place of residence. The distance between a graduate's place of residence and place of study is expected to depend upon the graduate's personal features, characteristics of the household, attributes of the municipalities of study and residence, the distance between the place of study and the workplace, and the commuting distance between the graduate's place of residence and workplace. At the same time, the commuting distance between a graduate's place of residence and workplace will be determined by the graduate's personal features, characteristics of the household, qualities of the job obtained after graduation, attributes of the municipalities of work and residence, the distance between the place of study and the workplace, and the distance between the graduate's place of residence and place of study.

Since the dependent variables - the distances between the locations of interest - are naturally left-censored at zero ${ }^{40}$, Tobit regression models are used to examine the influence of personal, household, employment and locational characteristics as well as distances between locations of interest on graduates' college-to-work, college-to-residence and commuting distances. The Tobit model is based on the unobserved continuous dependent variable $y_{i}^{*}$ for which the dependent variable (distance) $y_{i}=y_{i}{ }^{*}$ if $y_{i}^{*}>c$ and $y_{i}=c$ if $y_{i}^{*} \leq c$, with $c=0$ being the threshold for censoring.

\footnotetext{
40 Theoretically, the dependent variables would also have to be right-censored, since the maximum distance between two Dutch municipalities is $314.48 \mathrm{~km}$. Yet, as values of this magnitude are exceptionally rare, we abstained from right-censoring.
} 


\subsubsection{Variables}

Table 4.2 displays the variables employed in the analysis. (Note: for all dummy variables, the value ' 1 ' signifies 'yes', and the value ' 0 ' denotes 'no'.)

Table 4.2: Definitions of variables

\begin{tabular}{|l|l|}
\hline \multicolumn{1}{|c|}{ Variable } & \\
\hline D_SW & Graduate's college-to-work distance (in km) \\
\hline D_WR & Graduate's commuting distance (in km) \\
\hline D_SR & Graduate's college-to-residence distance (in km) \\
\hline AGE & Age of the graduate (in years) \\
\hline FEMALE & $1=$ female, 0 = male \\
\hline PARTNER & $1=$ graduate lives in registered partnership, 0 = otherwise \\
\hline CHILDREN & $\begin{array}{l}1=\text { at least one child is living in the graduate's household, } \\
0=\text { otherwise }\end{array}$ \\
\hline SALARY & Graduate's daily salary (in $€$ ) \\
\hline FTE & Part-time factor of graduate's job \\
\hline POP_S & Population of municipality of study (in 1,000 inhabitants) \\
\hline GROWTH_REL_S & Relative change in employment in municipality of study \\
\hline SALARY_S & Average daily salary (in $€$ ) in municipality of study \\
\hline HIGH_EDUC_S & Share of highly educated employees in municipality of study \\
\hline SPEC_S & $\begin{array}{l}\text { Sectoral specialization in graduate's sector of employment } \\
\text { in municipality of study }\end{array}$ \\
\hline TOP_50_S & $\begin{array}{l}1 \text { = municipality of study has been ranked as one of the } 50 \text { most } \\
\text { attractive Dutch municipalities for individuals, } 0 \text { = otherwise }\end{array}$ \\
\hline CAR_S & $\begin{array}{l}\text { Accessibility of municipality of study by car, } \\
1=\text { poor accessibility, } 5=\text { excellent accessibility }\end{array}$ \\
\hline POP_W & Population of municipality of work (in 1000 inhabitants) \\
\hline GROWTH_REL_W & Relative change in employment in municipality of work \\
\hline SALARY_W & Average daily salary (in $€$ ) in municipality of work \\
\hline HIGH_EDUC_W & Share of highly educated employees in municipality of work \\
\hline SPEC_W & $\begin{array}{l}\text { Sectoral specialization in graduate's sector of employment } \\
\text { in municipality of work }\end{array}$ \\
\hline TOP_50_W & $\begin{array}{l}1=\text { municipality of work has been ranked as one of the } 50 \text { most } \\
\text { attractive Dutch municipalities for individuals, } 0 \text { = otherwise }\end{array}$ \\
\hline CAR_W & $\begin{array}{l}\text { Accessibility of municipality of work by car, } \\
1=\text { poor accessibility, } 5=\text { excellent accessibility }\end{array}$ \\
\hline
\end{tabular}


Table 4.2: Definitions of variables (continued)

\begin{tabular}{|l|l|}
\hline POP_R & Population of municipality of residence (in 1000 inhabitants) \\
\hline GROWTH_REL_R & Relative change in employment in municipality of residence \\
\hline SALARY_R & Average daily salary (in $€$ ) in municipality of residence \\
\hline HIGH_EDUC_R & Share of highly educated employees in municipality of residence \\
\hline SPEC_R & $\begin{array}{l}\text { Sectoral specialization in graduate's sector of employment } \\
\text { in municipality of residence }\end{array}$ \\
\hline TOP_50_R & $\begin{array}{l}1=\text { municipality of residence has been ranked as one of the 50 } \\
\text { most attractive Dutch municipalities for individuals, } \\
0=\text { otherwise }\end{array}$ \\
\hline CAR_R & $\begin{array}{l}\text { Accessibility of municipality of residence by car, } \\
1=\text { poor accessibility, } 5=\text { excellent accessibility }\end{array}$ \\
\hline
\end{tabular}

The variables D_SW, D_WR and D_SR measure the respective distances (in $\mathrm{km}$ ) between the municipalities a graduate's place of study, workplace and place of residence are located in. All variables are measured in 2004 (or, in the case of D_SW, D_SR and GROWTH_REL, between 2003 and 2004).

AGE is the age of the graduate (in years), and FEMALE indicates whether a graduate is female. PARTNER denotes whether a graduate is married ${ }^{41}$, and CHILDREN indicates the presence of at least one child in the graduate's household. SALARY is the daily salary (in €) earned by the graduate, and PTF is the part-time factor of the job (the values of this variable range between 6000 , indicating a 0.6 -FTE-job, and 10000, denoting a full-time position).

All municipal-level variables are available for each graduate's place of study, workplace and place of residence, distinguished by the suffixes_S, _W and _R. POP indicates the population of a municipality (in 1,000 inhabitants), and GROWTH_REL is the relative change in employment in comparison to the previous year. SALARY denotes the average daily salary (in $€$ ) in a municipality, and HIGH_EDUC indicates its share of highly educated employees (aged 22-40). SPEC denotes the sectoral specialization (or location quotient) of a municipality, referring to the sector the graduate is

${ }^{41}$ With the available data, it is only possible to determine whether or not an individual is living in a registered partnership. While in most cases, registered partners are indeed married, the variable also captures those who registered their partnership without getting married. 
employed in. This variable measures the share of employees in the graduate's sector (2-digit level) in the municipality relative to the share of employees in the graduate's sector in the Netherlands. A value of 1 indicates that in the municipality, the graduate's industry is as present as in the rest of the Netherlands, a value smaller than 1 indicates that in the municipality, the industry is underrepresented, and a value greater than 1 indicates that in the municipality, the industry is overrepresented. TOP_50 denotes whether a municipality has been ranked as one of the 50 most attractive Dutch municipalities for individuals, and CAR indicates the accessibility of a municipality by car (on a Likert-scale with values ranging from 1 to 5 , with 1 indicating very poor accessibility, and 5 indicating excellent accessibility).

Furthermore, dummy variables in order to control for the graduates' fields of study are included, classifying the following nine subject areas: education (1), agricultural and life sciences (2), natural sciences (3), engineering sciences (4), healthcare (5), economics and business sciences (6), law (7), social sciences (8), and linguistics and cultural sciences (9), with the latter being the reference category. Descriptive statistics for the explanatory and control variables are presented in Table 4.3.

Graduates were on average 24.97 years old, with $50.4 \%$ being female. Slightly more than one third of the graduates had at least one child, and 31\% were living in a registered partnership. The average daily salary earned in the year following graduation amounted to $€ 60.09$, and the average part-time factor (for jobs between 0.6 and 1.0 FTE) was 0.89 .

The average population (in 1000 inhabitants) of a graduate's place of study was 273.8, and the average relative employment growth in the municipality in which a graduate's university/college was located in was $1.2 \%$. The average daily salary in a graduate's place of study amounted to $€$ 99.56, the average share of employees with a degree in higher education in the municipality in which a graduate's university/college was located in was $31.8 \%$, and the average sectoral specialization (in the graduate's sector) was 1.29. Some $57.5 \%$ of the graduates had studied in a city which had been ranked as one of the 50 most attractive places in the Netherlands, and the average accessibility (by car) of a graduate's place of study was 2.8 (on a 5point Likert-scale). 
Table 4.3: Descriptive statistics

\begin{tabular}{|l|r|r|r|r|}
\hline & \multicolumn{1}{|c|}{ Mean } & \multicolumn{1}{c|}{ SD } & Minimum & Maximum \\
\hline AGE & 24.967 & 2.883 & 20.00 & 56.00 \\
\hline FEMALE & 0.504 & 0.500 & 0.00 & 1.00 \\
\hline PARTNER & 0.310 & 0.463 & 0.00 & 1.00 \\
\hline CHILDREN & 0.353 & 0.478 & 0.00 & 1.00 \\
\hline SALARY & 60.088 & 25.825 & 17.95 & 601.00 \\
\hline FTE & $8,869.319$ & $1,404.244$ & $6,000.00$ & $10,000.00$ \\
\hline POP_S & 273.817 & 207.461 & 24.05 & 739.10 \\
\hline GROWTH_REL_S & -0.012 & 0.045 & -0.09 & 0.11 \\
\hline SALARY_S & 99.564 & 11.826 & 76.56 & 129.56 \\
\hline HIGH_EDUC_S & 0.318 & 0.064 & 0.14 & 0.41 \\
\hline SPEC_S & 1.289 & 1.574 & 0.00 & 70.87 \\
\hline TOP_50_S & 0.575 & 0.494 & 0.00 & 1.00 \\
\hline CAR_S & 2.750 & 1.337 & 1.00 & 5.00 \\
\hline POP_W & 211.675 & 239.195 & 1.16 & 739.10 \\
\hline GROWTH_REL_W & -0.005 & 0.059 & -0.34 & 0.64 \\
\hline SALARY_W & 96.854 & 14.537 & 64.57 & 179.10 \\
\hline HIGH_EDUC_W & 0.264 & 0.084 & 0.06 & 0.41 \\
\hline SPEC_W & 2.240 & 6.213 & 0.03 & 123.54 \\
\hline TOP_50_W & 0.375 & 0.484 & 0.00 & 1.00 \\
\hline CAR_W & 2.710 & 1.317 & 1.00 & 5.00 \\
\hline POP_R & 194.494 & 224.059 & 2.53 & 739.10 \\
\hline GROWTH_REL_R & -0.011 & 0.057 & -0.34 & 0.64 \\
\hline SALARY_R & 0.261 & 0.091 & 0.03 & 179.10 \\
\hline HIGH_EDUC_R & 1.292 & 2.170 & 0.00 & 0.41 \\
\hline SPEC_RE & 0.368 & 0.482 & 0.00 & 70.87 \\
\hline TOP_50_R & 2.729 & 1.321 & 1.00 & 1.00 \\
\hline CAR_R & & & & 5.00 \\
\hline
\end{tabular}

Number of observations $=5,665$

The average population (in 1000 inhabitants) in the municipality in which a graduate's workplace was located in was 211.7, and the average relative employment growth in the municipality was $-0.5 \%$. The average daily salary in the municipality in which a graduate's workplace was located in amounted to $€ 96.85$, the average share of employees with a degree in higher education was $26.4 \%$, and the average sectoral specialization (in the 
graduate's sector) was 2.24 . Some $37.5 \%$ of the graduates worked in a municipality which had been ranked as one of the 50 most attractive places in the Netherlands, and the average accessibility (by car) of the municipality in which a graduate's workplace was located in was 2.7 (on a 5-point Likertscale).

The average population (in 1000 inhabitants) in the municipality in which a graduate's place of residence was located in was 194.5, and the average relative employment growth in the municipality was $-1.1 \%$. The average daily salary in the municipality in which a graduate's place of residence was located in amounted to $€ 94.99$, the average share of employees with a degree in higher education was $26.1 \%$, and the average sectoral specialization (in the graduate's sector) was 1.29 . Some $36.8 \%$ of the graduates lived in a municipality which had been ranked as one of the 50 most attractive places in the Netherlands, and the average accessibility (by car) of the municipality in which a graduate's place of residence was located in was 2.7 (on a 5-point Likert-scale).

\subsection{Results and discussion}

\subsubsection{Determinants of the distance between place of study and place of work}

Results are presented in Table 4.4. They show that graduates living in a registered partnership, and those having children indeed cover shorter distances between their place of study and workplace. Female and male graduates do not differ in their behavior regarding the choice of their workplace location, but, somewhat surprisingly, one's college-to-work distance increases with age. This finding may be attributed to the fact that most of the graduates are between 20 and 30 years of age, and therefore will not have developed any strong ties with the current environment which may have affected their locational choices. Instead, slightly older graduates, due to knowledge and experience, might be more proficient in locating suitable employment elsewhere.

As expected, the distance covered increases with the salary earned in the accepted position, and also with the part-time factor of the job. These 
findings are in line with Hensen et al. (2008), suggesting that one's willingness to look for employment within a larger radius increases the chances of fulltime employment as well as a competitive salary. Equally, it may also be the case that graduates secure adequate compensation for the commuting efforts, relocation costs or the general uprooting which may accompany the acceptance of a job in a distant location.

The better the career opportunities at the location of study, the shorter the distance between the locations of study and work. These findings confirm our expectations, and illustrate that favorable economic conditions, also with respect to a graduate's sector of specialty, can retain graduates in the region. The results also point at the significance of a 'good match' between the education provided at an institution of higher education, and related employment in local industries, as adjacent career opportunities may prevent the 'brain drain' of a capable workforce, and help to retain graduates in the region in which they obtained their degree. Correspondingly, the college-to-work distance generally increases with the career prospects at the selected location of work, indicating that graduates indeed cover large distances in order to work in an area which offers favorable conditions such as high salaries, employment growth, and a specialization in the graduate's area of work.

The better the accessibility of the place of study, the larger the collegeto-work distances of graduates. This finding indicates that graduates may indeed be willing to accept job offers at a larger distance in case their place of study can be easily reached, as daily commutes or return visits are facilitated by the ease of access.

Furthermore, the attractiveness of one's place of work also increases the college-to-work distance, possibly suggesting that graduates who are willing to cover large distances between their place of study and place of work prefer to live and work in close proximity, and are therefore drawn to municipalities offering residential amenities. 


\subsubsection{Determinants of the commuting distance between place of residence and place of work}

Results are presented in Table 4.5. Graduates' commuting distances are not influenced by personal and household characteristics, indicating that recent graduates may form a rather homogeneous group for which the length of the daily commute is determined by other factors. As expected, the commuting distance increases with the salary earned, suggesting that persons with higher incomes may indeed bargain for higher wages in order to compensate for the costs and efforts associated with a longer commute, or simply have the financial means to realize living and working in different locations.

The commuting distance increases with certain career opportunities (salary, sectoral specialization) at the location of work, and decreases with those career opportunities at the location of residence. Especially since the local wage level may also capture rents and land prices, these findings also suggest that workers may indeed trade off housing attributes (e.g. size and quality of the dwelling and the surrounding premises) and commuting distance. At the same time, however, commuting distances are lower for those living and working in municipalities which are highly populated. This may indicate that recent graduates, being young and highly educated, may find it appealing to reside and work in large urban areas (Clark \& Hunter, 1992; Kim et al., 2005), also since these locations may be expected to offer superior 'marriage markets' for this demographic group (Adamson et al., 2004; Costa \& Kahn, 2000).

Somewhat surprisingly, residential amenities do not have the expected effect on commuting distance. Yet, as established by Chen and Rosenthal (2008) as well as Whisler et al. (2008), the locational decisions of recent graduates may be predominantly motivated by career considerations, and comparatively less by the appeal of a location regarding the residential amenities it may offer. Furthermore, attractive municipalities may also be characterized by higher costs of living which young graduates at the beginning of their professional careers may not be able to afford.

As hypothesized, one's commuting distance increases with the accessibility of the residential location, albeit not with the accessibility of the work location. These findings may indicate that young professionals expect 
to repeatedly change jobs in the near future, and aim to secure residential locations which are easily accessible in order to avoid further residential moves.

One's commuting distance, as expected, decreases with the college-toresidence distance, and increases with the distance between the place of study and the workplace. These findings illustrate that graduates indeed face a trade-off between minimizing their daily commute, and diminishing the distance to the location they may still feel emotionally attached to.

\subsubsection{Determinants of the distance between place of study and place of residence}

Results are presented in Table 4.6. We find that female graduates indeed move further away from their place of study, presumably in order to reduce the commuting distance between their workplace and place of residence, as gender bias in the labor market may have required them to accept a position in a distant location (Faggian et al., 2007). Age does not have an effect on the migration distance, yet the presence of additional household members has a positive impact. These findings may indicate that graduates already having a family may attach comparatively less importance to the social network they may have established at their place of study, or, already having a family, may even have abstained from moving to their university town while studying.

Residential amenities do not have the expected effect on one's college-toresidence distance, again suggesting that the spatial decisions of young professionals are not primarily driven by the attractiveness of regions (Chen \& Rosenthal, 2008; Whisler et al., 2008). Surprisingly, the effect of the accessibility of the locations of study and residence on the distance between the two locations is absent, or even negative.

As hypothesized, graduates with longer college-to-work distances also face longer distances between their places of study and residence, yet they appear to be confronted with a trade-off between longer commuting distances and a greater separation between their places of study and residence. 
Table 4.4: Tobit regression, distance between place of study and place of work (D_SW)

\begin{tabular}{|l|r|r|r|r|}
\hline & Coefficient & $S E$ & $t$ & $P>/ t /$ \\
\hline AGE & 0.891 & 0.292 & 3.05 & 0.002 \\
\hline FEMALE & -2.013 & 1.700 & -1.18 & 0.237 \\
\hline PARTNER & -2.970 & 1.761 & -1.69 & 0.092 \\
\hline CHILDREN & -3.916 & 1.762 & -2.22 & 0.026 \\
\hline SALARY & 0.147 & 0.032 & 4.59 & 0.000 \\
\hline FTE & 0.002 & 0.001 & 4.23 & 0.000 \\
\hline POP_S & -0.024 & 0.008 & -3.16 & 0.002 \\
\hline GROWTH_REL_S & -109.125 & 20.959 & -5.21 & 0.000 \\
\hline SALARY_S & -0.384 & 0.127 & -3.03 & 0.002 \\
\hline HIGH_EDUC_S & -51.709 & 19.469 & -2.66 & 0.008 \\
\hline SPEC_S & -6.339 & 0.918 & -6.91 & 0.000 \\
\hline TOP_50_S & -2.166 & 2.147 & -1.01 & 0.313 \\
\hline CAR_S & 9.459 & 0.829 & 11.41 & 0.000 \\
\hline POP_W & -0.019 & 0.005 & -4.06 & 0.000 \\
\hline GROWTH_REL_W & 40.750 & 13.012 & 3.13 & 0.002 \\
\hline SALARY_W & 0.444 & 0.076 & 5.81 & 0.000 \\
\hline HIGH_EDUC_W & -129.927 & 14.526 & -8.94 & 0.000 \\
\hline SPEC_W & 0.672 & 0.118 & 5.70 & 0.000 \\
\hline TOP_50_W & 3.959 & 2.032 & 1.95 & 0.051 \\
\hline CAR_W & -3.247 & 0.658 & -4.93 & 0.000 \\
\hline Dummiesfor field of & & & & \\
\hline study' & & & & \\
\hline
\end{tabular}

Pseudo R ${ }^{2}$ : $\quad 0.0217$

Number of observations: $\quad 5,665$ 
Table 4.5: Tobit regression, distance between place of work and place of residence (D_WR)

\begin{tabular}{|l|r|r|r|r|}
\hline & Coefficient & $S E$ & $t$ & $P>|t|$ \\
\hline AGE & 0.251 & 0.226 & 1.11 & 0.267 \\
\hline FEMALE & -1.381 & 1.325 & -1.04 & 0.297 \\
\hline PARTNER & -0.730 & 1.399 & -0.52 & 0.602 \\
\hline CHILDREN & 0.855 & 1.508 & 0.57 & 0.571 \\
\hline SALARY & 0.051 & 0.025 & 2.05 & 0.041 \\
\hline FTE & -0.000 & 0.000 & -0.46 & 0.645 \\
\hline POP_W & -0.021 & 0.004 & -5.69 & 0.000 \\
\hline GROWTH_REL_W & 16.069 & 10.179 & 1.58 & 0.114 \\
\hline SALARY_W & 0.316 & 0.061 & 5.21 & 0.000 \\
\hline HIGH_EDUC_W & 22.279 & 11.667 & 1.91 & 0.056 \\
\hline SPEC_W & 0.525 & 0.092 & 5.72 & 0.000 \\
\hline TOP_50_W & -1.668 & 1.630 & -1.02 & 0.306 \\
\hline CAR_W & -0.870 & 0.525 & -1.66 & 0.097 \\
\hline POP_R & -0.020 & 0.004 & -4.85 & 0.000 \\
\hline GROWTH_REL_R & -15.879 & 10.436 & -1.52 & 0.128 \\
\hline SALARY_R & -0.098 & 0.059 & -1.67 & 0.096 \\
\hline HIGH_EDUC_R & -18.500 & 11.420 & -1.62 & 0.105 \\
\hline SPEC_R & -3.755 & 0.503 & -7.47 & 0.000 \\
\hline TOP_50_R & -1.738 & 1.703 & -1.02 & 0.307 \\
\hline CAR_R & 1.250 & 0.509 & 2.46 & 0.014 \\
\hline D_SW & 0.641 & 0.016 & 39.61 & 0.000 \\
\hline D_SR & -0.347 & 0.017 & -19.89 & 0.000 \\
\hline Dummies for ffield of & & $Y e s$ & & \\
study' & & & & \\
\hline & & & & \\
\hline & & & & \\
\hline
\end{tabular}

Pseudo R ${ }^{2}$ : $\quad 0.0451$

Number of observations: $\quad 5,665$ 
Table 4.6: Tobit regression, distance between place of study and place of residence (D_SR)

\begin{tabular}{|l|r|r|r|r|}
\hline & Coefficient & $S E$ & $t$ & $P>|t|$ \\
\hline AGE & 0.082 & 0.220 & 0.37 & 0.710 \\
\hline FEMALE & 3.828 & 1.278 & 3.00 & 0.003 \\
\hline PARTNER & 3.351 & 1.360 & 2.46 & 0.014 \\
\hline CHILDREN & 5.232 & 1.439 & 3.64 & 0.000 \\
\hline SALARY & 0.026 & 0.024 & 1.06 & 0.287 \\
\hline FTE & 0.001 & 0.000 & 1.76 & 0.079 \\
\hline POP_S & -0.009 & 0.006 & -1.62 & 0.106 \\
\hline GROWTH_REL_S & 12.643 & 15.736 & 0.80 & 0.422 \\
\hline SALARY_S & -0.241 & 0.094 & -2.55 & 0.011 \\
\hline HIGH_EDUC_S & 48.878 & 14.751 & 3.31 & 0.001 \\
\hline SPEC_S & 0.617 & 0.334 & 1.85 & 0.065 \\
\hline TOP_50_S & -2.598 & 1.620 & -1.60 & 0.109 \\
\hline CAR_S & 0.436 & 0.624 & 0.70 & 0.485 \\
\hline POP_R & -0.016 & 0.004 & -4.07 & 0.000 \\
\hline GROWTH_REL_R & 21.194 & 9.925 & 2.14 & 0.033 \\
\hline SALARY_R & 0.302 & 0.055 & 5.44 & 0.000 \\
\hline HIGH_EDUC_R & -166.000 & 10.748 & -15.44 & 0.000 \\
\hline SPEC_R & -0.101 & 0.239 & -0.42 & 0.672 \\
\hline TOP_50_R & 2.327 & 1.610 & 1.45 & 0.148 \\
\hline CAR_R & -1.419 & 0.474 & -2.99 & 0.003 \\
\hline D_SW & 0.842 & 0.014 & 62.07 & 0.000 \\
\hline D_WR & -0.333 & 0.017 & -20.09 & 0.000 \\
\hline Dummiesfor ffield of & & $Y e s$ & & \\
study' & & & & \\
\hline & & & & \\
\hline & & & & \\
\hline
\end{tabular}

Pseudo R ${ }^{2}$ : $\quad 0.0875$

Number of observations: $\quad 5,665$ 


\subsection{Conclusions}

The results of this study illustrate the challenges graduates face when selecting the locations of their first post-study workplaces and places of residence. Graduates in the Netherlands - a comparatively small country - do not insist on living and working in the same locality, but apparently select their location of residence with the intention that both their place of work and place of study - which they may still feel emotionally attached to - can be easily reached.

Several of the empirical findings merit further attention. We find that recent graduates appear to attach considerable importance to career prospects and choose their location of work correspondingly, thereby accepting residential relocation and/or long daily commutes. Yet, results suggest that they strive to balance their commuting distances and the distances to their previous place of study by locating their place of residence accordingly.

Furthermore, graduates may decide to live and work in different regions for reasons which may be (also) related to the availability of adequate and affordable housing, whereas residential amenities have a comparatively small impact on their locational choices. In addition, they apparently value residential locations which are easily accessible, supposedly as they expect to frequently change jobs in the near future, yet may want to avoid additional residential moves.

The results of this study contribute to explaining the increasing congestion which can be observed for the Netherlands, as individuals apparently do not feel compelled to colocate their workplace and place of residence, but trade-off the desired qualities of their workplace and place of residence with longer commutes and travel distances between relevant locations. These findings may be distinctive for a country with a comparatively small surface area, thus allowing for commutes between the majority of possible home and work locations, and for frequent (return) visits to any place of interest. The provision of better means of public transportation which are able to compete with the automobile in terms of speed and usability may be one measure to be taken. Furthermore, supplying attractive and affordable housing for young professionals located in urban areas respectively centers of economic growth may also be an instrument to be considered. 



\title{
CHAPTER 5
}

THE EFFECTS OF WORKFORCE COMPOSITION, LABOR TURNOVER, AND THE QUALITIES OF ENTERING AND EXITING WORKERS ON PRODUCTIVITY GROWTH

\begin{abstract}
This chapter analyzes the effects of firms' workforce composition, labor turnover, and the qualities of entering and exiting employees on productivity change, using register data provided by Statistics Netherlands. The results illustrate that, although the entry of new employees has a negative effect on labor productivity, firms tend to benefit more from the inflow of employees previously employed with other firms in the same industry, or with highly productive firms. The outflow of workers has a positive effect on productivity, especially if they exit to non-employment. However, the exit of workers to firms in the same industry, and of those who simultaneously relocate tends to have a more negative impact.
\end{abstract}




\subsection{Introduction}

With a growing number of linked employer-employee datasets available, researchers increasingly examine the relationship between employee characteristics and firm outcomes. Firms employing workers with specific characteristics (e.g. longer firm tenure or higher educational attainment) have been found to exhibit higher levels of productivity (e.g. Black \& Lynch, 1996; Blakemore \& Hoffman, 1989; Cörvers 1996; Eriksson \& Lindgren, 2009; Haltiwanger et al., 1999; Haskel et al., 2003; Ilmakunnas et al., 2004), or to experience higher productivity growth in the future (Cörvers, 1996). Furthermore, it has been established that the degree of labor turnover taking place within a firm has an impact on its future performance (e.g. Bingley \& Westergaard-Nielsen, 2004; Boschma et al., 2009; Ilmakunnas et al., 2005).

While many studies investigate how the qualities of a firm's current workforce or the entry and exit rates of employees are related to its productivity, the features of those workers who enter and exit the firm are rarely taken into account. There are two notable exceptions: Regarding employee entry, Boschma et al. (2009) found that the productivity growth of firms is positively influenced by the inflow of employees having skills which are related to the existing knowledge base of their new employer, while the inflow of workers having skills which are similar to those already present in the company has a negative effect. With respect to employee exit, Somaya et al. (2008) established that losing employees to competitors has a negative impact on the performance of firms.

Yet, as pointed out by Ettlie (1980) in his seminal paper on manpower flows and innovation three decades ago, 'manpower flows are likely to have an important direct influence on (...) the knowledge and skills of an organization' (p. 1087). It can thus be argued that especially when looking at changes regarding firms' future performance, the characteristics of those employees who alter the composition of a firm's workforce and add or subtract specific new qualities need to be considered.

This study contributes to the existing work in this field by investigating the effects of workforce composition, labor turnover, and particularly the qualities of entering and exiting workers on firm productivity growth. A matched employer-employee dataset provided by Statistics Netherlands (CBS) is used. It is based on register data, and consists of information 
regarding the characteristics of firms and their employees in the Dutch manufacturing sector between the years 2002 and 2005.

In the empirical analysis, we investigate the determinants of changes in firms' labor productivity. We specify a 'restricted model' which only incorporates information on workforce characteristics and labor turnover, and apply it to the complete dataset including all firms, and to a subsample of firms having experienced employee entries from and exits to other firms. Subsequently, we specify the 'full model', also incorporating the qualities of entering and exiting workers, and apply it to the subsample as well.

The qualities of entering employees are measured through their previous employment status, their age, their tenure with the previous employer, the scope of relocation due to a job change, their previous sectoral affiliation, and the performance of their previous employers. Likewise, the qualities of exiting employees are measured through their subsequent employment status, their age, their tenure with the employer they are exiting, the scope of relocation due to a job change, their subsequent sectoral affiliation, and the performance of their new employers.

The results illustrate that changes in firm productivity are indeed not only determined by the composition of the firm's current workforce and the labor turnover taking place, but also by the characteristics of the workers who enter and exit the firm. More specifically, we find that firms benefit from the inflow of employees who had previously been employed with other firms in the same industry, and with highly productive firms, whereas the entry of employees who had been employed with their previous employer for a long time has a negative effect. The outflow of workers with long tenure, into non-employment, and to highly productive firms is positively related to their old employers' productivity growth, while the exit of workers who leave for firms in the same industry, and of those who simultaneously relocate (over long distances) has a negative impact. These findings demonstrate that the qualities of entering and exiting workers, especially in terms of the characteristics (industrial sector, level of productivity) of their previous respectively future employers, have a considerable impact on the productivity growth of their current employers.

The chapter is organized as follows: Section 5.2 provides an overview regarding the theoretical background of the research. In Section 5.3, we outline the features of the data used in the study, and indicate the sources 
they originate from. Section 5.4 presents the model employed in the empirical analysis, and defines the variables which are used. In Section 5.5, we outline the results, discuss or findings, and indicate possible limitations of the research. Section 5.6 concludes.

\subsection{Theoretical framework}

\subsubsection{Workforce composition and firm productivity}

Many studies have analyzed the relationship between the characteristics of a firm's workforce and its performance. Plant productivity has been found to be higher in firms employing workers with higher educational attainment (Black \& Lynch, 1996; Cörvers, 1996; Eriksson \& Lindgren, 2009; GalindoRueda \& Haskel, 2005; Haltiwanger et al., 1999; Haskel et al., 2003; Ilmakunnas et al., 2004; Jones, 2001), or with longer firm tenure (e.g. Bertschek \& Meyer, 2008; Blakemore \& Hoffman, 1989; Börsch-Supan \& Weiss, 2004; Ilmakunnas et al., 2004). These findings are generally interpreted along the lines of human capital theory, since employees' firm- or job-specific human capital is assumed to increase with firm tenure, and workers with higher levels of specific knowledge and skills are expected to be comparatively more capable of contributing to the performance of their employers. Likewise, highly educated employees are argued to possess higher amounts of general human capital, enabling them to work more efficiently (Cörvers, 1996), and to adapt more easily to technological change and the consequent use of new technologies (Cörvers, 1996; Ilmakunnas et al., 2004), thereby also having a positive impact on their employers' performance.

Regarding the effect of workers' age on firm productivity, the findings are more ambiguous. Eriksson and Lindgren (2009), Haltiwanger et al. (1999) and Van Ours (2009) found that firms employing higher fractions of older workers are less productive, while e.g. Hellerstein et al. (1999) observed that productivity increases with age. Many studies (e.g. Ilmakunnas et al., 2004; Grund \& Westergaard-Nielsen, 2005) established an inverse U-shaped relationship between the average age of a firm's workforce and its productivity. These findings suggest that earlier in their careers, workers 
accumulate valuable job- or task-specific knowledge and skills, but adapt less quickly to new production technologies after having reached a certain age.

The composition of a firm's workforce may not only have an effect on the level, but also on the growth of its productivity over time. As argued by Cörvers (1996), workers with higher levels of education may be more capable of detecting profitable innovations. Thus, firms with better-educated workers have a higher chance to quickly and successfully innovate, and will therefore experience higher productivity growth.

\subsubsection{Labor turnover and firm productivity}

Not only the composition of a firm's workforce, but also its dynamics can be expected to have an effect on a firm's subsequent performance. Ilmakunnas et al. (2005), for example, found that the employee inflow rate positively affects firm productivity growth. This is argued to be consistent with human capital theory, as firms are assumed to hire workers who possess specific valuable skills and attributes they gained with their previous employers. Boschma et al. (2009), conversely, observed that labor inflows negatively affect the productivity growth of plants, and Bingley and WestergaardNielsen (2004) likewise established a negative relationship between a firm's fraction of newly hired employees and its profitability. These findings are argued to reflect the costs associated with hiring new employees (e.g. training).

Regarding the effect of separations on firm performance, Ilmakunnas et al. (2005) found that firm productivity growth is negatively affected by the employee outflow rate, assuming that this effect reflects layoffs and quits of high-productivity workers. Bingley and Westergaard-Nielsen (2004), on the other hand, identified a positive relationship between a firm's employee outflow rate and its profitability. They argued that exits are mostly involuntary, as employers may predominantly lay off the least productive or the most overpaid workers. 


\subsubsection{The qualities of entering and exiting employees and firm productivity}

Both the characteristics of a firm's current workforce, and the extent of employee turnover taking place have been analyzed with respect to their effect on the level or growth of firms' productivity. To this point, however, much less attention has been paid to the relationship between the characteristics of those employees who enter or leave, and the consequent changes in the performance of the firm which experiences these entries and exits.

Notable exceptions are Boschma et al. (2009), analyzing the effect of the relatedness between an employee's previous and current employer on consequent changes regarding the productivity of the latter, and Somaya et al. (2008), investigating the impact of employee in- and outflows to and from competitors and potential clients on firm performance. Regarding the entry of new workers, Boschma et al. (2009) found that the inflow of employees having skills which are related to the existing knowledge base of their new employer positively affects productivity growth, while the inflow of workers having skills which are similar to those already present in the company has a negative effect. It could thus be demonstrated that the qualities of newly hired employees, especially seen in relation to the characteristics of their previous employer, affect the performance of their new employer. With respect to the outflow of employees, Somaya et al. (2008) discovered that losing employees to competitors has a negative impact on a firm's performance. This illustrates that the qualities of exiting employees, particularly when seen in relation to the characteristics of their new employer, have an impact on the performance of their old employer.

These findings suggest that when analyzing changes regarding the performance of a firm, not only the characteristics of its current workforce and the extent of employee turnover taking place have to be taken into account. Additionally, it is crucial to examine the qualities of those employees entering or exiting the firm, particularly in relation to the characteristics of their previous respectively future employers. In this study, we therefore investigate the effects of workforce composition, labor turnover, and the qualities of entering and exiting workers on firm productivity growth. 
More specifically, we argue that the share of entries from nonemployment, the average age and firm tenure (with the old employer) of entering employees, the average distance between entering employees' places of residence before and after changing jobs, the share of entries from firms in the same sector (5-digit level), and the average performance of entering employees' previous employers may relate to their new employers' productivity growth. Likewise, the share of exits into non-employment, the average age and firm tenure of exiting employees, the average distance between exiting employees' places of residence before and after changing jobs, the share of exits to firms in the same sector (5-digit level), and the average performance of exiting employees' new employers may relate to their old employers' productivity growth.

Workers who were non-employed (including students) before entering a firm may have stronger adjustment problems to the demands of their new job. Furthermore, as argued by Bingley and Westergaard-Nielsen (2004), employers may predominantly lay off their least productive employees. Hence, workers who have been unemployed before entering a new firm might not be the most industrious employees, and therefore hamper the productivity growth of their new employer.

It is generally assumed that employees' knowledge and skills increase with experience, and productivity has consequently been found to be higher in firms which employ workers with longer firm tenure (e.g. Bertschek \& Meyer, 2008; Blakemore \& Hoffman, 1989; Börsch-Supan \& Weiss, 2004; Ilmakunnas et al., 2004). Besides firm-specific skills, workers will also accumulate job-, task- or industry-specific knowledge over time, and can consequently put these skills to use with other employers. We therefore hypothesize that particularly workers who had been working with another employer for a long time possess valuable expertise, and will be able to facilitate the productivity growth of their new employers.

Especially ambitious (highly-educated, well-paid) individuals who aim to advance their careers appear to be willing to simultaneously change employers and relocate (Kronenberg \& Carree, 2012), since 'individuals with high human capital move to productive locations (...) in order to take advantage of their skills' (Chen \& Rosenthal, 2008, p. 520). We thus assume that employees who relocate will foster the productivity growth of their new 
employer, and this effect will be particularly strong in the case of longdistance migration.

As previously argued, the qualities of employees entering a firm should be seen in relation to the characteristics of their previous employers. It has been demonstrated that firms benefit from gaining employees from competitors (Somaya et al., 2008). At the same time, the outflow of workers to competitors has been found to be detrimental to the performance of their old employers (Campbell et al., 2012). These findings can be interpreted along the lines of human capital theory, since employees who have previously been working with a competitor in the same industry are likely to possess useful industry- or task-specific knowledge. We therefore expect that the inflow of employees from direct competitors in the same industry will positively affect the productivity growth of their new employers.

Furthermore, it is likely that employees who had previously been employed with well-performing firms contributed to the performance of their old employers by putting their knowledge and skills to use. We thus hypothesize that employees who have previously been working for wellperforming firms will be able to also enhance the productivity of their new employers.

It has been established that employers tend to lay off those workers who are least productive (Bingley \& Westergaard-Nielsen, 2004), and it might be comparatively difficult for these individuals to find a new job after having become non-employed. We therefore expect that firms will benefit from the exit of employees into non-employment.

Productivity has been found to increase with firm tenure (e.g. Bertschek \& Meyer, 2008; Blakemore \& Hoffman, 1989; Börsch-Supan \& Weiss, 2004; Ilmakunnas et al., 2004), as employees build up knowledge, skills and experience. Yet, as previously argued, workers not only accumulate firmspecific skills, but also job-, task- or industry-specific knowledge which they may also use with other employers. We thus hypothesize that particularly workers who had been employed with a firm for a long time possess valuable expertise, and will hamper the productivity growth of their old employer when leaving.

Ambitious employees may be willing to simultaneously change employers and relocate (Kronenberg \& Carree, 2012) in order to advance their careers. We therefore expect that the exit of employees who also 
relocate will hamper the productivity growth of their old employers, and this effect will be particularly strong in the case of long-distance migration.

It has been demonstrated that firms suffer from losing employees to competitors (Somaya et al., 2008; Campbell et al., 2012), as these individuals are likely to possess useful industry- or task-specific knowledge which they can also put to use with their new employers. We thus assume that the outflow of employees to direct competitors in the same industry will negatively affect the productivity growth of their old employers.

It can be expected that employees who leave for a firm which consequently performs well have also been able to contribute to the performance of their old employers. We therefore hypothesize that employees who exit in order to work for well-performing firms will hamper the productivity growth of their old employers.

\subsection{Data}

\subsubsection{Data sources}

The data employed in this study were provided by Statistics Netherlands (CBS), allowing for the creation of an employer-employee matched dataset which consists of information regarding a firm's characteristics as well as the composition and the dynamics of its workforce.

Firm data (industrial sector, age, size, financial outcomes) are available on the level of the firm. The data originate from the business register (ABR), the Survey on Employment and Wages (EWL), the Survey Production Statistics (SBS and STS), and data provided by the Dutch Tax Administration.

Information regarding employees stems from the Social Statistical Database (SSB), and is compiled on the basis of register data from two main sources. Personal information (e.g. date of birth, gender, address) within the SSB originates from the municipal registration system (GBA), while data regarding employees' jobs (e.g. employer, duration of employment) is provided by the Dutch Tax Administration.

As the location of employees' place of residence is known for each year at a specific reference date (last Friday in September) on the level of the municipality, the distance between the location of an employee's place of 
residence in 2002 and 2003 is used as a measure of the distance covered in case of a residential relocation.

\subsubsection{Data description}

In order to analyze the effects of workforce composition, labor turnover, and the qualities of entering and exiting employees on changes in firm productivity, we selected firms which were active with employees between January 2002 and December 2005, and for which information regarding the firm's financial performance (sales per year) was available for the years 2002 until 2005. The analysis was restricted to fulltime employees (at least 0.8 FTE), and therefore excluded firms which only employed parttime workers in any of the years between 2002 and 2005.

The study focuses on the manufacturing sector (NACE ${ }^{42}$ 15-37). Many studies dealing with the relationship between employee characteristics and firm outcomes concentrate on the manufacturing industry (see e.g. Cörvers, 1996; Hellerstein et al., 1999; Ilmakunnas et al., 2004), so the results of this study can be compared to the findings presented in these papers ${ }^{43}$.

While information regarding employees' duration of employment is available with exact start and end dates, individuals' personal characteristics (e.g. place of residence) are determined once a year at a specific reference date (last Friday in September). Since only at those points in time, reliable information regarding all variables of interest is available, 'employee snapshots' were taken at the reference dates in the two consecutive years 2002 and 2003.

The dataset thus consists of information regarding a firm's workforce composition in 2002, its entry and exit rates between the reference dates in 2002 and 2003, the qualities of those employees who entered or left the firm between those reference dates, and changes in its labor productivity (natural logarithm of sales per employee) between the years 2003 and 2005.

\footnotetext{
42 Nomenclature statistique des activités économiques dans la Communauté européenne

43 Findings for other sectors (Construction; Retail and wholesale; Hotels and restaurants; Transport, storage and communication; Real estate, renting and business activities) are available from the authors upon request.
} 
Especially with respect to larger firms with more than one establishment, determining changes in labor productivity (sales per employee) can be difficult, since both the firm's employees and its sales may be allocated to different establishments in consecutive years. We therefore decided to only incorporate firms in the analysis which did not exhibit disproportionate variation regarding the size of their workforce between 2002 and 2005. The selection thus only includes those companies for which the the average number of employees in the years 2002, 2003, 2004 and 2005 respectively divided by the overall average number of employees for those four years was higher than 0.5 and lower than 2 .

Furthermore, in order to exclude e.g. holdings with a high yearly sales volume and a comparatively low number of employees from the analysis, we discarded all firms for which sales per employee were higher than $€$ $5,000,000$ in any year between 2002 and 2005. Likewise, firms for which sales per employee were lower than $€ 5,000$ in any year between 2002 and 2005 were also excluded ${ }^{44}$.

With all these restrictions imposed, the dataset consists of 15,794 firms for which information on workforce composition, labor turnover and changes in labor productivity is available. Yet, since only 3,672 of these firms had entries from and exits to other firms, information on the qualities of employees entering from and leaving for other firms were only available for this subsample of firms.

\subsection{Methodology}

\subsubsection{Model}

We employ a least squares regression model, assuming that changes in a firm's level of productivity depend on the composition of its current workforce, the share of entries and exits, and the qualities of workers entering and exiting the firm. The model is weighted by the square root of

\footnotetext{
${ }^{44}$ It has been validated that stricter or more lenient restrictions (e.g. including only firms for which sales per employee amounted to a value between 10,000 and 1,000,000) in this regard would not have a relevant impact on the results of the analysis. Not imposing any suchlike restrictions, though, generated results which were hard to interpret.
} 
the size of the firm (average number of employees) in 2002 in order to diminish the otherwise comparatively large impact of small firms (see e.g. Boschma et al., 2009) often having few entries and exits.

Let $Q_{i t}$ be total output and $L_{i t}$ be total labor force (in FTE) for firm $i$ in year $t$, then our measure of labor productivity is $y_{i t}=\ln \left(Q_{i t} / L_{i t}\right)$. Let also $W_{i t}$ be the set of incumbent employees, $E_{i t}$ the set of entering employees, and $X_{i t}$ the set of exiting employees. Hence, $L_{i t}=\#\left(W_{i t}\right)$ where \#(.) is the number of persons in a set. The rate of entry and exit are calculated as $e_{i t}=\#\left(E_{i t}\right) / L_{i t}$ and $x_{i t}=\#\left(X_{i t}\right) / L_{i t}$.

We assume a partial adjustment process of the labor productivity towards the industry average $\alpha_{S}$ where $S$ is the industry that firm $i$ is in, as follows:

$$
\Delta y_{i t}=\lambda\left(\alpha_{S}-y_{i, t-1}\right)
$$

The period under consideration is assumed to be relatively short, so that the industry can be assumed constant over time. The parameter $\lambda$ is expected to be positive and reflects the speed of adjustment. The index $j$ denotes employees, and $c_{j, t-1}$ describes their relevant 'characteristics' (e.g. experience). An error term $\varepsilon_{i t}$ is added, and the model is extended by including relevant characteristics of the incumbent workforce:

$$
\Delta y_{i t}=\lambda \alpha_{S}-\lambda y_{i, t-1}+\beta \sum_{j \in W_{i, t-1}} c_{j, t-1} / L_{i, t-1}+\varepsilon_{i t}
$$

The model can be further extended by taking the dynamics of the workforce into account. The effects of the entry and exit rates are added as follows:

$$
\Delta y_{i t}=\lambda \alpha_{S}-\lambda y_{i, t-1}+\beta \sum_{j \in W_{i, t-1}} c_{j, t-1} / L_{i, t-1}+\gamma e_{i, t-1}+\delta x_{i, t-1}+\varepsilon_{i t}
$$

Model (3) is estimated, also incorporating control variables, using the full and restricted samples. The final extension can be found in model (4), where the relevant characteristics of the entering and exiting employees are also taken into consideration: 


$$
\begin{aligned}
& \Delta y_{i t}=\lambda \alpha_{S}-\lambda y_{i, t-1}+\beta \sum_{j \in W_{i, t-1}} c_{j, t-1} / L_{i, t-1}+\gamma e_{i, t-1}+\delta X_{i, t-1} \\
& +\varsigma \sum_{j \in E_{i, t-1}} c_{j, t-1} / \#\left(E_{i, t-1}\right)+\eta \sum_{j \in X_{i, t-1}} c_{j, t-1} / \#\left(X_{i, t-1}\right)+\varepsilon_{i t}
\end{aligned}
$$

Model (4) is estimated, including the same control variables, using the restricted sample consisting of those firms which experienced entries from and exits to other firms.

\subsubsection{Variables}

Table 5.1 presents the variables employed in the analysis. The dependent variable measures changes in the labor productivity of firms, measured as the natural logarithm of sales per employee in 2005 minus the natural logarithm of sales per employee in 2003, multiplied with 100 for reasons of presentation (D_LOGSPE).

AGE is the average age of a firm's workforce in 2002, and FIRM_TENURE denotes the average tenure of a firm's employees with their current employer. In order to check for non-linear effects, we also incorporate AGE_SQ (squared) and FIRM_TENURE_SQ (squared) in the analysis. As information on educational attainment is not available for all employees, we use employees' salaries in 2002 as a proxy for their level of human capital. SALARY denotes the average daily salary a firm's employees receive. ENTRY is the rate of employee entry between the reference dates in 2002 and 2003, and EXIT is the rate of exit.

ENTRY_NO_JOB is the share of a firm's new employees entering the firm from non-employment in the previous year, and ENTRY FIRM_TENURE denotes the average time a firm's new employees had been employed with the previous employer. ENTRY_DISTANCE indicates the average distance (in $10 \mathrm{~km}$ ) between the places of residence in 2002 and 2003 among those employees entering the firm between the reference dates in 2002 and 2003, ENTRY_SAME_SBI is the share of a firm's new employees coming from a firm in the same sector (5-digit level), and ENTRY_LOGSPE_OLDFIRM denotes the average labor productivity - 
proxied by the natural logarithm of sales per employee - of a firm's new employees' previous employers in 2002.

Table 5.1: Definitions of variables used in the analysis

\begin{tabular}{|c|c|}
\hline Variable & Definition \\
\hline D_LOGSPE & $\begin{array}{l}\text { Change in productivity (natural log of sales per } \\
\text { employee in } 2005 \text { minus natural log of sales per } \\
\text { employee in 2003, multiplied with 100) }\end{array}$ \\
\hline AGE & $\begin{array}{l}\text { Average age of the firm's workforce in } 2002 \text { (in } \\
\text { decades) }\end{array}$ \\
\hline AGE_SQ & $\left(\right.$ Average age of the firm's workforce in 2002) ${ }^{2}$ \\
\hline FIRM_TENURE & $\begin{array}{l}\text { Average firm tenure of the firm's workforce in } 2002 \\
\text { (in decades) }\end{array}$ \\
\hline FIRM_TENURE_SQ & (Average age of the firm's workforce in 2002) ${ }^{2}$ \\
\hline SALARY & Average daily salary (in $100 €$ ) \\
\hline ENTRY & Rate of employee entry between 2002 and 2003 \\
\hline EXIT & Rate of employee exit between 2002 and 2003 \\
\hline ENTRY_NO_JOB & Share of entries from non-employment \\
\hline ENTRY_AGE & Average age of entering employees (in decades) \\
\hline ENTRY_FIRM_TENURE & $\begin{array}{l}\text { Average firm tenure (with previous employer) of } \\
\text { entering employees (in decades) }\end{array}$ \\
\hline ENTRY_DISTANCE & $\begin{array}{l}\text { Average distance between entering employees' places } \\
\text { of residence in } 2002 \text { and } 2003 \text { (in } 10 \mathrm{~km} \text { ) }\end{array}$ \\
\hline ENTRY_SAME_SBI & Share of entries from same sector (5-digit level) \\
\hline ENTRY_LOGSPE_OLDFIRM & $\begin{array}{l}\text { Average performance (natural log of sales per } \\
\text { employee) of new employees' old employers in } 2002\end{array}$ \\
\hline EXIT_NO_JOB & Share of exits into non-employment \\
\hline EXIT_AGE & Average age of exiting employees (in decades) \\
\hline EXIT_FIRM_TENURE & Average firm tenure of exiting employees (in decades) \\
\hline EXIT_DISTANCE & $\begin{array}{l}\text { Average distance between exiting employees' places of } \\
\text { residence in } 2002 \text { and } 2003 \text { (in } 10 \mathrm{~km} \text { ) }\end{array}$ \\
\hline EXIT_SAME_SBI & Share of exits to same sector (5-digit level) \\
\hline EXIT_LOGSPE_NEWFIRM & $\begin{array}{l}\text { Average performance (natural log of sales per } \\
\text { employee) of exiting employees' new employers in } \\
2003\end{array}$ \\
\hline FIRM_AGE & Age of the firm in 2002 (in years) \\
\hline FIRM_SIZE & Size of the firm in 2002 (in 1000 employees) \\
\hline LOGSPE_LAGGED & $\begin{array}{l}\text { Firm productivity (natural log of sales per employee) } \\
\text { in } 2002\end{array}$ \\
\hline
\end{tabular}


EXIT_NO_JOB is the share of a firm's exiting employees who were nonemployed in the following year, and EXIT_FIRM_TENURE denotes the average time a firm's exiting employees had been employed with the firm. EXIT_DISTANCE indicates the average distance (in $10 \mathrm{~km}$ ) between the places of residence in 2002 and 2003 among the employees exiting the firm between the reference dates in 2002 and 2003, EXIT_SAME_SBI is the share of a firm's exiting employees leaving for a firm in the same sector (5-digit level), and EXIT_LOGSPE_NEWFIRM denotes the average labor productivity - proxied by the natural logarithm of sales per employee - of a firm's exiting employees' new employers in 2003.

Since older firms have been found to be less productive than younger organizations (e.g. Addison and Belfield 2004), we include the age of a firm as a control variable. FIRM_AGE indicates the age of the company in 2002. As the size of a firm can also be expected to have an influence on its subsequent growth (e.g. Griliches 1986), FIRM_SIZE denotes the number of a firm's employees in 2002. In the full model, the average age of those employees entering a firm between the reference dates in 2002 and 2003 (ENTRY_AGE) as well as the average age of those employees exiting a firm between these reference dates (EXIT_AGE) are also added as controls. Furthermore, sector dummies (2-digit level) are included, distinguishing the 23 manufacturing industries (NACE 15-37). Furthermore, as demonstrated by Haltiwanger et al. (1999), a firm's previous level of productivity negatively impacts future productivity growth. In the model, the impact is measured through the parameter $\lambda$. A firm's level of productivity in 2002 is thus also included, and is denoted by the natural logarithm of sales per employee in 2002 (LOGSPE_LAGGED).

The descriptive statistics for the explanatory and control variables used in the study are displayed in Table 5.2 and 5.3. Table 5.2 refers to the complete dataset, and Table 5.3 refers to the subsample of firms with entries from and exits to other firms.

On average, a firm's workforce was 37.8 years old in 2002, and its employees had been employed with their current employer for 5.6 years. On average, a firm paid its employees an average daily salary of $€ 76$. Firms had an average employee entry rate of $14 \%$ between the reference dates in 2002 and 2003, and an employee exit rate of $15 \%$. On average, these firms had 40 
employees, and their average labor productivity (natural logarithm of sales per employee) amounted to 11.61 .

Table 5.2: Descriptives (all firms)

\begin{tabular}{lrrrr}
\hline & Minimum & Maximum & \multicolumn{1}{c}{ Mean } & \multicolumn{1}{c}{$S D$} \\
\hline D_LOGSPE & -463.28 & 372.46 & 5.44 & 45.571 \\
& & & & \\
AGE & 1.50 & 7.30 & 3.78 & 0.732 \\
AGE_SQ & 2.25 & 53.29 & 14.86 & 5.671 \\
FIRM_TENURE & 0.00 & 3.30 & 0.56 & 0.367 \\
FIRM_TENURE_SQ & 0.00 & 10.89 & 0.45 & 0.623 \\
SALARY & 0.09 & 5.79 & 0.76 & 0.234 \\
ENTRY & 0.00 & 1.00 & 0.14 & 0.186 \\
EXIT & 0.00 & 1.00 & 0.15 & 0.185 \\
FIRM_AGE & 0.00 & 35.00 & 19.27 & 12.108 \\
FIRM_SIZE & 0.00 & 34.07 & 0.04 & 0.312 \\
LOGSPE_LAGGED & 8.56 & 15.36 & 11.61 & 0.756 \\
\hline
\end{tabular}

Number of observations: 15,794

With respect to firms having entries from and exits to other firms, the average age of a firm's workforce was 37.8 years, and its employees had been employed with their current employer for 6.3 years. On average, a firm paid its employees an average daily salary of $€ 82$. Firms had an average employee entry rate of 19\% between the reference dates in 2002 and 2003, and an employee exit rate of $20 \%$. On average, these firms had 130 employees, and their average labor productivity (natural logarithm of sales per employee) amounted to 11.78 .

For those firms with entries from and exits to other firms, a firm's average share of employees entering from non-employment was $34 \%{ }^{45}$. On average, a firm had incoming employees who were 32.5 years old, had been employed with their previous employer for 3.0 years, and had moved 2.8 kilometers during the year in which they changed jobs. Some $12 \%$ of a firm's

45 This number may appear quite high at first glance. It should be noted that 'nonemployment' includes those employees who were previously unemployed, had not yet finished education, or changed from a parttime to a fulltime job. 
new employees came from a firm in the same industry (5-digit level). On average, a firm had incoming employees who had previously been employed with employers for which the log of sales per employee in 2002 amounted to 11.62 .

Table 5.3: Descriptives (firms with entries from and exits to other firms)

\begin{tabular}{|c|c|c|c|c|}
\hline & Minimum & Maximum & Mean & $S D$ \\
\hline D_LOGSPE & -352.59 & 372.46 & 9.22 & 38.477 \\
\hline AGE & 1.70 & 5.29 & 3.78 & 0.478 \\
\hline AGE_SQ & 2.89 & 27.97 & 14.52 & 3.492 \\
\hline FIRM_TENURE & 0.00 & 2.44 & 0.63 & 0.379 \\
\hline FIRM_TENURE_SQ & 0.00 & 5.93 & 0.54 & 0.667 \\
\hline SALARY & 0.20 & 2.00 & 0.82 & 0.182 \\
\hline ENTRY & 0.01 & 1.00 & 0.19 & 0.170 \\
\hline EXIT & 0.01 & 1.00 & 0.20 & 0.162 \\
\hline ENTRY_NO_JOB & 0.00 & 0.98 & 0.34 & 0.249 \\
\hline ENTRY_AGE & 1.50 & 7.10 & 3.25 & 0.690 \\
\hline ENTRY_FIRM_TENURE & 0.00 & 3.70 & 0.30 & 0.328 \\
\hline ENTRY_DISTANCE & 0.00 & 20.36 & 0.28 & 0.956 \\
\hline ENTRY_SAME_SBI & 0.00 & 1.00 & 0.12 & 0.263 \\
\hline ENTRY_LOGSPE_OLDFIRM & 8.60 & 15.29 & 11.62 & 0.833 \\
\hline EXIT_NO_JOB & 0.00 & 0.97 & 0.48 & 0.269 \\
\hline EXIT_AGE & 1.50 & 6.90 & 3.27 & 0.703 \\
\hline EXIT_FIRM_TENURE & 0.00 & 3.20 & 0.32 & 0.324 \\
\hline EXIT_DISTANCE & 0.00 & 23.61 & 0.38 & 1.390 \\
\hline EXIT_SAME_SBI & 0.00 & 1.00 & 0.10 & 0.241 \\
\hline EXIT_LOGSPE_NEWFIRM & 8.52 & 14.89 & 11.72 & 0.893 \\
\hline FIRM_AGE & 0.00 & 35.00 & 20.66 & 12.324 \\
\hline FIRM_SIZE & 0.00 & 34.07 & 0.13 & 0.638 \\
\hline LOGSPE_LAGGED & 8.61 & 14.86 & 11.78 & 0.781 \\
\hline
\end{tabular}

Number of observations: 3,672 
A firm's average share of employees exiting into non-employment was $48 \%{ }^{46}$. On average, a firm had exiting employees who were 32.7 years old, had been employed with their employer for 3.2 years, and moved 3.8 kilometers during the year in which they changed jobs. Some $10 \%$ of a firm's exiting employees switched to a firm in the same industry (5-digit level). On average, a firm had exiting employees who changed to employers for which the log of sales per employee in 2003 amounted to 11.72 .

\subsection{Results and discussion}

The results of the empirical analysis (Tables 5.4 to 5.6) illustrate that changes in firm productivity are indeed determined by the composition of the firm's current workforce, the degree of labor turnover taking place, and the characteristics of the employees who enter and exit the firm.

\subsubsection{The impact of workforce composition and firm characteristics on productivity growth}

The characteristics of a firm's workforce have an impact on its productivity growth over the next years. AGE has a positive effect on consequent productivity growth, while the effect of AGE_SQUARED is generally negative. This suggests that firms employing a prime age workforce will experience future increases in productivity, whereas firms which employ workers which are either younger, or older benefit less from their choice of employees. These findings indicate that prime age workers may indeed have the knowledge, experience, and the capacity to cope with pressure, all of which are necessary in order to increase their employers' performance.

We also find that firms employing workers with longer firm tenure generally experience higher productivity growth, indicating that employees' firm- or job-specific human capital indeed increases with firm tenure, and

\footnotetext{
${ }^{46}$ Likewise, this number appears to be fairly high. This may be explained by the fact that employees who became unemployed, retired, or changed from a fullltime to a parttime job were included.
} 
workers with more experience and higher levels of specific knowledge and skills will be capable of contributing to the future growth of their employers' productivity. Furthermore, the positive impact of firm tenure on productivity growth is not linear, but appears to increase over time, suggesting that firms with a stable workforce will benefit from their employees' capabilities.

Firms paying higher average salaries also experience higher productivity growth. These findings illustrate that firms employing workers with a higher skill level not only exhibit higher productivity levels, but also higher productivity growth.

Older firms tend to experience lesser amounts of subsequent productivity growth, whereas the size of a firm does not have a notable effect. As predicted by Haltiwanger et al. (1999), firms with higher present levels of productivity will grow less in upcoming years. As $\lambda$ is found to be around 0.05 , a slow adjustment process towards the industry average is implied.

\subsubsection{The impact of labor turnover on productivity growth}

The rate of employee entry has a negative impact on productivity growth, indicating that the hiring of new employees indeed entails considerable adjustment costs (Boschma et al., 2009; Bingley \& Westergaard-Nielsen, 2004), and therefore negatively affects firm performance.

Productivity growth is positively affected by the rate of employee exit. This suggests that employers may indeed predominantly lay off the least productive or the most overpaid workers (Bingley \& Westergaard-Nielsen, 2004) in order to increase their future productivity.

\subsubsection{The impact of the qualities of entering and exiting employees on productivity growth}

As expected, the share of employees exiting into non-employment has a positive impact on firms' productivity growth. This might indicate that these employees have indeed been laid off due to unsatisfactory performance, and consequently experienced difficulties in finding a new employer, whereas 
their old employers benefited from their exit. However, this outcome could also concern employees who retire.

The results show that the average firm tenure (with their previous employer) of entering employees negatively affects their new employers' productivity growth. These finding suggests that workers who had been working with another employer for a long time do not possess exceptional amounts of valuable expertise which they can transfer to and use with their new employers. Instead, it seems to be the case that these employees have become less capable of adjusting to and working efficiently in a new environment, and might therefore hamper the productivity growth of their new employers. The average firm tenure of exiting employees, on the other hand, has a positive effect on the productivity growth of their old employers. This might indicate that employees who had been working with the same employer for a long time have become less motivated and productive over time, hence their employers ultimately benefit from their exit. Interestingly, the average age of entering employees has a positive effect on productivity growth, while this effect is negative for exiting workers. It might thus be the case that valuable and transferable experience is rather captured by variables concerning employees' age, while the measure 'firm tenure' appears to capture detrimental effects related to inflexibility and inertia.

As hypothesized, we found the average distance between exiting employees' places of residence before and after changing jobs to have a negative impact on the productivity growth of their old employers. This suggests that highly productive individuals who are able to substantially contribute to their employers' performance aim to advance their careers by selecting the job which enables them to make the most of their skills, even if this entails relocating (e.g. Chen \& Rosenthal, 2008; Kronenberg \& Carree, 2012). Thus, firms which are not capable of retaining ambitious workers who are willing to change jobs and relocate in order to advance their careers will consequently suffer from losing these employees. Yet, the average distance between entering employees' places of residence before and after changing jobs also has a negative impact on the performance of their new employers. This might indicate that the hiring of these employees does not instantaneously lead to beneficial outcomes, but new workers who underwent major changes regarding both their private and professional 
surroundings may require a considerable amount of time in order to adjust to the new enviroment before they are able to perform as desired.

As expected, it could be demonstrated that higher shares of inflows from firms in the same sector (5-digit level) have a positive effect on productivity growth. This finding is in line with Somaya et al. (2008), who demonstrated that firms profit from acquiring employees from competitors. It can thus be assumed that employees who have previously been working with a firm in the same industry are likely to possess valuable industry- or task-specific knowledge, and their inflow will therefore positively affect the productivity growth of their new employers. Likewise, results show that the share of employee outflows to firms in the same industry (5-digit level) negatively affects productivity growth, indicating that losing employees to competitors indeed has a negative impact on a firm's performance (Somaya et al. 2008; Campbell et al., 2012). This suggests that these employees are likely to possess useful industry- or task-specific knowledge which they can put to use in their new positions, whereas their old employers have to deal with the loss of these workers' experience and skills.

We also established that productivity growth is indeed positively affected by the average performance of entering employees' previous employers. This result indicates that qualified employees who had been able to contribute to the performance of their old employers will also enhance the productivity of the firms they newly enter. The average performance of exiting employees' new firms was also found to have a positive impact on productivity growth. This may appear surprising at first sight, since it had been hypothesized that the exit of valuable employees who are sought after by other employers would mean that their capabilities leave with them, thus hampering the functioning of their old employers. Yet, it may be the case that the capable employees of well-performing firms may advance their careers by changing employers, while their old employers - having a good reputation - will easily be able to find other talented workers to replace those (see e.g. Haltiwanger et al., 2007, and Mendes et al., 2010, who found that productive workers and firms generally team up).

The model which also incorporates the qualities of entering and exiting workers exhibits higher adjusted $\mathrm{R}^{2}$-values than the model which only includes workforce characteristics and labor turnover (0.048 compared to 0.041), indicating the relevance of the additional predictors. 
Table 5.4: Ordinary least squares regression for change in firm productivity (D_LOGSPE), restricted model, all firms

\begin{tabular}{lrrrr}
\hline & Coefficient & \multicolumn{1}{l}{ SE } & \multicolumn{1}{c}{ S } & \multicolumn{1}{l}{ Sig. } \\
\hline Constant & 15.876 & 4.634 & 3.426 & 0.001 \\
AGE & 20.985 & 2.137 & 9.819 & 0.000 \\
AGE_SQ & -3.078 & 0.273 & -11.266 & 0.000 \\
FIRM_TENURE & 3.680 & 1.355 & 2.717 & 0.007 \\
FIRM_TENURE_SQ & 1.742 & 0.670 & 2.598 & 0.009 \\
SALARY & 7.864 & 1.021 & 7.706 & 0.000 \\
FIRM_AGE & -0.030 & 0.014 & -2.081 & 0.037 \\
FIRM_SIZE & 0.520 & 0.100 & 5.229 & 0.000 \\
LOGSPE_LAGGED & -4.516 & 0.228 & -19.815 & 0.000 \\
ENTRY & -4.866 & 1.232 & -3.949 & 0.000 \\
EXIT & 7.364 & 1.209 & 6.092 & 0.000 \\
Industry Dummies & & \multicolumn{2}{c}{ Yes } & \\
\hline
\end{tabular}

$\mathrm{R}^{2}$ :

0.024

Adjusted $\mathrm{R}^{2}$ :

0.024

Number of observations: $\quad 15,794$ 
Table 5.5: Ordinary least squares regression for change in firm productivity (D_LOGSPE), restricted model, firms with entries from and exits to other firms

\begin{tabular}{lrrrr}
\hline & Coefficient & \multicolumn{1}{l}{ SE } & \multicolumn{1}{c}{ Sig. } \\
\hline Constant & -7.725 & 12.737 & -0.607 & 0.544 \\
AGE & 36.665 & 6.644 & 5.519 & 0.000 \\
AGE_SQ & -5.316 & 0.875 & -6.072 & 0.000 \\
FIRM_TENURE & 1.049 & 2.014 & 0.521 & 0.602 \\
FIRM_TENURE_SQ & 2.005 & 0.948 & 2.114 & 0.035 \\
SALARY & 18.692 & 1.689 & 11.067 & 0.000 \\
FIRM_AGE & -0.031 & 0.018 & -1.702 & 0.089 \\
FIRM_SIZE & 0.167 & 0.106 & 1.575 & 0.115 \\
LOGSPE_LAGGED & -5.080 & 0.317 & -16.007 & 0.000 \\
ENTRY & -16.838 & 2.239 & -7.519 & 0.000 \\
EXIT & 7.125 & 2.251 & 3.166 & 0.002 \\
Industry Dummies & & Yes & & \\
\hline
\end{tabular}

$\begin{array}{ll}\mathrm{R}^{2}: & 0.041 \\ \text { Adjusted R2: } & 0.041 \\ \text { Number of observations: } & 3,672\end{array}$


Table 5.6: Ordinary least squares regression for change in firm productivity (D_LOGSPE), full model, firms with entries from and exits to other firms

\begin{tabular}{|c|c|c|c|c|}
\hline & Coefficient & $S E$ & $t$ & Sig. \\
\hline Constant & -41.851 & 13.203 & -3.170 & 0.002 \\
\hline AGE & 36.426 & 6.661 & 5.469 & 0.000 \\
\hline AGE_SQ & -5.355 & 0.876 & -6.114 & 0.000 \\
\hline FIRM_TENURE & -0.720 & 2.041 & -0.353 & 0.724 \\
\hline FIRM_TENURE_SQ & 2.077 & 0.949 & 2.189 & 0.029 \\
\hline SALARY & 18.115 & 1.725 & 10.502 & 0.000 \\
\hline FIRM_AGE & -0.030 & 0.018 & -1.679 & 0.093 \\
\hline FIRM_SIZE & 0.123 & 0.106 & 1.154 & 0.248 \\
\hline LOGSPE_LAGGED & -5.599 & 0.328 & -17.048 & 0.000 \\
\hline ENTRY & -16.435 & 2.276 & -7.221 & 0.000 \\
\hline EXIT & 7.452 & 2.273 & 3.279 & 0.001 \\
\hline ENTRY_NO_JOB & -0.419 & 0.930 & -0.451 & 0.652 \\
\hline ENTRY_AGE & 2.261 & 0.390 & 5.803 & 0.000 \\
\hline ENTRY_FIRM_TENURE & -2.944 & 0.756 & -3.896 & 0.000 \\
\hline ENTRY_DISTANCE & -0.570 & 0.237 & -2.403 & 0.016 \\
\hline ENTRY_SAME_SBI & 5.830 & 1.000 & 5.832 & 0.000 \\
\hline ENTRY_LOGSPE_OLDFIRM & 2.462 & 0.269 & 9.138 & 0.000 \\
\hline EXIT_NO_JOB & 6.261 & 0.965 & 6.489 & 0.000 \\
\hline EXIT_AGE & -1.459 & 0.398 & -3.667 & 0.000 \\
\hline EXIT_FIRM_TENURE & 3.287 & 0.759 & 4.329 & 0.000 \\
\hline EXIT_DISTANCE & -0.622 & 0.165 & -3.756 & 0.000 \\
\hline EXIT_SAME_SBI & -4.582 & 1.031 & -4.444 & 0.000 \\
\hline EXIT_LOGSPE_NEWFIRM & 0.693 & 0.257 & 2.694 & 0.007 \\
\hline Industry Dummies & \multicolumn{4}{|c|}{ Yes } \\
\hline
\end{tabular}

$\mathrm{R}^{2}$ : 0.049

Adjusted R ${ }^{2}$ : $\quad 0.048$

Number of observations: $\quad 3,672$ 


\subsubsection{Limitations}

This study is, however, not without limitations. First of all, regarding the information available on employees, an analysis of the effects of labor turnover and employee characteristics on changes in firm productivity would certainly have benefited from differentiating between voluntary and involuntary interfirm mobility. Furthermore, it would have been worthwhile to differentiate between occupations of workers. Unfortunately, the data available neither provide information regarding the reasons underlying the job mobility of employees, nor regarding their occupations.

Regarding firm-level information, our analysis would have gained from the inclusion of variables covering e.g. firms' R\&D efforts, importing/exporting intensity, or the amount of FDI taking place, since these attributes have been found to have an effect on (changes in) firm productivity (e.g. Belderbos et al., 2004; Griliches, 1986; Keller \& Yeaple, 2009; Fryges \& Wagner, 2010; Vogel \& Wagner, 2010). Yet, with the available data, originating from register information, including such variables was unfortunately not possible.

\subsection{Conclusions}

Although researchers increasingly examine the relationship between employee characteristics and firm outcomes, studies dealing with the relationship between the characteristics of those workers who enter or exit the firm, and consequent changes in firm productivity are still remarkably scarce. This study therefore contributes to the existing body of literature by investigating the effects of workforce composition, labor turnover, and particularly the qualities of entering and exiting workers on firm productivity growth.

The results illustrate that changes in firm productivity are not only determined by the composition of the firm's current workforce and the degree of labor turnover taking place, but also by the characteristics of the workers who enter and exit the firm. Firms benefit from the inflow of employees who had previously been employed with other firms in the same industry, and with highly productive firms, whereas the entry of employees 
who had been employed with their previous employer for a long time has a negative effect. The outflow of workers with long tenure, into nonemployment, and to highly productive firms positively affects their old employers' productivity growth, while the exit of workers who leave for firms in the same industry, and of those who simultaneously relocate (over long distances) has a negative impact. These findings demonstrate that the qualities of entering and exiting workers, especially seen in relation to the features of their previous respectively future employers, have a considerable impact on their current employers' subsequent productivity growth.

Following Boschma et al. (2009), this study demonstrates that 'the effects of labor mobility on firm performance can only be accounted for after differentiating between different types of labor inflows' (p. 186), as well as the respective outflows. Our findings highlight that the productivity of firms is influenced by the qualities of its workers, by the selection of valuable new employees, and the attrition of those who have not been able to contribute to the growth of the firm. 


\section{CHAPTER 6}

\section{CONCLUSION}

\subsection{Concluding remarks}

'Finding the right location is essential to successful life, but it is essential also to a successful enterprise, [and] to the establishment of a lasting settlement' (Lösch, 1954, p. 3).

As both the wants and needs of an individual or firm, and the characteristics of a locality may change over time, even a location which had once been optimal may gradually have become less advantageous. Graduates finish their studies, now looking for employment and their first non-student residence, employees aim to advance their careers by changing employers, yet take into consideration the residential wishes of their families, and firms recognize changes in the economic landscape which will render a different location more profitable.

This dissertation aims to elucidate the locational choices and spatial mobility of individuals and firms, to identify possible interconnections between these two entities, and to analyze the advances which originate from these dynamics. For this purpose, four empirical investigations were realized. In Chapter 2, the determinants motivating the job and residential mobility of employees in different industrial sectors are investigated. Chapter 3 analyzes the reasons underlying firm relocation, and identifies regional characteristics which attract relocating firms. Chapter 4 assesses the determinants of graduates' college-to-work, college-to-residence and commuting distances, and the relationships between these three locations of interest, thereby illustrating the manner in which individuals trade off locational benefits and the costs associated with the distances between relevant localities. The focus of Chapter 5 lies on analyzing the effects of firms' workforce composition, labor turnover, and the qualities of entering and exiting workers on subsequent productivity growth. The remainder of this chapter summarizes the main findings of the four empirical studies, 
indicates limitations of the work, and presents some suggestions for further research.

\subsection{Summary of main findings}

\subsubsection{Chapter 2}

In Chapter 2, the determinants underlying the job and residential mobility of employees in different sectors are investigated. The results of the empirical analysis illustrate that across all sectors, individuals assess the advantages and disadvantages of changing one's job and/or place of residence by taking into account the strength of their family- and job-related ties, their attachment to the present residence, and their current commute.

Furthermore, the presence of internal career opportunities generally impedes job changes, while interfirm mobility is promoted by the existence of external options. However, for employees in Law \& Order, job mobility becomes more likely with increasing firm size. A possible explanation might be that for employees in this sector, a 'larger firm' equals a larger institution respectively an institution located in a densely populated area as employer, which may be perceived as an unpleasant work environment.

The effect of employees' presumed chances of alternative employment on consequent interfirm mobility is also evidently sector-dependent. While external options generally have the expected positive impact on job mobility, the mobility decisions of workers in Building and in Finance are not affected by the availability of external options. These findings suggest that employees in these sectors do not change employers in order to advance their careers, but may move forward internally.

Findings regarding the effect of salary on job mobility were mixed. A negative impact of salary on interfirm mobility was established for employees in Building and in Finance, whereas we found this effect to be positive and significant for employees in Law \& Order and Healthcare. The positive effect of salary on the propensity to change jobs suggests that for well-paid, presumably ambitious employees in the latter sectors, changing employers is the usual way to advance one's career. 
As hypothesized, we found that employees earning comparatively high salaries are generally more likely to migrate, indicating the precondition of having the necessary financial means in order to realize a residential move. Interestingly, the effect does not hold for employees in Finance, Law \& Order, and Healthcare, the latter two being (primarily) public service sectors. These results suggest that for employees working in the public service sector, the impact of one's salary on the likelihood of relocation is smaller than for employees in the private sector. It was further established that a high salary generally encourages joint job and residential mobility, suggesting that skilled, ambitious individuals already in advantageous positions decide to switch employers in order to further advance their careers.

The main insight of this investigation is that the determinants of employees' interfirm and/or residential mobility are evidently sectordependent. We established differences between employees in the public and the private sectors, mainly with regard to residential mobility. Internal and external job opportunities also appear to play different roles across different sectors of the economy.

\subsubsection{Chapter 3}

Chapter 3 analyzes determinants of firm relocation, and identifies regional characteristics which attract relocating firms. Results indicate that the relocation decisions of firms are sector-dependent, and the migratory behavior of firms in knowledge-intensive respectively high-tech sectors notably differs from that in less knowledge-intensive respectively low-tech sectors.

The results of this investigation indicate that a firm's decision to relocate is rather determined by firm-specific factors than by the characteristics of the region the firm is located in. Predominantly low-tech respectively less knowledge-intensive firms paying high average salaries have an increased propensity to relocate, whereas this effect cannot be observed for high-tech manufacturing respectively knowledge-intensive service firms. This suggests that firms depending less on a specifically qualified (and correspondingly expensive) workforce may relocate in order to save labor costs, while in the high-tech respectively knowledge-intensive sectors, salaries reflect the 
qualities and capacities of a firm's employees whom it supposedly wants to retain.

The expected negative effect of population density on the likelihood to relocate is confirmed for firms in the knowledge-intensive market service sector, whereas the proposed positive effect is found for (comparatively large) medium-low-tech manufacturing firms. These findings illustrate the differences in the valuation of densely populated regions between firms in manufacturing and services. Being located in an area which appeals to individuals induces knowledge-intensive high-tech service firms to stay in their present location, possibly since (labor-intensive) service firms situated in attractive localities may be capable of paying lower wages. These firms might also be able to 'afford' being located in appealing regions due to the fact that they have to spend comparatively less than firms in other sectors on rents or machinery. Furthermore, for less knowledge-intensive service firms depending on local demand, the general average wage level in the municipality firm is located in negatively affects the firm's propensity to relocate, whereas the average wage level in the firm's sector has a positive effect. These findings suggest that general demand conditions keep these firms within a region, while they are pushed out by high labor costs.

Regional characteristics do, on the other hand, profoundly affect the choice of where to move, as relocating firms are 'pulled' into densely populated municipalities with high wage levels and, in the case of services and low-tech manufacturing, into municipalities which are specialized in the firm's own sector and appeal to individuals. Results for the effect of sectorspecific wages on the inmigration of firms are mixed, suggesting that possibly contingent on sectoral specificities - local wage levels may be perceived as indicators of both labor costs and labor quality.

\subsubsection{Chapter 4}

This chapter identifies and analyzes the determinants of graduates' collegeto-work, college-to-residence and commuting distances, and the relationships between these three locations of interest. By this means, it illustrates the trade-offs individuals have to make between locational benefits and the costs associated with the distances between relevant localities. 
The results of this study illustrate the challenges graduates face when selecting the locations of their first post-study workplaces and places of residence. Recent graduates appear to attach considerable importance to career prospects and choose their location of work correspondingly, thereby accepting residential relocation and/or long daily commutes. Yet, results suggest that graduates in the Netherlands - being a comparatively small country - apparently do not insist on living and working in the same locality, but select their location of residence with the intention that both their place of work and place of study - which they may still feel attached to - can be easily reached.

Furthermore, graduates may decide to live and work in different regions for reasons which may be (also) related to the availability of adequate housing, whereas residential amenities have a comparatively small impact on their locational choices. In addition, these young professionals apparently value residential locations which are easily accessible, supposedly as they expect to frequently change jobs in the near future, yet may want to avoid additional residential moves.

\subsubsection{Chapter 5}

The focus of Chapter 5 lies on analyzing the effects of firms' workforce composition, labor turnover, and particularly the qualities of entering and exiting workers on subsequent productivity growth. Results suggest that firms employing a prime age workforce will experience future increases in productivity, whereas firms which employ predominantly younger or older workers benefit less from their choice of employees. These findings indicate that prime age workers may be able to contribute to their employers' performance due to their knowledge and experience, as well as their capacity to cope with pressure.

Firms were found to benefit from the inflow of older employees, and of those who had previously been employed with other firms in the same industry, and with highly productive firms. These findings suggest that these workers possess valuable and transferable task- or industry-specific knowledge and experience which they can put to use with their new employer. The entry of employees who had been employed with their 
previous employer for a long time, however, has a negative effect, suggesting that workers who had been working with another employer for a long time do not automatically possess exceptional amounts of valuable expertise which they can transfer to and use with their new employers. Instead, it seems to be the case that these employees have become less capable of adjusting to and working efficiently in a new environment, and might therefore hamper the productivity growth of their new employers.

Correspondingly, the outflow of workers with long tenure positively affects their old employers' productivity growth, implying that employees who had been working with the same employer for a long time might have become less motivated and productive over time, so that their employers ultimately benefit from their exit. Firms also benefit from the exit of workers to highly productive firms, and into non-employment, as those may have been laid off due to unsatisfactory performance, and consequently experienced difficulties in finding new employers. The exit of workers who leave for firms in the same industry, and of those who simultaneously relocate (over long distances) has a negative impact, indicating that losing employees to competitors indeed has negative consequences, and illustrating that highly productive individuals who are able to substantially contribute to their employers' performance may be those who advance their careers by selecting the job which enables them to make the most of their skills, even if this entails relocating.

The results of this investigation illustrate that changes in firm productivity are not only determined by the composition of the firm's current workforce and the degree of labor turnover taking place. Additionally, the qualities of entering and exiting workers, especially seen in relation to the features of their previous respectively future employers, also have a considerable impact on their current employers' subsequent productivity growth.

\subsection{Limitations and future outlook}

Register data such as the information employed in this dissertation are complete in scope, as they cover virtually all employees, households and employers in the Netherlands, yet naturally lack depth. Certainly, the 
analyses presented in this dissertation would have benefited from more detailed information on individuals and firms such as the data obtained in surveys on labor force characteristics or the innovativeness of firms.

It should be acknowledged that the available data do not provide information regarding the reasons underlying employees' job changes, hence it was not possible to differentiate between voluntary and involuntary job changes, possibly biasing the results. Furthermore, the available data also lack any details regarding employees' occupations, the inclusion of which would have substantially enriched the empirical analyses.

Regarding chapters 3 and 4, it should also be noted that only single-site firms respectively employees working at firms with only location could be included in the different analyses, as the exact location of a firm with multiple establishments, as well as the work locations of its employees could not be determined. Sadly, this led to the exclusion of predominantly large companies, thus possibly biasing the data, as only the spatial behavior of smaller, single-site firms respectively their employees could be analyzed.

It became apparent that the information on individuals' yearly salaries was not reliable for those who changed jobs within that year, since bonus payments (e.g. compensation of unused hours of leave, 'golden handshake') might incorrectly suggest that job changers received higher salaries in their previous positions than it was actually the case. Hence, a positive bias regarding the effect of a person's salary on the propensity to change employers may have resulted due to reverse causality, an issue which had to be solved by using alternative information on employees' remuneration in chapter 2 .

With respect to chapter 5, the analysis would certainly have gained from the inclusion of variables covering e.g. firms' $R \& D$ efforts, importing/exporting intensity, or the amount of FDI taking place, since these attributes have been found to have an effect on (changes in) firm productivity. Yet, with the available data, the inclusion of such variables was unfortunately not possible.

Despite these limitations, I like to believe that the work presented in this dissertation contributes to our understanding of the spatial behavior of individuals and firms. In the future, it may be fruitful to link register data to surveys such as the Community Innovation Survey (CIS) on the innovativeness of firms in different sectors and regions, the Survey on 
Employment and Wages (EWL), or the Labor Force Survey (EBB), which also covers issues such as commuting distance. By this means, it will be possible to answer questions regarding the locational choices of employees and employers by taking into account register-based information regarding the entirety of workers respective organizations, as well as data obtained by the means of a survey, thus providing detailed information on specific matters of interest. I consider the realization of suchlike investigations to be a fruitful endeavor, as they will allow for an even deeper look into the spatial dynamics of individuals and firms. 


\section{References}

Acemoglu, D., \& Pischke, J.-S. (1999). The structure of wages and investment in general training. Journal of Political Economy, 107(3), 539-572.

Adamson, D. W., Clark, D. E., \& Partridge, M. D. (2004). Do urban agglomeration effects and household amenities have a skill bias? Journal of Regional Science, 44(2), 201-223.

Addison, J. T., \& Belfield, C. R. (2007). Unions, training and firm performance: evidence from the British workplace relations survey. Journal for Labour Market Research, 40(4), 361-381.

Arauzo-Carod, J. M. (2005). Determinants of industrial location: an application for Catalan municipalities. Papers in Regional Science, 84(1), 105-120.

Arauzo-Carod, J. M. (2009). Location determinants of high-tech manufacturing activities: a preliminary analysis. Letters in Spatial and Resource Sciences, 2(1), 23-29.

Arauzo-Carod, J. M., \& Viladecans-Marsal, E. (2009). Industrial location at the intrametropolitan level: the role of agglomeration economies. Regional Studies, 43(4), 545-558.

Bailey, A. J., \& Cooke, T. J. (1998). Family migration and employment: the importance of migration history and gender. International Regional Science Review, 21(2), 99-118.

Bartel, A. P. (1979). The migration decision: what role does job mobility play? American Economic Review, 69(5), 775-786.

Bartik, T. J. (1985). Business location decisions in the U.S.: estimates of the effects of unionization, taxes, and other characteristics of states. Journal of Business and Economic Statistics 3(1), 14-22.

Becker, G. S. (1962). Investment in human capital: a theoretical analysis. Journal of Political Economy, 70(5), 9-49.

Becker, G. S. (1981). Altruism in the family and selfishness in the market place. Economica, 48(189), 1-15.

Belderbos, R., Carree, M. A., \& Lokshin, B. (2004). Cooperative R\&D and firm performance. Research Policy, 33(10), 1477-1492.

Bergin, A. (2009). Job mobility in Ireland. The Economic and Social Review, 4O(1), 15-47. 
Berry, C. R., \& Glaeser, E. L. (2005). The divergence of human capital level across cities. Papers in Regional Science, 84(3), 407-444.

Bertschek, I., \& Meyer, J. (2009). Do older workers lower IT-enabled productivity? Firmlevel evidence from Germany. Jahrbücher für Nationalökonomie und Statistik, 29(2-3), 327-342.

Bingley, P., \& Westergaard-Nielsen, N. (2004). Personnel policy and profit. Journal of Business Research, 57(5), 557-563.

Black, S. E., \& Lynch, L. M. (1996). Human-capital investments and productivity. AEA Papers and Proceedings, 86(2), 263-267.

Blakemore, A. E., \& Hoffman, D. L. (1989). Seniority rules and productivity: an empirical test. Economica, 56(223), 359-371.

Böheim, R., \& Taylor, M. P. (2007). From the dark end of the street to the bright side of the road? The wage returns to migration in Britain. Labour Economics, 14(1), 99-117.

Borghans, L., \& Heijke, H. (2005). The production and use of human capital: introduction. Education Economics, 13(2), 133-142.

Börsch-Supan, A. (1990). Education and its double-edged impact on mobility. Economics of Education Review, 9(1), 39-53.

Börsch-Supan, A., \& Weiss, M. M. (2008). Productivity and the age composition of work teams: evidence from the assembly line. MEA Discussion Paper 148-07.

Boschma, R., Eriksson, R., \& Lindgren, U. (2009). How does labour mobility affect the performance of plants? The importance of relatedness and geographical proximity. Journal of Economic Geography, 9(2), 169-190.

Boswell, C. (2008). Combining economics and sociology and migration theory. Journal of Ethnic and Migration Studies, 34(4), 549-566.

Brouwer, A. E., Mariotti, I., \& Van Ommeren, J. N. (2004). The firm relocation decision: an empirical investigation. Annals of Regional Science, 38(2), 335-347.

Burdett, K. (1978). A theory of employee job search and quit rates. American Economic Review, 68(1), 212-220. 
Campbell, B., Ganco, M., Franco, A., \& Agarwal, R. (2012). Who leaves, where to, and why worry? Employee mobility, entrepreneurship and effects on source firm performance. Strategic Management Journal, 33(1), 65-87.

Camstra, R. (1996). Commuting and gender in a lifestyle perspective. Urban Studies, 33(2), 283-300.

Capasso, M., Cefis, E., \& Frenken, K. (2010). Spatial differentiation in industrial dynamics. Utrecht School of Economics, Discussion Paper 10-21.

Carree, M. A., Verheul, I., \& Santarelli, E. (2011). Sectoral patterns of firm exit in Italian provinces. Journal of Evolutionary Economics, 21(3), 499-517.

Chen, Y., \& Rosenthal, S. S. (2008). Local amenities and life-cycle migration: do people move for jobs or fun? Journal of Urban Economics, 64(3), 519-537.

Clark, D. E., \& Cosgrove, J. C. (1991). Amenities versus labor market opportunities: choosing the optimal distance to move. Journal of Regional Science, 31(3), 311-328.

Clark, D. E., \& Hunter, W. J. (1992). The impact of economic opportunity, amenities and fiscal factors on age-specific migration rates. Journal of Regional Science, 32(3), 349-365.

Clark, W. A. V. \& Burt, J. E. (1980). The impact of workplace on residential relocation. Annals of the Association of American Geographers, 70(1), 59-67.

Clark, W. A. V., \& Davies Withers, S. (2007). Family migration and mobility sequences in the United States: spatial mobility in the context of the life course. Demographic Research, 17(2), 591-622.

Clark, W. A. V., Deurloo, M. C., \& Dieleman, F. M. (1984). Housing consumption and residential mobility. Annals of the Association of American Geographers, 74(1), 29-43.

Clark, W. A. V., \& Huang, Y. (2004). Linking migration and mobility: individual and contextual effects of housing markets in the UK, Regional Studies, 38(6), 617-628.

Clark, W. A. V., Huang, Y., \& Withers, S. (2003). Does commuting distance matter? Commuting tolerance and residential change. Regional Science and Urban Economics, 33(2), 199-221.

Cooke, T. W. (1983). Testing a model of intraurban firm relocation. Journal of Urban Economics, 13(3), 257-282. 
Cörvers, F. (1997). The impact of human capital on labour productivity in manufacturing sectors of the European Union. Applied Economics, 29(8), 975-987.

Costa, D. L., \& Kahn, M. E. (2000). Power couples: changes in the locational choice of the college educated: 1940-1990. Quarterly Journal of Economics, 115(4), 1287-1315.

Crane, R. (2007). Is there a quiet revolution in women's travel? Revisiting the gender gap in commuting. Journal of the American Planning Association, 73(3), 298-316.

Davies, P. S., Greenwood, M. J., \& Li, H. (2001). A conditional logit approach to U.S. state-to-state migration. Journal of Regional Science, 41(2), 337-360.

Deurloo, M. C., Clark, W. A. V., \& Dieleman, F. M. (1990). Choice of residential environment in the Randstad. Urban Studies, 27(3), 335-351.

Dieleman, F. M. (2001). Modelling residential mobility; a review of recent trends in research. Journal of Housing and the Built Environment, 16(3-4), 249-265.

Dieleman, F. M., Clark, W. A. V., \& Deurloo, M. C. (2000). The geography of residential turnover in twenty-seven large US metropolitan housing markets, 1985-95. Urban Studies, 37(2), 223-245.

Duranton, G., \& Puga, D. (2001). Nursery cities: urban diversity, process innovation and the life cycle of products. American Economic Review, 91(5), 1454-1477.

Eliasson, K., Lindgren, U., \& Westerlund, O. (2003). Geographical labour mobility: migration or commuting? Regional Studies, 37(8), 827-837.

Elsevier (June 24, 2010). Elsevier-onderzoek: Naarden beste gemeente 2010. Retrieved from http:/www.elsevier.nl/web/Nieuws/Nederland/268954/Elsevieronderzoek-Naardenbeste-gemeente-2010.htm on August 18, 2010.

Elsevier (June 24, 2010). Top-50 Beste Gemeenten. Retrieved from www.elsevier.nl on August 18, 2010.

Erickson, R. A., \& Wasylenko, M. (1980). Firm relocation and site selection in suburban municipalities. Journal of Urban Economics, 8(1), 69-85.

Eriksson, R., \& Lindgren, U. (2008). Localized mobility clusters: impacts of labour market externalities on firm performance. Journal of Economic Geography, 9(1), 33-53. 
Ettlie, J.E. (1980). Manpower flows and the innovation process. Management Science, 26(11), 1086-1095.

EUROSTAT (2005). Statistics in Focus 4/2005. Luxembourg: EUROSTAT.

Faggian, A., McCann, P., \& Sheppard, S. (2007). Some evidence that women are more mobile than men: gender differences in U.K. graduate migration behavior. Journal of Regional Science, 47(3), 517-539.

Feijten, P., \& Van Ham, M. (2007). Residential mobility and migration of the divorced and separated. Demographic Research, 17(21), 623-654.

Figueiredo, O., Guimarães, P., \& Woodward, D. (2002). Home-field advantage: location decisions of Portuguese entrepreneurs. Journal of Urban Economics, 52(2), 341-361.

Finney, M. M., \& Kohlhase, J. E. (2008). The effect of urbanization on labor turnover. Journal of Regional Science, 28(2), 311-328.

Frenken, K., Van Oort, F., \& Verburg, T. (2007). Related variety, unrelated variety and regional economic growth. Regional Studies, 41(5), 685-697.

Fryges, H., \& Wagner, J. (2010). Exports and productivity growth: First evidence from a continuous treatment approach. Review of World Economics, 144(4), 695-722.

Galindo-Rueda, F., \& Haskel, J. E. (2005). Skills, workforce characteristics and firm-level productivity in England. Report prepared for the Department of Trade and Industry, Department for Education and Skills, Office for National Statistics, 1-44.

Glaeser, E. L., Kallal, H. D., Scheinkman, J. A., \& Shleifer, A. (1992). Growth in cities. Journal of Political Economy, 100(6), 1126-1152.

Gottlieb, P. D. (1995). Residential amenities, firm location and economic development. Urban Studies, 32(9), 1413-1436.

Gottlieb, P. D., \& Joseph G. (2006). College-to-work migration of technology graduates and holders of doctorates within the United States. Journal of Regional Science, 46(4), 627-659.

Graves, P. E. (1983). Migration with a composite amenity: the role of rents. Journal of Regional Science, 23(4), 541-546. 
Greenwood, M. J., \& Hunt, G. L. (1989). Jobs versus amenities in the analysis of metropolitan migration. Journal of Urban Economics, 25(1), 1-16.

Griliches, Z. (1986). Productivity, R\&D, and basic research at the firm level in the 1970's. American Economic Review, 76(1), 141-154.

Grund, C., \& Westergaard-Nielsen, N. (2008). Age structure of the workforce and firm performance. International Journal of Manpower, 29(5-6), 410-422.

Haltiwanger, J. C., Lane, J. I., \& Spletzer, J. R. (1999). Productivity differences across employers: the roles of employer size, age, and human capital. AEA Papers and Proceedings, 89(2), 94-98.

Haltiwanger, J. C., Lane, J. I., \& Spletzer, J. R. (2007). Wages, productivity, and the dynamic interaction of businesses and workers. Labour Economics, 14(3), 575-602.

Hansen, S. B., Ban, C., \& Huggins, L. (2003). Explaining the 'brain drain' from older industrial cities: the Pittsburgh region. Economic Development Quarterly, 17(2), 132-147.

Haskel, J. E., Hawkes, D., \& Pereira, S. (2003). Skills and productivity in the UK using matched establishment, worker and workforce data. CeRiBA Discussion Paper.

Helderman, A. C., Mulder, C. H., \& Van Ham, M. (2004). The changing effect of home ownership on residential mobility in the Netherlands, 1980-98. Housing Studies, 1944), 601-616.

Helderman, A. C., Van Ham, M., \& Mulder, C. H. (2006). Migration and home ownership. Tijdschrift voor Economische en Sociale Geografie, 97(2), 111-125.

Hellerstein, J. K., Neumark, D., \& Troske, K. R. (1999). Wages, productivity, and worker characteristics: evidence from plant-level production functions and wage equations. Journal of Labor Economics, 17(3), 409-446.

Henneberger, F., \& Sousa-Poza, A. (2002). Beweggründe und Determinanten zwischenbetrieblicher Mobilität: Die Schweiz in einer internationalen Perspektive, MittAB, 2/2002, 205-231.

Hensen, M. M., De Vries, M. R., \& Cörvers, F. (2008). The role of geographic mobility in reducing education-job mismatches in the Netherlands. Papers in Regional Science, $88(3)$, 667-682. 
Herzog, H. W., \& Schlottmann, A. M. (1986). What can be learned from the recent migrants? Growth and Change, 17(1), 37-50.

Holl, A. (2004a). Start-ups and relocations: manufacturing plant location in Portugal. Papers in Regional Science, 83(4), 649-668.

Holl, A. (2004b). Manufacturing location and impacts of road transport infrastructure: empirical evidence from Spain. Regional Science and Urban Economics, 34(3), 341-363.

Ilmakunnas, P., Maliranta, M., \& Vainiomäki, J. (2004). The roles of employer and employee characteristics for plant productivity. Journal of Productivity Analysis, 21(3), 249-276.

Ilmakunnas, P., Maliranta, M., \& Vainiomäki, J. (2005). Worker turnover and productivity growth. Applied Economics Letters, 12(7), 395-398.

Jones, P. (2001). Are educated workers really more productive? Journal of Development Economics, 64(1), 57-79.

Juster, F. T., \& Stafford, F. P. (1991). The allocation of time: empirical findings, behavioral models, and problems of measurement. Journal of Economic Literature, 29(2), 471-522.

Kain, J. F. (1962). The journey-to-work as a determinant of residential location. Papers and Proceedings of the Regional Science Association, 9(1), 137-160.

Kalleberg, A. L., \& Mastekaasa, A. (1998). Organizational size, layoffs, and quits in Norway. Social Forces, 76(4), 1243-1273.

Kalleberg, A. L., \& Van Buren, M. E. (1996). Is bigger better? Explaining the relationship between organization size and job rewards. American Sociological Review, 61(1), 47-66.

Kan, K. (2003). Residential mobility and job changes under uncertainty. Journal of Urban Economics, 54(3), 566-586.

Keller, W., \& Yeaple, S. R. (2009). Multinational enterprises, international trade, and productivity growth: firm level evidence from the United States. Review of Economics and Statistics, 91(4), 821-831.

Kim, T.-K., Horner, M. W., \& Marans, R. W. (2005). Life cycle and environmental factors in selecting residential and job locations. Housing Studies, 20(3), 457-473. 
Kim, J. H., Pagliara, F., \& Preston, J. (2005). The intention to move and residential location choice behaviour. Urban Studies, 42(9), 1621-1636.

King, G., \& Zeng, L. (2001a). Explaining rare events in international relations. International Organization, 55(3), 693-715.

King, G., \& Zeng, L. (2001b). Logistic regression in rare events data. Political Analysis, $9(2), 137-163$.

Knapp, T. A., White, N. E., \& Clark, D. E. (2001). A nested logit approach to household mobility. Journal of Regional Science, 41(1), 1-22.

Knoben, J., \& Oerlemans, L. A. G. (2008). Ties that spatially bind? A relational account of the causes of spatial firm mobility. Regional Studies, 42(3), 385-400.

Knoben, J., \& Weterings, A. (2010). Employment dynamics on business estates. European Planning Studies, 18(7), 1077-1095.

Kodrzycki, Y. K. (2001). Migration of recent college graduates: evidence from the National Longitudinal Survey of Youth. New England Economic Review, January/February, 13-34.

Kohler, H. P. (1997). The effect of hedonic migration decisions and region-specific amenities on industrial location: could Silicon Valley be in South Dakota? Journal of Regional Science, 37(3), 379-394.

Kronenberg, K., \& Carree, M. (2012). On the move: determinants of job and residential mobility in different sectors. Forthcoming in Urban Studies.

Kwan, M.-P. (1999). Gender, the home-work link, and space-time patterns of nonemployment activities. Economic Geography, 75(4), 370-394.

Linneman, P., \& Graves, P. E. (1983). Migration and job change: a multinomial logit approach. Journal of Urban Economics, 14(3), 263-279.

List, J. A. (2001). U.S. county-level determinants of inbound FDI: evidence from a twostep modified count data model. International Journal of Industrial Organization, 1966), 953-973.

Love, L. L., \& Crompton, J. L. (1999). The role of quality of life in business (re)location decisions. Journal of Business Research, 44(3), 211-222. 
Lösch, A. (1954). The economics of location (2 ${ }^{\text {nd }}$ edition). New Haven, USA: Yale University Press \& London, England: Oxford University Press.

Manaugh, K., Miranda-Moreno, L. F., \& El-Geneidy, A. M. (2010). The effect of neighbourhood characteristics, accessibility, home-work location, and demographics on commuting distances. Transportation, 37(4), 627-646.

Mendes, R., Van den Berg, G. J., \& Lindeboom, M. (2010). An empirical assessment of assortative matching in the labor market. Labour Economics, 17(6), 919-929.

Mincer, J. (1978). Family migration decisions. Journal of Political Economy, 86(5), 749773.

Molho, I. (1984). A dynamic model of interregional migration flows in Great Britain. Journal of Regional Science, 24(3), 317-334.

Molho, I. (1987). The migration decisions of young men in Great Britain. Applied Economics, 19(2), 221-243.

Mulalic, I., Van Ommeren, J. N., \& Pilegaard. N. (2010). Wages and commuting: quasinatural experiments' evidence from firms that relocate. Tinbergen Institute Discussion Paper, TI 2010-093/3.

Nakosteen, R. A., \& Zimmer. M. A. (1982). The effects on earnings of interregional and interindustry migration. Journal of Regional Science, 22(3), 325-341.

Nivalainen, S. (2004). Determinants of family migration: short moves vs. long moves. Journal of Population Economics, 17(1), 157-175.

Ng, T. W. H., Sorensen, K. L., Eby, L. T., \& Feldman, D. C. (2007). Determinants of job mobility: a theoretical integration and extension. Journal of Occupational and Organizational Psychology, 80(3), 363-386.

OECD (2009). Science, Technology and Industry Scoreboard 2009. Paris: OECD.

Pekkala, S. (2003). Migration flows in Finland: regional differences in migration determinants and migrant types. International Regional Science Review, 26(4), 466-4482.

Pellenbarg, P. H. (2002). Sustainable Business Sites in the Netherlands: A Survey of Policies and Experiences. Journal of Environmental Planning and Management, 45(1), 5984. 
Pellenbarg, P. H., \& Kemper, N. J. (1999). Industrial mobility in the Netherlands. University of Groningen, SOM Research Report 99d34.

Pellenbarg, P. H., \& Van Steen, P. J. M. (2003). Spatial perspectives on firm dynamics in The Netherlands. Tijdschrift voor Economische en Sociale Geografie, 94(5), 620-630.

Pellenbarg, P. H. (2005). Firm migration in the Netherlands. Contributed paper, $45^{\text {th }}$ ERSA congress, August 2005, Amsterdam.

Plaut, P. O. (2006). The intra-household choices regarding commuting and housing. Transportation Research Part A, 40(7), 561-571.

Rappaport, J. (2007). Moving to nice weather. Regional Science and Urban Economics, 37(3), 375-391.

Rebitzer, J. B. (1986). Establishment size and job tenure. Industrial Relations, 25(3), 292302.

Ritsilä, J., \& Ovaskainen, M. (2001). Migration and regional centralization of human capital. Applied Economics, 33(3), 317-325.

Rosenfeld, R. A. (1992). Job mobility and career processes. Annual Review of Sociology, 18(1992), 39-61.

Rosenthal, S. S., \& Strange, W. C. (2003). Geography, industrial organization, and agglomeration. Review of Economics and Statistics, 85(2), 377-393.

Rouwendal, J., \& Meijer, E. (2001). Preferences for housing, jobs and commuting: a mixed logit analysis. Journal of Regional Science, 41(3), 475-505.

Rouwendal, J., \& Nijkamp, P. (2004). Living in two worlds: a review of home-to-work decisions. Growth and Change, 35(3), 287-303.

Sandell, S. H. (1977). Women and the economics of family migration. Review of Economics and Statistics, 59(4), 406-414.

Sang, S., O’Kelly, M. E., \& Kwan, M.-P. (2011). Examining commuting patterns: results from a journey-to-work model disaggregated by gender and occupation. Urban Studies, 48(5), 891-909.

Schmenner, R. W. (1993). Service firm location decisions: some Midwestern evidence. International Journal of Service Industry Management, 5(3), 35-56. 
Schneider, L. (2007). Zu alt für einen Wechsel? Zum Zusammenhang von Alter, Lohndifferentialen und betrieblicher Mobilität. IWH-Diskussionspapiere 1/2007.

Schwanen, T., Dijst, M., \& Dieleman, F. M. (2004). A microlevel analysis of residential context and travel time. Environment and Planning A, 34(8), 1487-1507.

Schwanen, T., Dieleman, F. M., \& Dijst, M. (2004). The impact of metropolitan structure on commute behavior in the Netherlands: a multilevel approach. Growth and Change, 35(3), 304-333.

Shuttleworth, I., \& Gould, M. (2010). Distance between home and work: a multilevel analysis of individual workers, neighbourhoods, and employment sites in Northern Ireland. Environment and Planning A, 42(5), 1221-1238.

Sjaastad, L. (1962). The costs and returns of human migration. Journal of Political Economy, 70(5), part 2, 80-93.

So, K. S., Orazem, P. F., \& Otto, D. M. (2001). The effects of housing prices, wages, and commuting time on joint residential and job location choices. American Journal of Agricultural Economics, 83(4), 1036-1048.

Somaya, D., Williamson. I. O., \& Lorinkova, N. (2008). Gone but not lost: the different performance impacts of employee mobility between cooperators versus competitors. Academy of Management Journal, 51(5), 936-953.

Stolzenberg, R. M. (1978). Bringing the boss back in: employer size, employee schooling, and socioeconomic achievement. American Sociological Review, 43(6), 813-828.

Strauss-Kahn, V., \& Vives, X. (2009). Why and where do headquarters move? Regional Science and Urban Economics, 39(2), 168-186.

Susilo, Y. O., \& Maat, K. (2007). The influence of built environment to the trends in commuting journeys in the Netherlands. Transportation, 34(5), 589-609.

Van der Vlist, A. J., Gorter, C., Nijkamp, P., \& Rietveld, P. (2002). Residential mobility and local housing-market differences. Environment and Planning A, 34(7), 1147-1164.

Van Dijk, J., \& Pellenbarg, P. H. (2000). Firm relocation decisions in the Netherlands: an ordered logit approach. Papers in Regional Science, 79(2), 191-219. 
Van Ham, M., Mulder, C. H., \& Hooimeijer, P. (2001). Spatial flexibility in job mobility: macrolevel opportunities and microlevel restrictions. Environment and Planning A, 33(5), 921-940.

Van Huis, M., Nicolaas, H., \& Croes, M. (1999). Migration of the four largest cities in the Netherlands. Contributed paper, European Population Conference (EPC99), The Hague, The Netherlands.

Van Ommeren, J. (2000). Job and residential search behaviour of two-earner households. Papers in Regional Science, 79(4), 375-391.

Van Ommeren, J., Rietveld, P., \& Nijkamp, P. (2000). Job mobility, residential mobility and commuting: a theoretical analysis using search theory. Annals of Regional Science, 34(2), 213-232.

Van Oort, F., Ponds, R., Van Vliet, J., Van Amsterdam, H., Declerck, S., Knoben, J., Pellenbarg, P., \& Weltevreden, J. (2007). Verhuizingen van bedrijven and groei van werkgelegenheid. Rotterdam/Den Haag: NAi Uitgevers/Ruimtelijk Planbureau.

Van Ours, J. C. (2009). Will you still need me - when I'm 64? De Economist, 157(4), 441460 .

Van Wissen, L. (2000). A micro-simulation model of firms: applications of concepts of the demography of the firm. Papers in Regional Science, 79(2), 111-134.

Venhorst, V., Van Dijk, J., \& Van Wissen, L. (2010). Do the best graduates leave the peripheral areas in the Netherlands? Tijdschrift voor Economische en Sociale Geografie, 101(5), 521-537.

Venhorst, V., Van Dijk, J., \& Van Wissen, L. (2011). An analysis of trends in spatial mobility of Dutch higher educated graduates. Spatial Economic Analysis, 6(1), 57-82.

Vogel, A., \& Wagner, J. (2010). Higher productivity in importing German manufacturing firms: Self-selection, learning from importing, or both? Review of World Economics, 145(4), 641-665.

Wasylenko, M. J. (1980). Evidence of fiscal differentials and intrametropolitan firm relocation. Land Economics, 56(3), 339-349.

Weiss, A. (1984). Determinants of quit behavior. Journal of Labor Economics, 2(3), 371387. 
Whisler, R. L., Waldorf, B. S., Mulligan, G. F., \& Plane, D. A. (2008). Quality of life and the migration of the college-educated: a life-course approach. Growth and Change, 39(1), 58-94.

Yousefi, M., \& Rives, J. (1987). Migration behavior of college graduates: an empirical analysis. Journal of Behavioral Economics, 16(3), 35-49.

Zax, J. S. (1991). The substitution between moves and quits. Economic Journal, 101(409), 1510-1521. 



\section{Samenvatting}

Deze scriptie wil een licht werpen op de locatiespecifieke keuzes en ruimtelijke mobiliteit van personen en bedrijven, mogelijke verbindingen tussen die twee entiteiten identificeren, en de vooruitgang afkomstig van die dynamiek analyseren. Daartoe werden vier empirische onderzoeken uitgevoerd. In hoofdstuk 2 worden de determinanten die bepalend zijn voor de woon- en werkmobiliteit van werknemers in verschillende industriële sectoren onderzocht. Hoofdstuk 3 analyseert de redenen die ten grondslag liggen aan bedrijfsmigratie en identificeert regionale kenmerken die verhuizende bedrijven aantrekken. In hoofdstuk 4 worden de determinanten van de afstanden school-werk, school-huis en woon-werkverkeer van afgestudeerden bestudeerd, en de relaties tussen die drie belangrijke locaties, waarbij wordt geilllustreerd hoe individuen de locatiespecifieke voordelen en de kosten verbonden aan de afstanden tussen de desbetreffende locaties tegen elkaar afwegen. Hoofdstuk 5 richt zich op het analyseren van de effecten van de samenstelling van het personeelsbestand van een firma, het personeelsverloop, en de kwaliteiten van intredende en uittredende werknemers op de verdere productiviteitsgroei.

\section{Hoofdstuk 2}

In hoofdstuk 2 worden de determinanten die ten grondslag liggen aan de woon- en werkmobiliteit van werknemers in verschillende sectoren onderzocht. De resultaten van de empirische analyse tonen aan dat individuen in alle sectoren de voor- en nadelen van het veranderen van baan en/of woonplaats tegen elkaar afwegen, rekening houdend met de sterkte van hun werkgerelateerde en familiaire banden, hun gehechtheid aan de huidige woonplaats, en hun huidige woon-werkverkeer.

Bovendien belemmert de aanwezigheid van interne carrièremogelijkheden over het algemeen eventuele veranderingen van baan, terwijl bedrijfsinterne mobiliteit wordt bevorderd door het bestaan van externe opties. Voor werknemers in de sector openbare orde en veiligheid wordt arbeidsmobiliteit echter waarschijnlijker naarmate de bedrijfsgrootte toeneemt. Een mogelijke verklaring zou kunnen zijn dat voor werknemers in 
deze sector een 'groter bedrijf' gelijk staat aan een grotere instelling respectievelijk een instelling die in een dichtbevolkt gebied als werkgever ligt, wat zou kunnen worden gezien als een onaangename werkomgeving.

Het effect van de vermoedelijke kansen van de werknemer op alternatieve werkgelegenheid op de daaruit voortvloeiende bedrijfsinterne mobiliteit is ook duidelijk sectorafhankelijk. Hoewel externe opties over het algemeen de verwachte positieve impact op de arbeidsmobiliteit hebben, worden de mobiliteitsbeslissingen van werknemers in de bouwsector en in de financiële sector niet beïnvloed door de beschikbaarheid van externe opties. Die bevindingen suggereren dat werknemers in deze sectoren niet van werkgever veranderen om hun carrière vooruit te helpen, maar om intern een stap vooruit te kunnen maken.

Bevindingen over het effect van salaris op arbeidsmobiliteit waren uiteenlopend. Er werd vastgesteld dat het salaris een negatieve invloed heeft op de bedrijfsinterne mobiliteit voor werknemers in de bouwsector en in de financiële sector, terwijl dat voor werknemers in de sector openbare orde en veiligheid en in de gezondheidszorg een positief en significant effect heeft. Het positieve effect van het salaris op de neiging om van baan te veranderen, veronderstelt dat voor goed betaalde, vermoedelijk ambitieuze werknemers in de laatstgenoemde sectoren het veranderen van werkgever de gebruikelijke manier is om de carrière te bevorderen.

Zoals verondersteld, stelden we vast dat werknemers die relatief hoge salarissen verdienen over het algemeen meer kans hebben om te migreren, op voorwaarde dat ze over de nodige financiële middelen beschikken om de verhuizing naar een andere woonplaats te realiseren. Opvallend is dat het effect niet opgaat voor werknemers in de financiële sector, in de sector openbare orde en veiligheid en in de gezondheidszorg, waarbij de laatste twee (primair) publieke dienstverleningssectoren zijn. Die resultaten suggereren dat de impact van het salaris op de kans op verhuizing voor werknemers werkzaam in de publieke dienstverleningssector kleiner is dan voor werknemers in de particuliere sector. Voorts werd vastgesteld dat een hoog salaris over het algemeen gezamenlijke woon- en werkmobiliteit bevordert, wat veronderstelt dat bekwame, ambitieuze individuen die reeds gunstige functies bekleden, besluiten om van werkgever te veranderen om op die manier hun carrière te bevorderen. 
Het belangrijkste inzicht van dit onderzoek is dat de determinanten voor de bedrijfsinterne en/of woonmobiliteit van werknemers duidelijk sectorafhankelijk zijn. We hebben verschillen tussen werknemers in de publieke en de particuliere sector vastgesteld, met name met betrekking tot de residentiële mobiliteit. Interne en externe werkgelegenheid blijkt ook verschillende rollen te spelen in de verschillende economische sectoren.

\section{Hoofdstuk 3}

Hoofdstuk 3 analyseert determinanten van bedrijfsmigratie en identificeert de regionale kenmerken die verhuizende bedrijven aantrekken. De resultaten geven aan dat de besluiten van bedrijven met betrekking tot het verhuizen sectorafhankelijk zijn, en dat het verhuisgedrag van bedrijven in kennisintensieve respectievelijk high-tech sectoren met name verschilt van dat van minder kennisintensieve respectievelijk low-tech sectoren.

De bevindingen van dit onderzoek geven aan dat de beslissing van een bedrijf om te verhuizen eerder wordt bepaald door bedrijfsspecifieke factoren dan door de kenmerken van de regio waar de onderneming is gevestigd. Met name low-tech respectievelijk minder kennisintensieve bedrijven die hoge gemiddelde salarissen betalen, hebben een verhoogde neiging om te verhuizen, terwijl dat effect niet kan worden waargenomen bij high-tech productiebedrijven respectievelijk kennisintensieve dienstverlenende bedrijven. Dat veronderstelt dat bedrijven die minder afhankelijk zijn van een specifiek gekwalificeerd (en dienovereenkomstig duur) personeelsbestand zouden kunnen verhuizen om op die manier arbeidskosten te besparen, terwijl in de high-tech respectievelijk kennisintensieve sectoren salarissen de kwaliteiten en capaciteiten weerspiegelen van de medewerkers die het bedrijf verondersteld wil behouden.

Het verwachte negatieve effect van bevolkingsdichtheid op de kans om te verhuizen wordt bevestigd voor bedrijven in de kennisintensieve marktdienstensector, terwijl het veronderstelde positieve effect werd vastgesteld voor (relatief grote) medium-low-tech productiebedrijven. Die bevindingen illustreren de verschillen in de waardering van dichtbevolkte regio's tussen bedrijven in de productie en diensten. Doordat kennisintensieve high-tech dienstverlenende bedrijven zijn gevestigd in een gebied 
dat aantrekkelijk is voor individuen, blijven ze op hun huidige locatie, mogelijk omdat (arbeidsintensieve) dienstverlenende bedrijven die zijn gevestigd op aantrekkelijke locaties wellicht in staat zijn om lagere lonen te betalen. Die bedrijven kunnen het zich wellicht ook 'veroorloven' om in aantrekkelijke regio's te zijn gevestigd, doordat ze relatief minder geld uitgeven aan huur of machines dan bedrijven in andere sectoren. Verder heeft het algemeen gemiddelde loonniveau in de gemeente waarin het bedrijf is gevestigd een negatieve invloed op de neiging van het bedrijf om te verhuizen voor minder kennisintensieve dienstverlenende bedrijven die afhankelijk zijn van de lokale vraag, terwijl het gemiddelde loonniveau in de sector van het bedrijf een positief effect heeft. Die bevindingen veronderstellen dat de algemene vraagvoorwaarden deze bedrijven binnen een regio houden, terwijl ze door hoge loonkosten worden belemmerd.

Regionale kenmerken hebben, aan de andere kant, een enorme invloed op de keuze waar naartoe te verhuizen, aangezien verhuizende bedrijven naar dichtbevolkte gemeenten met hoge lonen worden 'getrokken' en, in het geval van diensten en low-tech productiebedrijven, naar gemeenten die zijn gespecialiseerd in de eigen bedrijfssector en aantrekkelijk zijn voor individuen. Resultaten voor het effect van sector-specifieke lonen op de immigratie van bedrijven zijn uiteenlopend, wat suggereert dat - eventueel afhankelijk van de sectorale kenmerken - het lokale loonniveau zou kunnen worden gezien als indicator van zowel de arbeidskosten als de arbeidskwaliteit.

\section{Hoofdstuk 4}

Dit hoofdstuk identificeert en analyseert de determinanten van de afstanden school-werk, school-huis en woon-werkverkeer van afgestudeerden, en de relaties tussen die drie belangrijke locaties. Op deze wijze illustreert het de afwegingen die individuen moeten maken tussen de locatiespecifieke voordelen en de kosten die verband houden met de afstanden tussen de desbetreffende locaties.

De resultaten van dit onderzoek illustreren de uitdagingen waarmee afgestudeerden worden geconfronteerd bij het kiezen van de locatie van hun eerste post-studie werkplekken en woonplaatsen. Recent afgestudeerden 
lijken relatief veel waarde te hechten aan loopbaanperspectieven en kiezen dienovereenkomstig hun werkplek uit, waarbij ze residentiële verhuizing en/of lang dagelijks woon-werkverkeer op de koop toe aanvaarden. Toch wijzen de resultaten erop dat afgestudeerden in Nederland - wat een relatief klein land is - blijkbaar niet vasthouden aan wonen en werken in dezelfde plaats, maar hun woonplaats kiezen met de bedoeling dat zowel hun studieals werkplek - waarmee ze zich nog steeds verbonden zouden kunnen voelen - gemakkelijk te bereiken zijn.

Bovendien kunnen afgestudeerden beslissen om in verschillende regio's te wonen en te werken om redenen die (ook) betrekking hebben op de beschikbaarheid van adequate huisvesting, terwijl residentiële voorzieningen een relatief kleine impact op hun locatiekeuzes hebben. Bovendien hechten deze jonge professionals blijkbaar veel waarde aan woonlocaties die gemakkelijk te bereiken zijn, vermoedelijk omdat ze verwachten in de nabije toekomst vaak van baan te veranderen, maar extra residentiële verhuizing mogelijkerwijze willen vermijden.

\section{Hoofdstuk 5}

Hoofdstuk 5 richt zich op het analyseren van de effecten van de samenstelling van het personeelsbestand van een firma, het personeelsverloop, en de kwaliteiten van intredende en uittredende werknemers op de verdere productiviteitsgroei. De resultaten suggereren dat bedrijven die een leeftijdsbewust personeelsbeleid hebben, toekomstig productiviteitsstijgingen zullen ervaren, terwijl bedrijven die voornamelijk jongere of oudere werknemers in dienst hebben, minder baat hebben bij hun keuze van medewerkers. Die bevindingen geven aan dat werknemers op actieve leeftijd in staat kunnen zijn om bij te dragen aan de prestaties van hun werkgever dankzij hun kennis en ervaring, maar ook door hun vermogen om met druk om te gaan.

Bedrijven profiteren van de instroom van oudere werknemers, en van werknemers die eerder in andere bedrijven in dezelfde branche en in zeer productieve ondernemingen werkzaam waren. Dat wijst erop dat die werknemers waardevolle en overdraagbare taak- of branchespecifieke kennis en ervaring bezitten die zij kunnen gebruiken bij hun nieuwe werkgever. De 
instroom van medewerkers die bij hun vorige werkgever voor lange tijd in dienst waren, heeft echter een negatief effect, wat erop wijst dat de werknemers die voor lange tijd voor een andere werkgever werkzaam waren niet automatisch over uitzonderlijke hoeveelheden waardevolle ervaring beschikken die zij kunnen overdragen aan en gebruiken bij hun nieuwe werkgevers. In plaats daarvan lijkt het erop dat die werknemers minder in staat zijn om zich aan te passen aan en efficiënt te werken in een nieuwe omgeving, en daarom de productiviteitsgroei van hun nieuwe werkgever zouden kunnen belemmeren.

Dienovereenkomstig heeft de uitstroom van werknemers met een lange ambtstermijn een positief effect op de productiviteitsgroei van hun oude werkgever, hetgeen impliceert dat werknemers die al lange tijd bij dezelfde werkgever werkten in de loop der tijd minder gemotiveerd en productief zouden kunnen zijn geworden, zodat hun werkgevers uiteindelijk baat hebben bij hun uitstroming. Bedrijven profiteren ook van de uitstroom van personeel aan zeer productieve bedrijven en in de WW, aangezien ze zouden kunnen zijn ontslagen als gevolg van onvoldoende prestaties, en als gevolg daarvan dus moeilijkheden ondervinden bij het vinden van nieuwe werkgevers. De uitstroom van werknemers die vertrekken naar bedrijven in dezelfde branche, en van werknemers die tegelijkertijd verhuizen (over lange afstanden) heeft een negatief effect, wat aangeeft dat het verliezen van medewerkers aan concurrenten wel degelijk negatieve gevolgen heeft, en illustreert dat zeer productieve individuen die in staat zijn om een substantiële bijdrage te leveren aan de prestaties van hun werkgever, degenen zouden kunnen zijn die hun carrière verder ontwikkelen door te kiezen voor een baan die hen in staat stelt het meeste uit hun vaardigheden te halen, ook als dat een verhuizing met zich meebrengt.

De resultaten van dit onderzoek illustreren dat veranderingen in de productiviteit van het bedrijf niet alleen worden bepaald door de huidige samenstelling van het personeelsbestand van het bedrijf en de mate van personeelsverloop dat plaatsvindt. Daarnaast hebben de kwaliteiten van het instromende en uitstromende personeel, met name in relatie tot de kenmerken van hun vorige respectievelijk toekomstige werkgevers, ook een aanzienlijke impact op de verdere productiviteitsgroei van hun huidige werkgever. 


\section{About the author}

Kristin Kronenberg was born on 31 December 1977 in Gießen, Germany. She received her undergraduate degree in Recording Arts from Middlesex University, London in 2003, and followed the European Programme on Society, Science and Technology at Maastricht University, the Netherlands from 2003 until 2004. She graduated with a MA, and worked at the Faculty of Arts and Social Sciences as a junior researcher in 2005. From 2006 until 2007, Kristin studied International Business (Strategy and Innovation) at Maastricht University. After having graduated with a MSc, she joined the Department of Organization and Strategy as a $\mathrm{PhD}$ candidate in September 2007. In 2011, she visited the Research Institute for Regional and Urban Development (ILS) in Dortmund, Germany as a guest researcher. Since February 2012, Kristin has been employed at the Open University of the Netherlands in Heerlen as a postdoctoral researcher. 